Aus der Abteilung Humangenetik

(Prof. Dr. med. W. Engel)

Schwerpunktprofessur Molekulare Entwicklungsgenetik

(Prof. Dr. med. H. Hahn)

im Zentrum Hygiene und Humangenetik

der Medizinischen Fakultät der Universität Göttingen

\title{
Untersuchungen zur Rolle von Wnt5a beim Basalzellkarzinom
}

INAUGURAL - DISSERTATION

zur Erlangung des Doktorgrades der Medizinischen Fakultät der Georg-August-Universität zu Göttingen

\footnotetext{
vorgelegt von

Per-Ole Carstens

aus Verden (Aller)
}

Göttingen 2010 
Dekan:

I. Berichterstatterin:

II. Berichterstatter:

III. Berichterstatter/in:

Tag der mündlichen Prüfung:
Prof. Dr. med. C. Frömmel

Prof. Dr. med. H. Hahn

Prof. Dr. med. S. Emmert

\footnotetext{
27.07.2010
} 


\section{Inhaltsverzeichnis}

1

1.1

1.2

1.3

1.3.1

1.3.2

1.3.3

1.3.3.1

1.3.3.2

1.3.4

1.3.5

1.4

2

2.1

2.2

2.3

2.4

2.5

2.6

2.7

2.7.1

2.7.2

2.7.3

2.8

2.8 .1

2.8 .2

2.9

2.10

2.10 .1

2.10 .2

2.11

2.11.1

2.11 .2

2.12

2.12 .1

2.12.1.1

2.12.1.2

2.12.1.2.1 Isolierung von RNA aus Zellen

2.12 .2

2.12 .3

2.12 .4

2.12 .5

2.12.5.1

2.12.5.2

2.12.5.3

2.12 .6

Einleitung

Das Basalzellkarzinom....

Entstehung von BCC.

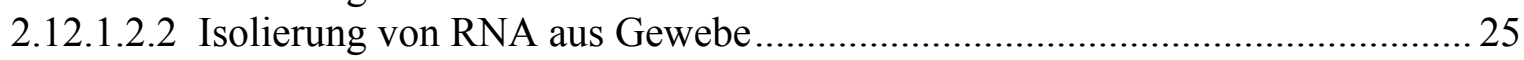

Die Rolle des Hh/Ptch-Signalwegs beim BCC ............................................... 2

Funktion der Wnt5a-Signalkaskade in der Entwicklung der Haut und bei der

Die Wnt-Familie und ihre Rezeptoren ........................................................ 5

Aktivierung des kanonischen Wnt-Signalweges durch Wnt5a ........................ 5

Aktivierung der nicht-kanonischen Wnt-Signalwege durch Wnt5a ................ 7

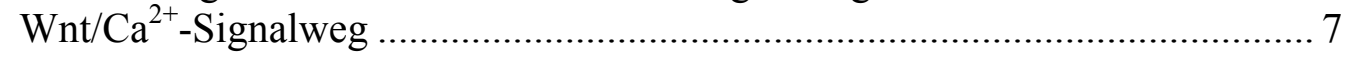

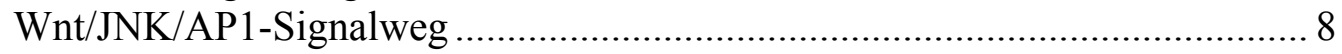

Wnt5a in der Entwicklung normaler Haut ................................................. 8

Expression von Wnt5a und seine potentielle Funktion in BCC ........................ 8

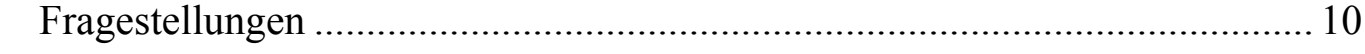

Material und Methoden ..................................................................... 11

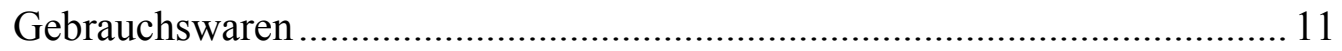

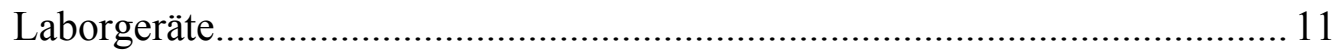

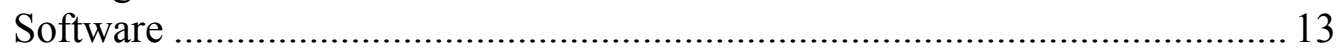

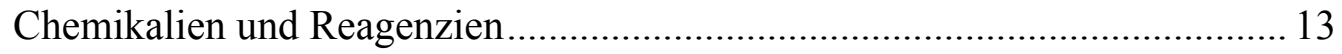

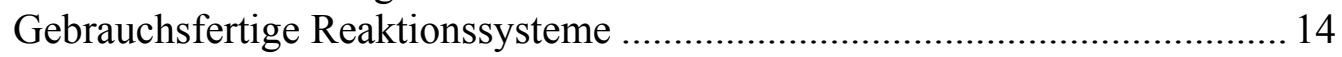

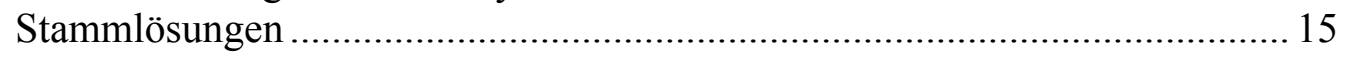

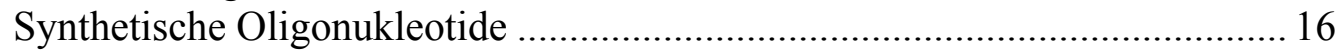

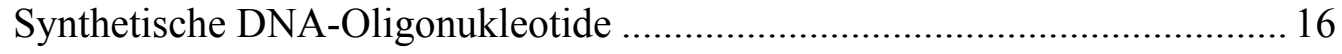

DNA-Oligonukleotide zur Genotypisierung von Mäusen ............................. 16

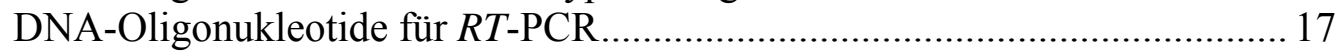

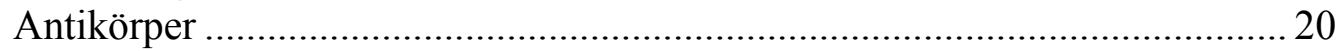

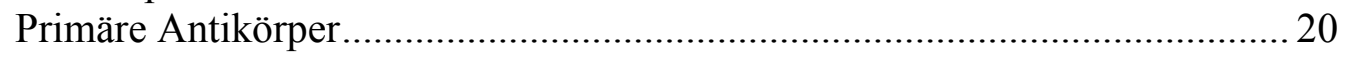

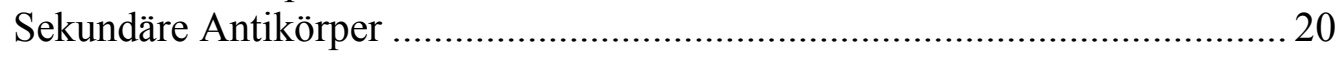

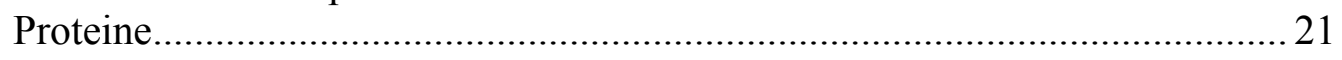

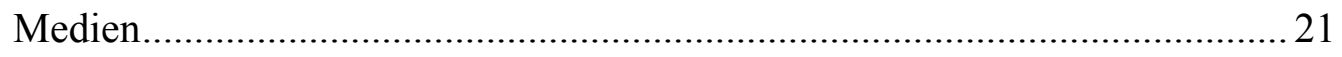

Medien für die Kultur eukaryotischer Zellen ................................................ 21

Herstellung von Shh-konditioniertem Medium........................................... 22

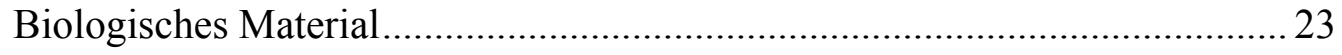

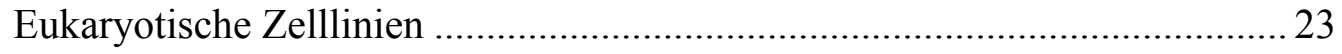

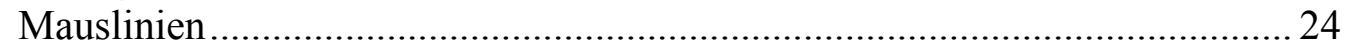

Molekularbiologische Methoden................................................................... 24

Isolierung und Aufreinigung von Nukleinsäuren.......................................... 24

Isolierung von genomischer DNA aus Gewebeproben ................................ 24

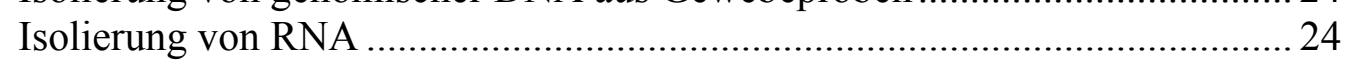

Konzentrationsbestimmung von Nukleinsäurelösungen............................... 25

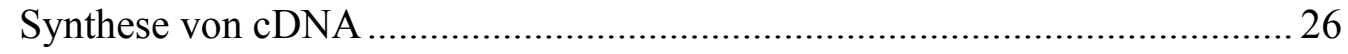

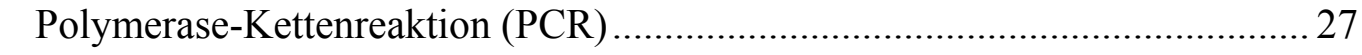

Quantitative Real Time PCR (qRT-PCR) .................................................. 28

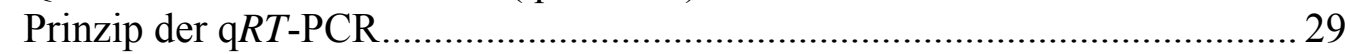

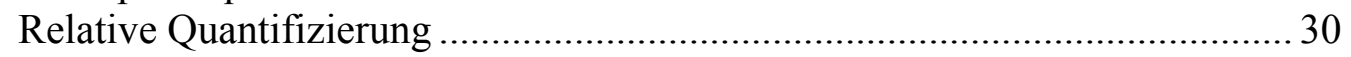

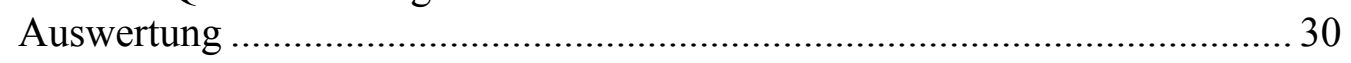

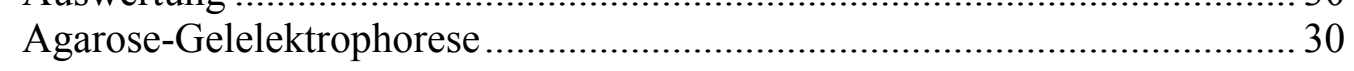




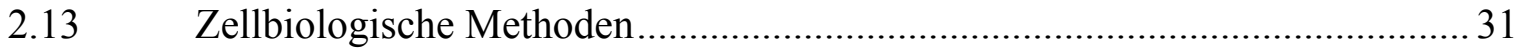

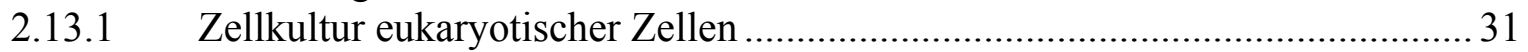

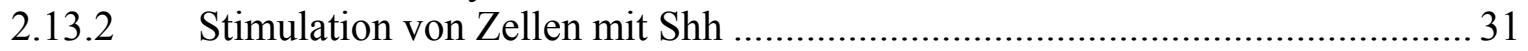

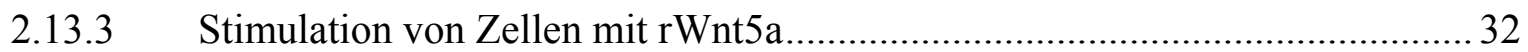

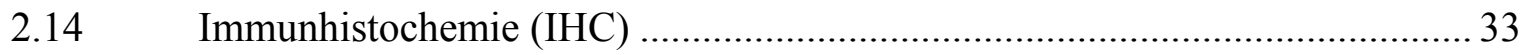

2.14.1 Gewebeeinbettung zum Anfertigen von Paraffinschnitten ............................. 33

2.14.2 Anfertigung von Paraffinschnitten und Entparaffinierung.............................. 33

2.14.3 Immunhistologische Antikörperfärbungen an Paraffinschnitten .................... 34

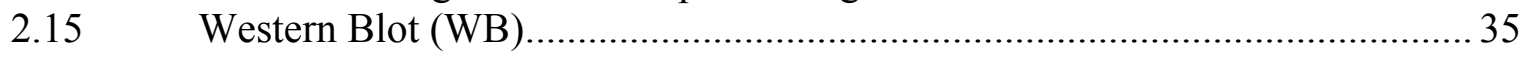

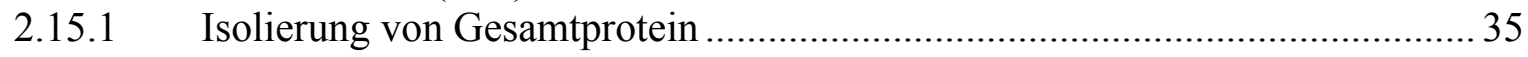

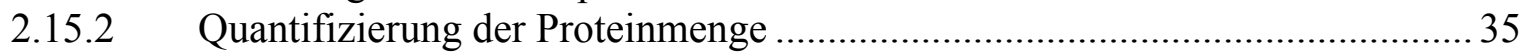

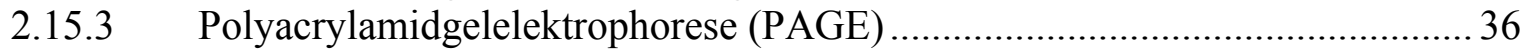

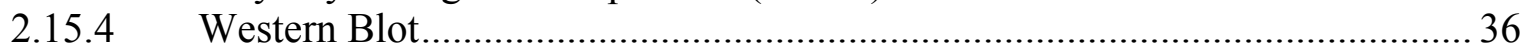

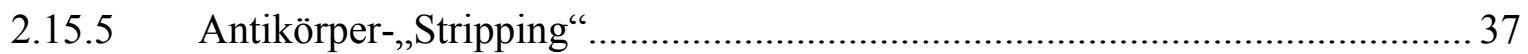

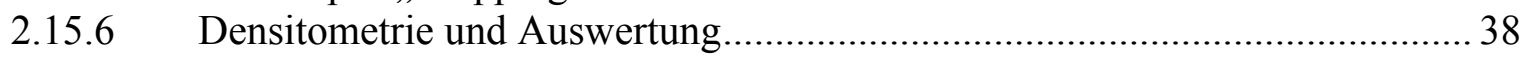

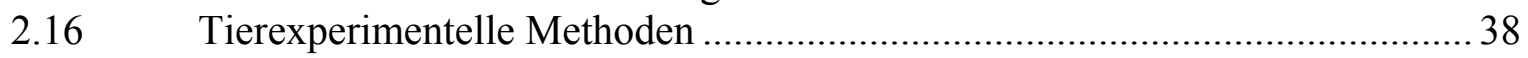

2.16.1 Zucht und Haltung von Mus musculus ...................................................... 38

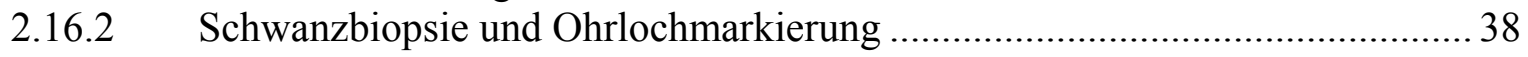

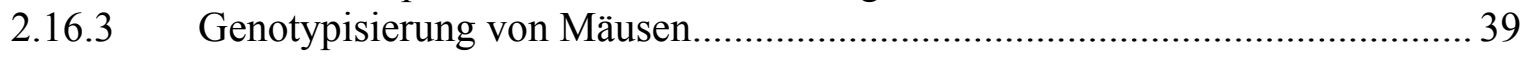

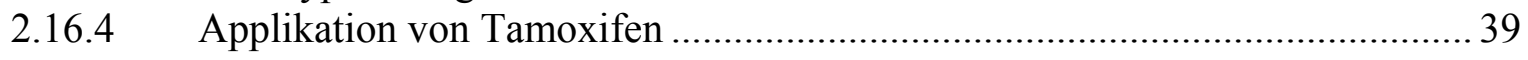

$3 \quad$ Ergebnisse ..................................................................................................... 40

3.1 Expressionsanalyse von Gli1 und Wnt5a in murinen und humanen BCC....... 40

3.2 Untersuchung der Wnt5a-Expression in den Keratinozytenzelllinien HaCaT und C5N nach Stimulation mit Shh............................................................ 43

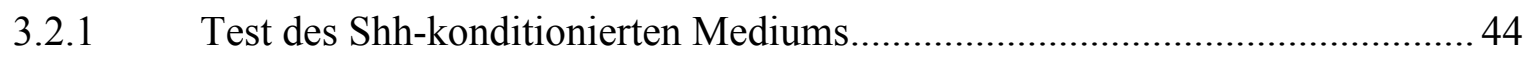

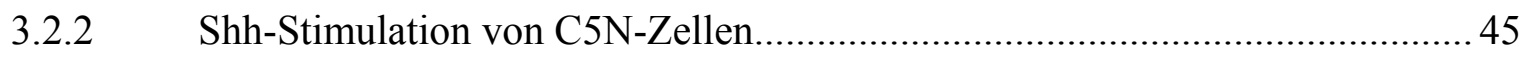

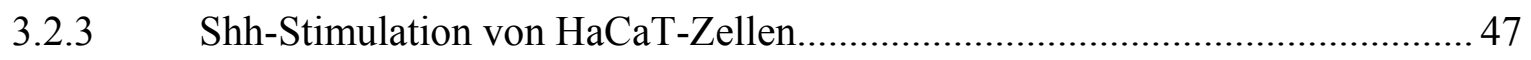

3.3 Untersuchung der Effekte von Wnt5a auf die Proliferation und/oder Differenzierung der BCC-Zelllinie ASZ001 .................................................. 48

3.4 Untersuchung der Aktivität der Wnt-Signalwege im murinen BCC ................ 50

3.4.1 Untersuchung der Aktivität des kanonischen Signalweges im BCC ............... 51

3.4.2 Untersuchung der Aktivität des $\mathrm{Wnt} / \mathrm{Ca}^{2+}$-Weges im BCC ............................ 54

3.4.3 Untersuchung der Aktivität des Wnt/JNK/AP1-Weges im BCC ...................... 58

3.5 Expressionsanalyse von potentiellen Wnt5a-Rezeptoren in murinen und humanen BCC sowie in den Keratinozytenzelllinien HaCaT und C5N und der

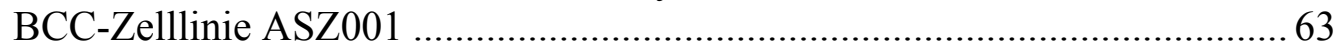

3.6 Untersuchung der Regulation von Cutl1 durch den Hh-Signalweg.................. 68

Diskussion ..................................................................................... 70

4.1 Ist Wnt5a ein Zielgen der Hh-Signalkaskade? .............................................. 70

4.2 Hat Wnt5a einen Effekt auf die Proliferation und/oder Differenzierung von

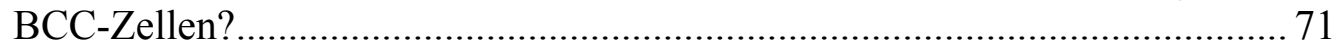

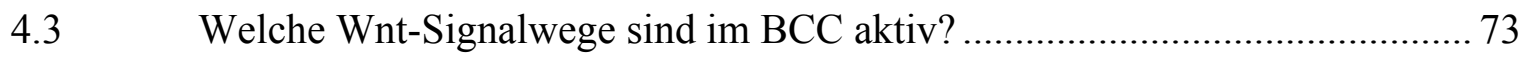

4.4 Exprimieren BCC Rezeptoren für Wnt5a?................................................ 75

Zusammenfassung der wichtigsten Ergebnisse und Modell der Rolle von Wnt5a beim Basalzellkarzinom ...................................................................... 77

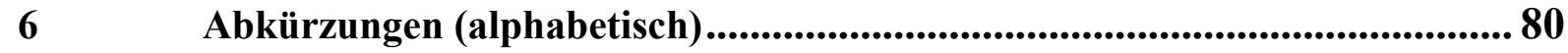

7 Literaturverzeichnis (alphabetisch) .................................................. 82 


\section{$1 \quad$ Einleitung}

\subsection{Das Basalzellkarzinom}

Das Basalzellkarzinom (BCC, von engl. „basal cell carcinoma“) ist der häufigste Tumor des Menschen (Reifenberger, 2007). Es entsteht meist im höheren Lebensalter auf sonnenexponierten Hautstellen wie beispielsweise im Gesicht oder auf den Handrücken (Rubin et al., 2005). Durch die Lokalisation und das Alter der Patienten wurde erkannt, dass chronische Sonneneinstrahlung auf die Haut der Hauptrisikofaktor für die Entstehung dieses Karzinoms ist. Die Lebenszeitinzidenz beträgt für Menschen mit heller Haut etwa $30 \%$, die Mortalität liegt unter $1 \%$ (Ting et al., 2005). Im Gegensatz zu den meisten anderen Karzinomen wächst das BCC zwar lokal infiltrierend, metastasiert aber nur in bis zu 0,5\% aller Fälle (Rubin et al., 2005). Dieses Verhalten eines Tumors bezeichnet die Pathologie als semimaligne.

Retrospektive Studien über die Häufigkeit von BCC zeigen, dass die Inzidenz dieses Tumors in Europa (Hoey et al., 2007), Nordamerika (Harris et al., 2001) und Australien (Staples et al., 2006) in den 1990er Jahren stark zugenommen hat. Auch in den nächsten Jahren wird die Inzidenz weiter zunehmen. Prognostiziert sind Steigerungen der Inzidenz zwischen 3 bis $8 \%$ jährlich (Reifenberger, 2007). Dabei werden verstärkt auch jüngere Menschen zwischen 15 und 64 Jahren betroffen sein (de Vries et al., 2005). Die Kosten, die das Gesundheitssystem zur Diagnose und Therapie von Hauttumoren aufbringen muss, sind bereits heute enorm. In Australien sind Hauttumore für $9 \%$ der Kosten verantwortlich, die durch Tumorerkrankungen insgesamt entstehen (Staples et al., 2006). In Großbritanien liegt der Anteil bei 4 \% (Hoey et al., 2007). Aufgrund der Inzidenzsteigerung entwickelt sich das BCC immer mehr zu einem Problem für das Gesundheitswesen (Roewert-Huber et al., 2007).

Durch verbesserte Therapieansätze könnten diese Kosten evtl. reduziert werden. Unser Wissen über die molekularen Vorgänge der Entstehung und der Progession des BCC ist bis heute gering. Aufgrund dieser Tatsache hat sich die Therapie kaum gewandelt. Die Standardbehandlung ist noch immer die Operation und in späteren Stadien die unspezifische Radio- oder Chemotherapie (Ceilley und Del Rosso, 2006). In frühen Tumorstadien kommen heute in zunehmendem Maße weniger invasive Therapieformen wie die photodynamische Therapie oder die Therapie mit Pharmakon Imiquimod zum Einsatz. Diese neuen Ansätze sind zwar mit einer geringeren Morbidität für den Patienten verbunden, ihre Wirkung ist 
jedoch weiterhin als unspezifisch zu bezeichnen. Medikamente hingegen, die spezifisch das weitere Wachstum dieses Tumors beeinflussen, konnten bisher noch kaum entwickelt werden.

Nach Jahren der Forschung sind heute einige Proteine und Rezeptoren bekannt, die an der Signaltransduktion bei BCC beteiligt und daher für die Progression dieses Tumors wichtig sind. Hierzu gehören Mutationen in Patched (Ptch), wodurch es zur Aktivierung der Hedgehog (Hh)/Ptch-Signalkaskade kommt. Außerdem konnte eine Überexpression von Wnt5a in BCC nachgewiesen werden (Saldanha et al., 2004). Aus diesem Grund schreibt man Wnt5a eine mögliche Funktion bei der Entstehung und/oder Progression von BCC zu. Beide Signalwege sind daher mögliche Ziele für ein therapeutisches Eingreifen in das Tumorwachstum.

\subsection{Die Rolle des Hh/Ptch- Signalwegs beim BCC}

Das Gen Ptch, welches in BCC häufig mutiert ist, ist eine Komponente des Hh/PtchSignalweges. Dieser Signalweg kontrolliert die Musterbildung in den meisten Tieren und ist sehr wichtig für die embryonale Entwicklung, speziell für das ZNS und die Extremitäten (Hammerschmidt et al., 1997), sowie die Zellproliferation und die Differenzierung (Varjosalo und Taipale, 2008). Die stärkste Aktivität zeigt der Signalweg während der Embryogenese (Evangelista et al., 2006). In Säugetieren sind insgesamt drei verschiedene Hh-Proteine bekannt: Sonic Hedgehog (Shh), Indian Hedgehog (Ihh) und Desert Hedgehog (Dhh) (Athar et al., 2006). Der wichtigste Hh-Ligand beim Säuger ist Shh (Daya-Grosjean und CouvéPrivat, 2005).

Der Hh/Ptch-Signalweg wird durch Bindung von Hh an den Rezeptor Ptch aktiviert. Ptch ist ein membrangebundenes Protein und hat 12 transmembrane Domänen. Im ungebundenen Zustand inhibiert Ptch Smo, welches ebenfalls ein membranständiges Protein ist (Abbildung 1A).

Bei Bindung von Hh wird Ptch in seiner Funktion gehemmt, Smo wird aktiviert und initiiert die Aktivierung seiner Signalkaskade (Abbildung 1B). Der Signaltransduktionsmechanismus verläuft über zytoplasmatische Proteine und ist bisher noch nicht vollständig bekannt (Evangelista et al., 2006). Eine wichtige Rolle nimmt dabei die Familie der Gliomassoziierten Zinkfinger-Transkriptionsfaktoren (Gli) ein, die bei Aktivierung der Kaskade in 
den Zellkern einwandern und zur Transkription spezifischer Zielgene führen (Hooper und Scott, 2005; Athar et al., 2006).

In Wirbeltieren gibt es drei Gli-Proteine (Matise und Joyner, 1999). Gli1 und Gli2 aktivieren Zielgene der Hh-Signalkaskade, während Gli3 als Repressor wirkt. Es ist bekannt, dass das Hh-Signal auch die Transkription von Gli1 aktiviert, wobei dieser Vorgang vom Vorhandensein funktioneller Gli2- und Gli3-Proteine abhängig ist (Ikram et al., 2004; Kasper et al., 2006). Ein weiteres heute bekanntes Zielgen ist Ptch, welches im Sinne eines negativen Regelkreises vermehrt exprimiert wird und so den Aktivitätszustand des Hh-Signalweges begrenzt (Dahmane et al., 1997; Athar et al., 2006).

Cyclopamin ist ein pflanzliches steroidales Alkaloid, welches den Hh-Signalweg durch Inhibition von Smo inhibiert (Taipale et al., 2000; Athar et al., 2006).

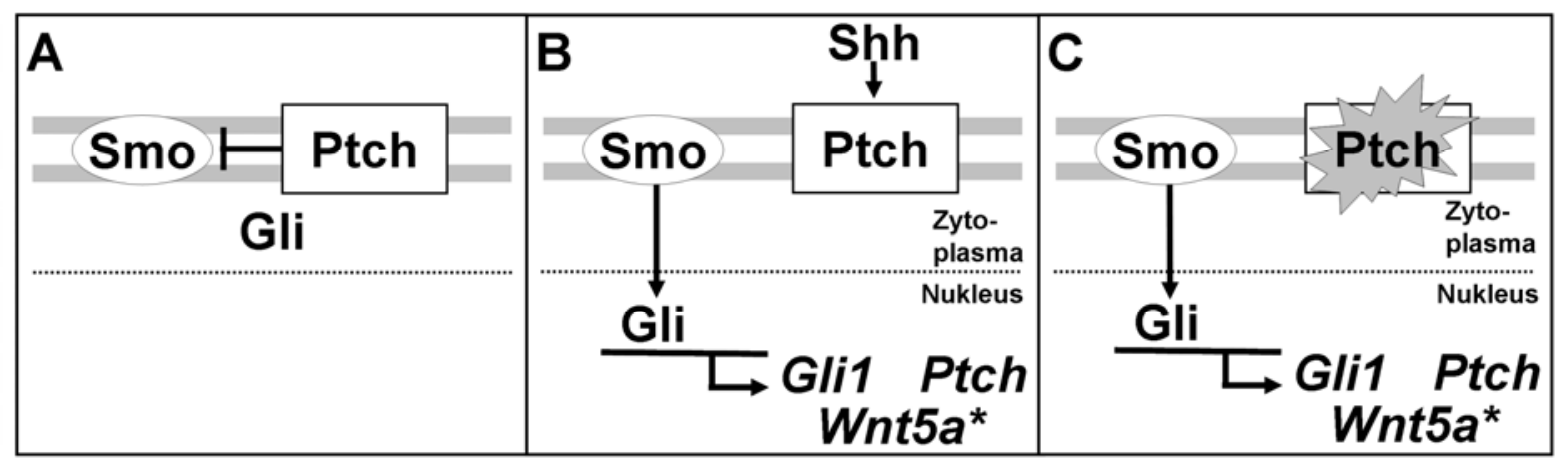

\section{Abbildung 1: Der Hh/Ptch-Signalweg}

Vereinfachte Übersicht über die verschiedenen Aktivitätszustände des Hh/Ptch-Signalweges. Nähere Erläuterungen im Text (Kapitel 1.2).

A: zeigt den inaktiven Zustand

B: zeigt den Zustand nach Aktivierung durch den Shh-Liganden (physiologisch-aktiv)

C: zeigt den aktiven Zustand nach Mutation in Ptch (pathologisch-aktiv)

Wnt5a* Hypothese: Eine mögliche Regulation der Expression von Wnt5a durch Gli ist eine der untersuchten Fragestellungen in der vorliegenden Arbeit.

$\rightarrow$ : Signalkaskade; $\dashv$ : Inhibitorischer Effekt

Shh: Sonic Hedgehog, Ptch: Patched, Smo: Smoothened, Gli: Gliom-assoziierten Zinkfinger- Transkriptionsfaktoren

Beim Adulten ist im Gegensatz zum Embryo die Aktivität im Hh-Signalweg normalerweise sehr gering (Athar et al., 2006). Die pathologische Reaktivierung des Signalweges kann zur Tumorentstehung führen. Heute ist bekannt, dass der Hh-Signalweg in einigen Tumoren wie beispielsweise dem BCC, dem Medulloblastom, dem Rhabdomyosarkom und anderen Tumoren aktiv ist (Hahn et al., 1999; Athar et al., 2006).

Der Zusammenhang zwischen der pathologischen Reaktivierung des Hh/Ptch-Signalweges und der daraus resultierenden Tumorentstehung wurde beim Gorlin-Goltz-Syndrom (Basalzellnaevus-Syndrom) erkannt. Dieses autosomal-dominant vererbte Syndrom ist v.a. 
durch das Auftreten multipler BCC gekennzeichnet, die bei mehr 90\% der Patienten entstehen (Gorlin, 2004; Daya-Grosjean und Couvé-Privat, 2005). Außerdem entwickeln die Patienten gehäuft Medulloblastome und Rhabdomyosarkome (Hahn et al., 1999; Gorlin, 2004, DayaGrosjean und Couvé-Privat, 2005). Es konnte gezeigt werden, dass das Gorlin-GoltzSyndrom auf eine Keimbahnmutation im Gen Ptch zurückzuführen ist (Hahn et al., 1996; Abbildung 1C).

Auch bei sporadischen BCC konnten Mutationen im Hh/Ptch-Signalweg nachgewiesen werden. Die weitaus am häufigsten detektierten Veränderungen (70\%) sind loss of functionMutationen des Ptch-Gens (Reifenberger et al., 2005; Reifenberger, 2007). Diese Mutationen führen zu einer Deregulation der gesamten Hh-Signalkaskade, da die Hemmung von Smo aufgehoben ist und Smo konstitutiv aktiviert wird (Abbildung 1C; Gailani und Bale, 1997). Neben inaktivierenden Mutationen in Ptch können auch aktivierende Mutationen im Gen Smo oder die Überexpression des Liganden Hh oder der Transkriptionsfaktoren Gli1 und Gli2 zur konstitutiven Aktivierung der Hh-Kaskade und damit zur Entstehung von BCC führen (Evangelista et al., 2006).

BCC entwickeln sich auch in verschiedenen Tiermodellen, in denen der Hh/Ptch-Signalweg dereguliert ist. Ptch $^{+/}$-Mäuse, welche heterozygot für eine Keimbahnmutation sind, entwickeln mit hoher Inzidenz Medulloblastome und Rhabdomyosarkome (Goodrich et al., 1997; Hahn et al., 1998). Nach Bestrahlung dieser Tiere entstehen BCC (Mancuso et al., 2004). In der AG Hahn generierte konditionelle Ptch-knock-out-Mäuse (Ptch flox/flox; ERT2 ${ }^{+/}$) entwickeln nach Injektion von Tamoxifen manifeste BCC (Kapitel 2.11.2).

Neben Mutationen in Ptch führt auch eine Überexpression von Shh, Gli1 und Gli2 in muriner Haut zu BCC (Oro et al., 1997; Athar et al., 2006).

All diese Daten zeigen, dass der Hh/Ptch-Signalweg bei der Entstehung von BCC von essentieller Bedeutung ist. 


\subsection{Funktion der Wnt5a-Signalkaskade in der Entwicklung der Haut und bei der Entstehung von BCC}

\subsubsection{Die Wnt-Familie und ihre Rezeptoren}

Die Wnt-Gene kodieren für eine große Familie sezernierter Proteine. Beim Menschen wurden bisher 19 Wnt-Proteine identifiziert. Sowohl die verschiedenen Untergruppen der Wnts in einzelnen Spezies, als auch Wnts im Vergleich zwischen verschiedenen Spezies zeigen zum Teil sehr große Homologien. Beim Menschen beispielsweise zeigen die einzelnen WntProteine eine Übereinstimmung von 27 bis 83\%. (Miller, 2001)

Die Signaltransduktion ins Zellinnere kommt nach Bindung eines Wnt-Proteins an einen Rezeptor der Frizzled-Familie (Fzd) sowie an dessen Korezeptoren LDL-receptor-related protein 5 und 6 (LRP) zustande (Willert und Jones, 2006). Die Fzd-Rezeptoren besitzen eine N-terminale cysteinreiche Domäne (CRD), an die Wnt-Proteine binden, sieben transmembranäre Regionen und eine intrazelluläre Domäne und ähneln damit sehr der Struktur G-Protein-gekoppelter Rezeptoren (Miller, 2001). Eine Untergruppe der FzdRezeptoren vermittelt ihre Signale über G-Proteine mit nachfolgendem Einstrom von Calcium $\left(\mathrm{Ca}^{2+}\right)$ und einer Aktivierung der Proteinkinase C (PKC). Bei einer anderen Untergruppe hingegen scheinen G-Proteine keine Rolle zu spielen. Auch die beiden Rezeptoren der LPRFamilie können Wnt binden und bilden zusammen mit den Fzd-Rezeptoren einen Komplex.

Das Wnt-Signal kann nun über drei verschiedene Signalwege in den Kern weitergeleitet

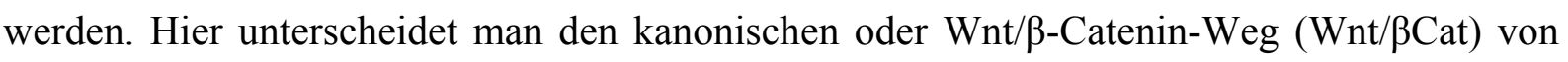
den beiden nicht-kanonischen Wegen $\mathrm{Wnt} / \mathrm{Ca}^{2+}$ und Wnt/JNK/AP1. Die Aktivierung der verschiedenen Signalwege hängt davon ab, welches der 19 Wnt-Proteine mit welchem der Frizzled-Rezeptoren oder eventuell bisher noch unbekannten Rezeptoren interagiert (Miller, 2001). Aaronson und Kollegen stellten die Theorie auf, dass die Affinität der verschiedenen Wnt-Liganden zu LPR für die Aktivierung der unterschiedlichen Wnt-Signalwege verantwortlich ist (Liu et al., 2005).

\subsubsection{Aktivierung des kanonischen Wnt-Signalweges durch Wnt5a}

Das zentrale Molekül der kanonischen Wnt-Signalkaskade ist das $\beta$-Catenin ( $\beta C$ at), dessen Stabilität durch die Wnt-Proteine reguliert wird. Der zentrale Bereich von $\beta C$ at enthält die sog. Armadillo-Wiederholungen, an welche verschiedene Moleküle wie z.B. APC (Adenomatosis polyposis coli) und Axin binden können. Am N-Terminus von $\beta C$ at befinden 
sich vier stark konservierte Phosphorylierungsstellen, die für die Regulation der Aktivität wichtig sind (Akiyama T, 2000).

Ist kein Wnt-Signal vorhanden, wird $\beta$ Cat im sog. Zerstörungskomplex gebunden. Dieser Komplex besteht aus den Komponenten Axin, APC, Glykogen-Synthase-Kinase 3 (GSK3), Casein-Kinase 1 (CK1), Dishevelled (Dsh) und anderen. Der Komplex bewirkt eine Phosphorylierung aller 4 Phoshorylierungsstellen von $\beta C$ at, wodurch es der E3-UbiquitinLigase möglich wird, zu binden. Anschließend wird $\beta$ Cat ubiquitiniert und im Proteasom abgebaut (Willert und Jones, 2006). Folglich ist die Konzentration von $\beta$ Cat in der Zelle gering. Gleichzeitig binden in Abwesenheit von $\beta$ Cat die Transkriptionsfaktoren der Tcf/LefFamilie (engl. Tcf: T-cell factor, Lef: engl. lymphoid enhancer factor) im Promotorbereich der Wnt-Zielgene. Durch die Bindung von Proteinen der Groucho-Familie fungiert Tcf/Lef in diesem Fall als Repressor (Akiyama T, 2000).

Die Aktivierung des Wnt/ßCat-Signalweges erfolgt durch Bindung eines Wnt-Moleküls an einen Fzd-Rezeptor und dessen Korezeptor LPR5/6. Dabei wird Axin an den zytoplasmatischen Teil von LPR5/6 gebunden (Mao et al., 2002). Des Weiteren wird Dsh durch CK1 phosporyliert und fördert so möglicherweise die Dissoziation der GSK3 $\beta$ von Axin (Willert und Jones, 2006). Beide Prozesse zusammen führen dazu, dass sich die Komponenten des Zerstörungskomplexes trennen und selbiger sich auflöst. $\beta$ Cat wird während dieser Reaktionen dephosphoryliert und kann nun in den Nukleus gelangen. Dort bindet es an Mitglieder der Tcf/Lef-Familie, welche ihre Repressorfunktion verlieren, und induziert so die Bildung seiner Zielgene. Zu diesen Genen gehören beispielsweise c-Myc und Cyclin D1 (Kolligs et al., 2002).

Wnt5a kann den kanonischen Signalweg aktivieren, wenn es an die Rezeptorkombination Fzd4/LPR5 (Mikels und Nusse, 2006; Umbhauer et al., 2000) oder an Fzd7 (Umbhauer et al., 2000) bindet. Wahrscheinlich ist die Wnt5a-vermittelte Aktivierung der Signalkaskade auch über Fzd8 möglich (Itoh et al., 1998; Abbildung 2). Vom Rezeptor Fzd8 ist bekannt, dass er in BCC vermehrt exprimiert ist (Asplund et al., 2008).

Liegt hingegen der Rezeptor Ror2 an einer Zelle vor, so inhibiert Wnt5a die Aktivierung des kanonischen Signalweges (Mikels und Nusse, 2006; Abbildung 2). Gleichzeitig wurde gezeigt, dass Ror2 die Jun N-terminale Kinase (JNK) aktiviert (Oishi et al., 2003; Schambony und Wedlich, 2007).

Die Wirkung von Wnt5a auf Zellen scheint also vom Vorliegen bestimmter Rezeptoren an der Zielzelle abhängig zu sein. 


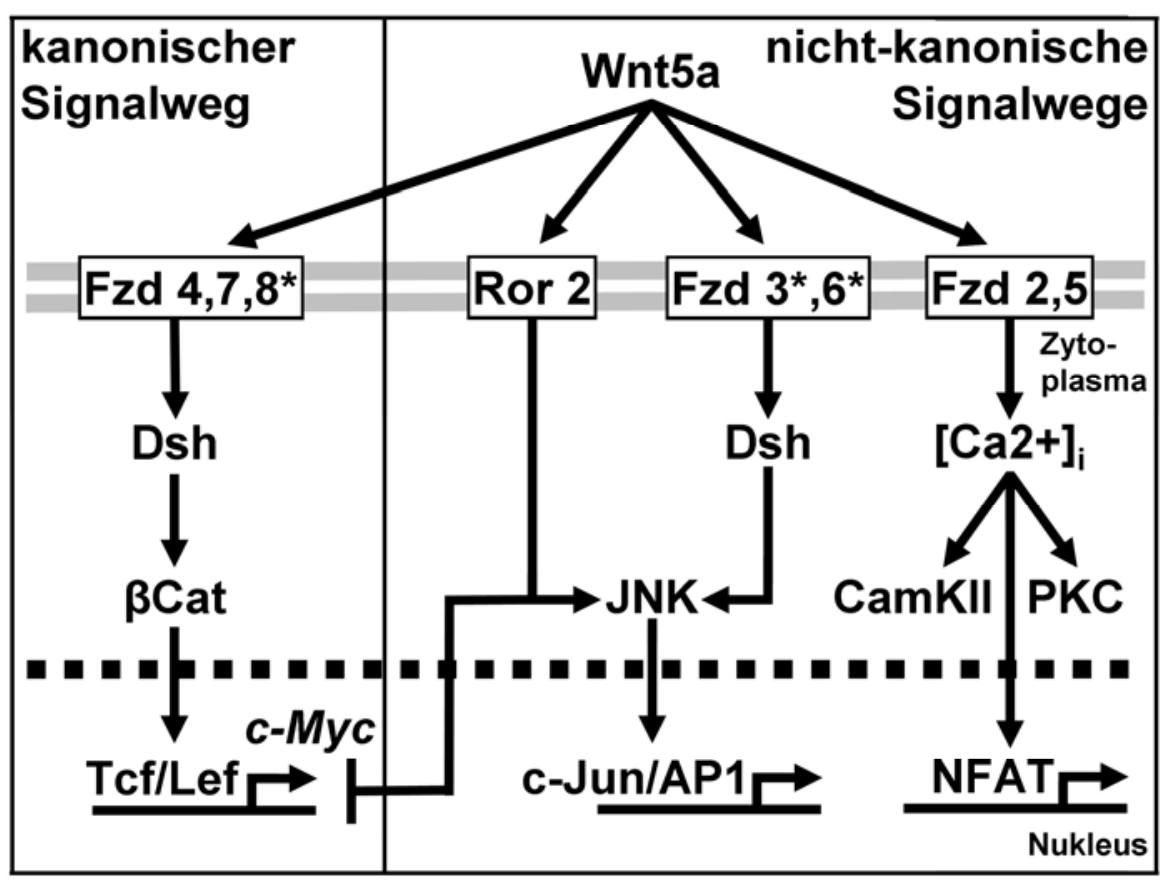

Abbildung 2: Wnt-Signalwege (modifiziert nach Pukrop und Binder, 2008, S. 260)

Stark vereinfachte Übersicht über die von Wnt5a aktivierten Signalwege: Abhängig vom Rezeptor, an den Wnt5a bindet, kommt es in den Zellen zur Aktivierung der verschiedenen Signalkaskaden. Nähere Erläuterungen im Text (Kapitel 1.3.2 und 1.3.3).

*: Hypothesen, Aktivierung der Signalkaskaden über diese Rezeptoren noch nicht abschließend belegt.

$\rightarrow$ : Signalkaskade; $\boldsymbol{-}$ : Inhibitorischer Effekt

Dsh: Dishevelled; $\beta$ Cat: $\beta$-Catenin; Tcf: T-Zell-Faktor; Lef: engl. lymphoid enhancer factor; c-Myc: Myelocytomatosis Onkogen; JNK: Jun N-terminale Kinase; $\left[\mathrm{Ca}^{2+}\right]_{\mathrm{i}}$ : intrazelluläre Kalziumkonzentration; CamKII: $\mathrm{Ca}^{2+} /$ Calmodulin-abhängige Kinase; PKC: Proteinkinase C; AP1: Aktivatorprotein 1; NFAT: nukleärer Faktor aktivierter T-Zellen.

\subsubsection{Aktivierung der nicht-kanonischen Wnt-Signalwege durch Wnt5a}

\subsubsection{Wnt $/ \mathrm{Ca}^{2+}$-Signalweg}

Der Wnt/Ca ${ }^{2+}$-Signalweg kann durch Wnt5a zusammen mit dem Rezeptor Fzd2 (Slusarski et al., 1997; Sheldahl et al. 1999; Kühl et al., 2000 b) oder Fzd5 (He et al., 1997; Weeraratna et al.; 2002, Blanc et al., 2005) angeschaltet werden. Die Bindung von Wnt führt zur Aktivierung eines heterotrimären G-Proteins, dessen Untereinheiten die Phospholipase C aktivieren. Diese wiederum bildet Diacylglycerol (DAG) und Inositoltrisphosphat $\left(\mathrm{IP}_{3}\right) . \mathrm{IP}_{3}$ bewirkt eine $\mathrm{Ca}^{2+}$-Freisetzung aus intrazellulären Speichern, wodurch die $\mathrm{Ca}^{2+} / \mathrm{Calmodulin}$ abhängige Kinase (CamKII) aktiv wird. Vermittelt durch das DAG kommt es außerdem zur Aktivierung von PKC (Kühl et al., 2000 a; Miller, 2001). Der Wnt/Ca ${ }^{2+}$-Signalweg ist vereinfacht in Abbildung 2 dargestellt. 


\subsubsection{Wnt/JNK/AP1-Signalweg}

In der Wnt/JNK/AP1-Signalkaskade vermittelt Wnt5a das Signal wahrscheinlich über die Rezeptoren Fzd3 und Fzd6 (Katoh, 2005; Qian et al., 2007). Ein direkter Nachweis dieser Vorgänge ist bisher noch nicht gelungen. Die Information wird über den second messenger Dishevelled (Dsh) nach intrazellulär weitergegeben. Wie die Signaltransduktion von Dsh bis zum Starten der JNK/AP1-Kaskade genau abläuft, ist nicht geklärt. Endpunkt der JNKKaskade ist die Phosphorylierung von c-Jun, welches dann zusammen mit Fos als sogenanntes AP1 die Expression der Zielgene aktiviert (Pukrop und Binder, 2008).

Über den Rezeptor Ror2 kommt es ebenfalls zur Aktivierung von JNK (Oishi et al., 2003; Schambony und Wedlich, 2007). In Abbildung 2 ist der Signalweg vereinfacht graphisch dargestellt.

\subsubsection{Wnt5a in der Entwicklung normaler Haut}

Untersuchungen an embryonaler und postnataler Haut haben gezeigt, dass Wnt-Proteine bei der Haarfollikelentwicklung eine essentielle Rolle spielen. Insbesondere die Proteine Wnt10a, Wnt10b und Wnt5a werden in frühen Stadien der Haarfollikelentwicklung spezifisch exprimiert.

Hierbei kann Wnt5a in der dermalen Papille und der inneren sowie der äußeren Wurzelscheide nachgewiesen werden (Reddy et al., 2001). Weiterhin wurde gezeigt, dass die Expression von Wnt5a in der Entwicklung der Haarfollikel durch Shh reguliert wird.

\subsubsection{Expression von Wnt5a und seine potentielle Funktion in BCC}

Von anderen Tumoren weiß man heute, dass Wnt5a in Abhängigkeit von der Tumorentität entweder eine onkogene oder suppressorische Wirkung hat. So ist die Wnt5a-Überexpression in Zellen des malignen Melanoms verantwortlich für dessen Invasivität (Weeraratna et al., 2002). In Karzinomzellen der Schilddrüse hingegen hemmt es die Proliferation, Migration, Invasivität und Klonogenität (Kremenevskaja et al. 2005). Die Wirkung von Wnt5a auf den einzelnen Tumor scheint durch den Rezeptorkontext der einzelnen Tumorentität bestimmt zu werden (Mikels und Nusse, 2006). 
Seit der Untersuchung von Bonifas ist bekannt, dass in humanen BCC neben Ptch und Gli1 auch Wnt5a überexprimiert wird (Bonifas et al., 2001; O’Driscoll et al., 2006). Zu Beginn dieser Arbeit war jedoch unbekannt, ob die Expression von Wnt5a in diesem Tumor durch den Hh-Signalweg induziert wird. Dies ist gut möglich, da Wnt5a während der Entwicklung der Haarfollikel durch Shh reguliert wird (Reddy et al., 2001, Kapitel 1.3.4).

Des Weiteren war unklar, ob Wnt5a in die Initiation von BCC involviert sein könnte. So ist es möglich, dass Wnt5a die Proliferation sowie die Apoptose- und Differenzierungsvorgänge von Keratinozyten moduliert und somit BCC initiiert.

Weiterhin herrscht bis heute Unklarheit darüber, ob der kanonische Wnt-Signalweg eine Rolle beim BCC spielt. So konnte bei einigen BCC eine nukleäre Lokalisation von $\beta C$ at detektiert werden (Yamazaki et al., 2001; El-Bahrawy et al., 2003; Saldanha et al., 2004; Salto-Tellez et al., 2006). Aufgrund dieser Erkenntnis wurde zunächst vermutet, Wnt5a würde über den kanonischen Signalweg $\beta$ Cat aktivieren und so die Progression und Proliferation der Tumoren verstärken. In einer anderen Studie (Bonifas et al., 2001) konnte in BCC-Tumorzellen jedoch kein Anstieg der Zielgene des kanonischen Wnt-Signalweges, bei denen es sich um c-Myc und Cyclin D1 handelt, nachgewiesen werden. Asplund et al. konnten diese Daten bestätigen und fanden sogar eine verminderte Expression von c-Myc in BCC (Asplund et al., 2008).

Es herrscht somit bis heute noch keine Klarheit darüber, ob der kanonische Signalweg in die Genese von BCC involviert ist. Außerdem ist nicht bekannt, ob Wnt5a in diesem Zusammenhang eine Rolle spielt. Da die Wirkung von Wnt5a vom Rezeptorkontext abhängig ist, könnte Wnt5a sowohl den kanonischen Signalweg aktivieren als auch inhibieren. Auch die Aktivierung der nicht-kanonischen Signalwege durch Wnt5a ist denkbar. Um diese Frage $\mathrm{zu}$ beantworten, muss zunächst die Expression von Fzd-Rezeptoren und die Aktivität von Wnt-Signalwegen in BCC erfasst werden. 


\section{$1.4 \quad$ Fragestellungen}

Wie ausführlich beschrieben wurde, werden sowohl der Hh/Ptch- als auch der WntSignalkaskade bei der Entstehung des BCC eine große Bedeutung zugeschrieben. Alle bisher durchgeführten Studien zeigen, dass es zwischen beiden Signalwegen mannigfaltige Interaktion geben könnte. Das Verständnis dieser Mechanismen ist für das Verständnis der Pathogenese von BCC essentiell und stellt einen möglichen pharmakologischen Angriffspunkt in der zukünftigen Therapie dieser Tumore dar.

Ziel dieser Arbeit war es, die Rolle von Wnt5a bei der Genese des BCC besser zu verstehen. Zunächst wurden im Rahmen dieser Arbeit nochmals die Aktivität der Hh-Signalkaskade und die Wnt5a-Expression in sowohl humanen und murinen BCC-Proben als auch in Keratinozyten- und BCC-Zelllinien überprüft.

Ein erster wichtiger Aspekt war die Frage, ob die erhöhte Expression von Wnt5a in BCC durch den Hh-Signalweg ausgelöst wird. Daten aus der Literatur legten nahe, dass die Expression von Wnt5a in Haarfollikeln durch Shh reguliert wird. Ob dies jedoch auch für BCC zutrifft, war unbekannt. Zur Beantwortung dieser Frage wurden deshalb zunächst Keratinozyten mit Shh stimuliert und die Expression von Wnt5a vermessen. Keratinozyten wurden deshalb verwendet, da sie als Modellvorläuferzellen des BCC gelten und im Gegensatz zu BCC-Zellen noch keine Aktivierung der Hh-Signalkaskade zeigen sollten.

Ein zweiter wichtiger Aspekt war die Frage nach dem Effekt von Wnt5a auf das Proliferations- und Differenzierungsverhalten von BCC-Zellen. Hierzu habe ich die BCCZelllinie ASZ001 mit rekombinantem Wnt5a behandelt und die Expression von Pcna und K10 untersucht.

Schließlich habe ich in murinen BCC-Proben versucht, die aktiven Wnt-Signalwege zu erfassen. Hierzu habe ich Western Blot und immunhistochemische Analysen durchgeführt. Von besonderem Interesse waren dabei die spezifisch durch Wnt5a aktivierten Signalwege. Da die Wirkung von Wnt5a auf seine Signalwege vom Rezeptorkontext abhängig ist, habe ich zusätzlich untersucht, welche Wnt-Rezeptoren in BCC, normaler Haut und in Keratinozytenund BCC-Zelllinien exprimiert werden. 


\section{Material und Methoden}

\subsection{Gebrauchswaren}

Tabelle 1: Gebrauchswaren

\begin{tabular}{|c|c|}
\hline Beschreibung & Hersteller \\
\hline 1,5-ml-SafeSeal-Reagiergefäß & Sarstedt AG \& Co., Nümbrecht, D \\
\hline 2 ml-PP-SafeSeal-Reagiergefäß & Sarstedt AG \& Co., Nümbrecht, D \\
\hline $\begin{array}{l}\text { serologische 5-ml-, } 10-\mathrm{ml}-\text { und } 25-\mathrm{ml} \\
\text { Pipetten }\end{array}$ & Sarstedt AG \& Co., Nümbrecht, D \\
\hline 6-Loch-Platten & Sarstedt AG \& Co., Nümbrecht, D \\
\hline 10- $\mu 1-$ und $20-\mu 1-$ Spitzen & Ochs GmbH, Bovenden, D \\
\hline 1000- $\mu 1$-Spitzen & Sarstedt AG \& Co., Nümbrecht, D \\
\hline $\begin{array}{l}\begin{array}{l}10-\mu 1-, \\
\text { spitzen }\end{array} \\
\text { spo- } \mu 1-, \quad 200-\mu 1-, \quad 1000-\mu 1-\text { Filter- }\end{array}$ & G. Kisker GbR, Steinfurt, D \\
\hline 15-ml- und 50-ml-PP-Test-tubes-Cellstar ${ }^{(R)}$ & Greiner Bio-One GmbH, Frickenhausen, D \\
\hline 96-Loch-PCR-Platten & 4titude ${ }^{(R)}$ Ltd., Ockley, GB \\
\hline Deckgläser & Menzel-Gläser, Braunschweig, D \\
\hline Dome Caped Stripes & $\begin{array}{l}\text { Thermo Scientific, Thermo Fisher Scientific } \\
\text { Corporate, Waltham, USA }\end{array}$ \\
\hline Filterpapier & Sartorius, Göttingen, D \\
\hline Glasküvetten & Carl Roth GmbH \& Co. KG, Karlsruhe, D \\
\hline Nitrocellulosemembran Hybond-C Extra & Amersham plc, Little Chalfont, UK \\
\hline Nunclon $^{\mathrm{TM}} \Delta$ surface Zellkultur-Platten & Nunc A/S, Roskilde, DK \\
\hline Objektträger SuperFrost ${ }^{\circledR}$ Plus & Menzel-Gläser, Braunschweig, D \\
\hline Plastikküvetten & Eppendorf, Hamburg, D \\
\hline QPCR Adhesive Clear Seals & 4titude ${ }^{\circledR}$ Ltd., Ockley, GB \\
\hline Röntgenfilm CL-XPosure ${ }^{\mathrm{TM}}$ Film & $\begin{array}{l}\text { Pierce, } \quad \text { Thermo Fisher } \\
\text { Corporate, Waltham, USA }\end{array}$ \\
\hline Thermo-Fast ${ }^{(B)}$ 384-Loch-PCR-Platten & Abgene Limited, Epsom, GB \\
\hline
\end{tabular}

\subsection{Laborgeräte}

Tabelle 2: Laborgeräte

\begin{tabular}{|l|l|}
\hline Laborgerät & Hersteller \\
\hline $\begin{array}{l}\text { ABI PRISM Sequence Detection System } \\
\text { HT7900 }\end{array}$ & Applied Biosystems, Darmstadt, D \\
\hline Analysenwaage ALC-110.4 & Sartorius, Göttingen, D \\
\hline Autoklav LaM-4-20-ECZ-J & $\begin{array}{l}\text { Adolf Wolf SANOclav, Bad Überkingen- } \\
\text { Hausen, D }\end{array}$ \\
\hline BioPhotometer 6131 & Eppendorf, Hamburg, D \\
\hline BP2100 und BP310 P Waagen & Sartorius, Göttingen, D \\
\hline Brutschrank BBD 6220 $\mathrm{CO}_{2}$ Inkubator & $\begin{array}{l}\text { Kendro Laboratory Products GmbH, Hanau, } \\
\text { D }\end{array}$ \\
\hline
\end{tabular}


Fortsetzung Tabelle 2: Laborgeräte

\begin{tabular}{|c|c|}
\hline Laborgerät & Hersteller \\
\hline Brutschrank B 6060 & $\begin{array}{l}\text { Kendro Laboratory Products GmbH, Hanau, } \\
\text { D }\end{array}$ \\
\hline $\begin{array}{l}\text { Elektrophoresestromquelle } \\
\text { 300V-500mA E385 }\end{array}$ & Consort, Turnhout, B \\
\hline $\begin{array}{l}\text { Entwicklungsmaschine für Röntgenfilme } \\
\text { CURIX } 60\end{array}$ & Agfa-Gevaert AG, Mortsel, B \\
\hline Gel Jet Imager & INTAS, Göttingen, D \\
\hline Heizblock Thermomixer compact & Eppendorf, Hamburg, D \\
\hline Homogenisator Miccra D-1 & $\begin{array}{l}\text { Art moderne Labortechnik e.K., Müllhausen, } \\
\text { D }\end{array}$ \\
\hline $\begin{array}{l}\text { Inverses Mikroskop mit Fluoreszenzfilter } \\
\text { Axiovert } 25 \text { (Filter Set 43, 01, 09) }\end{array}$ & Carl Zeiss AG, Oberkochen, D \\
\hline Kühlplatte Leika EG $1150 \mathrm{C}$ & Leika Microsystems, Nussloch, D \\
\hline Mastercycler epgradient $S$ & Eppendorf, Hamburg, D \\
\hline Microplate reader EL800 & Bio-Tek GmbH, Bad Fridrichshall, D \\
\hline Micro centrifuge & Carl Roth GmbH \& Co. KG, Karlsruhe, D \\
\hline Mikrotommesser Typ A35 & Feather Safety Razor Co. Ltd, Osaka, Japan \\
\hline Mikrowelle Dimension 4 & Panasonic \\
\hline Mitsubishi P91D & INTAS, Göttingen, D \\
\hline MR 3000 Heizrührer & Heidolph, Schwabach, D \\
\hline PAGE-Kammer (PerfectBlue S) & peqlab Biotechnologie $\mathrm{GmbH}$, Erlangen, D \\
\hline PA-Gelgießkammer (45-V10-SC2) & peqlab Biotechnologie $\mathrm{GmbH}$, Erlangen, D \\
\hline Peltier Thermal Cycler-100 & Bio-Rad, Hercules, USA \\
\hline pH-Meter inoLoab pH level 1 & $\begin{array}{l}\text { Wissenschaftlich-Technische Werkstätten } \\
\text { GmbH \& Co. KG, Weilheim, D }\end{array}$ \\
\hline Pipettierhilfe (Accu-jet) & Brand GmbH \& Co. KG, Wertheim, D \\
\hline Röntgenkassette & rego X-Ray GmbH, Augsburg, D \\
\hline Schlittenmikrotom Mod. Hn 40 & Reichert-Jung, Leica, München, D \\
\hline Sterilbank (Euroflow Klasse IIA) & Clean Air Techniek bv, Woerden, N \\
\hline UV-SYSTEME & INTAS, Göttingen, D \\
\hline Vip series $-86^{\circ} \mathrm{C}$ Freezer & Sanyo Electric Co., Ltd., Japan \\
\hline Vortex-Genie 2 & Bender \& Hobein AG, Zürich, CH \\
\hline Zählkammer nach Neubauer (Assistent) & Omnilab-Krannich, Göttingen, D \\
\hline Zentrifugen Biofuge pico, fresco und primo & Heraeus, Hanau, D \\
\hline Zentrifuge Multifuge 3 L-R & Heraeus, Hanau, D \\
\hline
\end{tabular}




\subsection{Software}

Tabelle 3 : Software

\begin{tabular}{|l|l|}
\hline Name & Hersteller \\
\hline FreeHand Mx 11.0.2 & Macromedia, Adobe Systems, San Jose, USA \\
\hline GDS & INTAS, Göttingen, D \\
\hline Microsoft Excel 2003 & Microsoft CO, Redmond, USA \\
\hline Microsoft Word 2003 & Microsoft CO, Redmond, USA \\
\hline Perl Primer 1.1.14 & Open Source, C Owen Marshall \\
\hline Quantity One 4.2.1 & Bio-Rad Laboratories GmbH, München, D \\
\hline SDS 2.2.1 & Applied Biosystems, Darmstadt, D \\
\hline
\end{tabular}

\subsection{Chemikalien und Reagenzien}

Tabelle 4: Chemikalien und Reagenzien

\begin{tabular}{|c|c|}
\hline Beschreibung / Name & Hersteller \\
\hline Ammoniumperoxodisulfat (APS) & Sigma-Aldrich Chemie GmbH, Steinheim, D \\
\hline Ampuwa $^{(B}$, Wasser für Injektionszwecke & $\begin{array}{l}\text { Fresenius Kabi Deutschland } \mathrm{GmbH} \text {, Bad } \\
\text { Homburg, D }\end{array}$ \\
\hline$\beta$-Mercaptoethanol & Sigma-Aldrich Chemie GmbH, Steinheim, D \\
\hline Borsäure & ICN Biomedicals INC., Eschwege, D \\
\hline Brilliant blue R250 & Sigma-Aldrich Chemie GmbH, Steinheim, D \\
\hline Bromphenol Blau & Sigma-Aldrich Chemie GmbH, Steinheim, D \\
\hline BSA (Albumin-FraktionV) & Carl Roth GmbH \& Co. KG, Karlsruhe, D \\
\hline Chloroform & Carl Roth GmbH \& Co. KG, Karlsruhe, D \\
\hline Citronensäuremonohydrat & Carl Roth GmbH \& Co. KG, Karlsruhe, D \\
\hline Cresol & Sigma-Aldrich Chemie GmbH, Steinheim, D \\
\hline di-Natriumhydrogenphosphat $\left(\mathrm{Na}_{2} \mathrm{HPO}_{4}\right)$ & Carl Roth GmbH \& Co. KG, Karlsruhe, D \\
\hline $\begin{array}{l}\text { EDTA (=Ethylendiamintetraessigsäure) } \\
\text { Dinatriumsalz Dihydrat }\end{array}$ & Carl Roth GmbH \& Co. KG, Karlsruhe, D \\
\hline Eisessig (=Essigsäure $>98 \%$ ) & Carl Roth GmbH \& Co. KG, Karlsruhe, D \\
\hline Ethanol 99\% & GeReSo GmbH, Einbeck, D \\
\hline Ethanol absolut & Mallinckrodt Baker, Deventer, H \\
\hline Formaldehyd $>35 \%$ & Carl Roth GmbH \& Co. KG, Karlsruhe, D \\
\hline GeneRulerTM 100 bp DNA Ladder Plus & Fermentas GmbH, St. Leon-Rot, D \\
\hline GeneRuler ${ }^{\mathrm{TM}} 1 \mathrm{~kb}$ DNA Ladder & Fermentas GmbH, St. Leon-Rot, D \\
\hline Glycerin & Carl Roth GmbH \& Co. KG, Karlsruhe, D \\
\hline Glycerol & Sigma-Aldrich Chemie GmbH, Steinheim, D \\
\hline I-Block & Tropix, Dedford, USA \\
\hline Immu-Mount & Thermo, Pittsburgh, USA \\
\hline Isopropanol $\geq 99,5 \%$ & Carl Roth GmbH \& Co. KG, Karlsruhe, D \\
\hline Kalziumchlorid $\left(\mathrm{CaCl}_{2}\right)$ & Sigma-Aldrich Chemie GmbH, Steinheim, D \\
\hline Mayers Hämalaunlösung & Merck, Darmstadt, D \\
\hline Methanol & Mallinckrodt Baker, Deventer, H \\
\hline Milchpulver & Carl Roth GmbH \& Co. KG, Karlsruhe, D \\
\hline
\end{tabular}


Fortsetzung Tabelle 4: Chemikalien und Reagenzien

\begin{tabular}{|l|l|}
\hline Beschreibung / Name & Hersteller \\
\hline Naphthol AS-BI Phosphat & Sigma-Aldrich Chemie GmbH, Steinheim, D \\
\hline Natriumchlorid (NaCl) & Carl Roth GmbH \& Co. KG, Karlsruhe, D \\
\hline Natriumdihydrogenphospaht $\left(\mathrm{NaH}_{2} \mathrm{PO}_{4}\right)$ & Carl Roth GmbH \& Co. KG, Karlsruhe, D \\
\hline Natriumdodecylsulfat (SDS) & ICN Biomedicals INC. Eschwege, D \\
\hline Natriumhydroxid (NaOH) & Carl Roth GmbH \& Co. KG, Karlsruhe, D \\
\hline Natriumnitrit & Sigma-Aldrich Chemie GmbH, Steinheim, D \\
\hline Natriumvanadat & Sigma-Aldrich Chemie GmbH, Steinheim, D \\
\hline Neufuchsin & Sigma-Aldrich Chemie GmbH, Steinheim, D \\
\hline N,N-Dimethylformamid & Sigma-Aldrich Chemie GmbH, Steinheim, D \\
\hline $\begin{array}{l}\text { N,N,N',N'-Tetramethylethylendiamin } \\
\text { (TEMED) }\end{array}$ & Sigma-Aldrich Chemie GmbH, Steinheim, D \\
\hline PBS Tabletten & \\
\hline peqGOLD TriFast TM reagent & Gibco, Invitrogen GmbH, Karlsruhe, D \\
\hline peqGOLD Universal Agarose & PeqLab Biotechnologie GmbH, Erlangen, D \\
\hline Phenylmethylsulfonylfluorid (PMSF) & PeqLab Biotechnologie GmbH, Erlangen, D \\
\hline Ponceau S & Carl Roth GmbH \& Co. KG, Karlsruhe, D \\
\hline Pufferlösung pH 4, pH 7, pH 9 & Sigma-Aldrich Chemie GmbH, Steinheim, D \\
\hline $\begin{array}{l}\text { Rotiphorese Gel 29:1 Acrylamid / Bisacryl- } \\
\text { amid }\end{array}$ & Carl Roth GmbH \& Co. KG, Karlsruhe, D \\
\hline RNAse-freies Wasser & Carl Roth GmbH \& Co. KG, Karlsruhe, D \\
\hline Salzsäure rauchend (HCl) & Qiagen GmbH, Hilden, D \\
\hline Sonnenblumenöl & Carl Roth GmbH \& Co. KG, Karlsruhe, D \\
\hline Tamoxifen & Sigma-Aldrich Chemie GmbH, Steinheim, D \\
\hline (-)-Tetramisol & Sigma-Aldrich Chemie GmbH, Steinheim, D \\
\hline Tris & Sigma-Aldrich Chemie GmbH, Steinheim, D \\
\hline Triton X-100 & Carl Roth GmbH \& Co. KG, Karlsruhe, D \\
\hline TrypLe & Sigma-Aldrich Chemie GmbH, Steinheim, D \\
\hline Tween 20 & Gibco, Invitrogen GmbH, Karlsruhe, D \\
\hline Xylol & Scharlau Chemie S.A, La Joto, ES \\
\hline & Mallinckrodt Baker, Deventer, H \\
\hline
\end{tabular}

\subsection{Gebrauchsfertige Reaktionssysteme}

Tabelle 5: Gebrauchsfertige Reaktionssysteme

\begin{tabular}{|l|l|}
\hline Reaktionssystem & Hersteller \\
\hline ECL plus-kit & Amersham plc, Little Chalfont, UK \\
\hline Nanoquant & Carl Roth GmbH \& Co. KG, Karlsruhe, D \\
\hline QuantiTect@ SYBR green PCR Kit & Qiagen GmbH, Hilden, D \\
\hline SuperScript II & Invitrogen GmbH, Karlsruhe, D \\
\hline
\end{tabular}




\subsection{Stammlösungen}

Tabelle 6 : Stammlösungen

\begin{tabular}{|c|c|}
\hline Lösung & Inhalte (Hersteller) \\
\hline Borsäure & $0,2 \mathrm{M}, \mathrm{pH} 5,1$ \\
\hline Casein & $2 \mathrm{~g}$ Casein, $1 \mathrm{ml} 100 \%$ Tween 20 \\
\hline Citrat-Puffer & $\begin{array}{l}\text { 1x; } 1 \mathrm{mM} \text { Citronensäuremonohydrat, } \mathrm{pH} 6,0 \\
\text { oder pH 3,0 }\end{array}$ \\
\hline Coomassie-Blau-Lösung & $\begin{array}{l}\text { 1x; } 0,25 \%(\mathrm{w} / \mathrm{v}) \text { Brilliant blue R250 gelöst } \\
\text { in } 40 \%(\mathrm{v} / \mathrm{v}) \text { Methanol; danach Zugabe von } \\
10 \%(\mathrm{v} / \mathrm{v}) \text { Eisessig und } 50 \%(\mathrm{v} / \mathrm{v}) \text { Aqua } \\
\text { dest. }\end{array}$ \\
\hline Cresol & $0,1 \%(\mathrm{w} / \mathrm{v})$ \\
\hline dNTP-Mix & $\begin{array}{l}\text { Je 10mM dATP, dTTP, dGTP und dCTP, } \\
\text { Roche Diagnostics GmbH, Mannheim, D }\end{array}$ \\
\hline DTT-Lösung & 0,1 M (Invitrogen $\mathrm{GmbH}$, Karlsruhe) \\
\hline EDTA-Lösung & 1x; 2 mM EDTA, pH 7,0 \\
\hline Ethidiumbromid-Lösung & $\begin{array}{l}0,07 \%, 1 \text { Tropfen pro } 50 \mathrm{ml} \text { Agarosegel, } \\
\text { Inno Train Diagnostik } \mathrm{GmbH} \text {, Kronberg, D }\end{array}$ \\
\hline FCS (Fetal Calf Serum) & Gibco, Invitrogen $\mathrm{GmbH}$, Karlsruhe \\
\hline First strand buffer & 5x, Invitrogen $\mathrm{GmbH}$, Karlsruhe \\
\hline Laemmli-Puffer & $\begin{array}{l}\text { 5x; } 100 \mathrm{mM} \text { Tris }(\mathrm{pH} 6,8), 5 \%(\mathrm{v} / \mathrm{v}) \\
\beta \text {-Mercaptoethanol, } 7 \% \text { (w/v) SDS, } 20 \% \\
\text { (v/v) Glycerol, } 2 \mathrm{mM} \text { EDTA (pH 7,0), } 0,1 \% \\
\text { Bromphenol Blau, 1 mM Natriumvanadat, } \\
1 \mathrm{mM} \text { PMSF, } 1 \mu \mathrm{g} / \mathrm{ml} \text { Aprotinin, } 1 \mu \mathrm{g} / \mathrm{ml} \\
\text { Leupeptin, } 1 \mu \mathrm{g} / \mathrm{ml} \text { Pepstatin }\end{array}$ \\
\hline Laufpuffer & $\begin{array}{l}\text { 1x; 0,2 M Glycin, } 25 \mathrm{mM} \text { Tris, } 0,1 \%(\mathrm{w} / \mathrm{v}) \\
\text { SDS, pH 8,3 }\end{array}$ \\
\hline Lysepuffer & $\begin{array}{l}\text { 1x; } 10 \mathrm{mM} \text { Tris } \mathrm{pH} 7,4,1 \mathrm{mM} \\
\text { Natriumvanadat, } 1 \mathrm{mM} \text { PMSF, } 1 \mu \mathrm{g} / \mathrm{ml} \\
\text { Leupeptin, } 1 \mu \mathrm{g} / \mathrm{ml} \text { Pepstatin, Zugabe von } \\
1 \%(\mathrm{w} / \mathrm{v}) \text { SDS nach Homogenisierung }\end{array}$ \\
\hline M-TBST & $\begin{array}{l}5 \%(\mathrm{w} / \mathrm{v}) \text { Milchpulver, } 0,1 \%(\mathrm{v} / \mathrm{v}) \text { Tween } 20 \\
\text { und } 1 \mathrm{x} \text { TBS }(\mathrm{pH} 7,45)\end{array}$ \\
\hline Neufuchsin-Entwicklerlösung & $\begin{array}{l}85-105 \mathrm{mM}(-)-T e t r a m i s o l, \\
30 \mathrm{mM} \text { Naphthol AS-BI Phosphat, } \\
145 \mathrm{mM} \text { Natriumnitrit, } \\
0,6 \%(\mathrm{v} / \mathrm{v}) \text { N,N-Dimethylformamid und } \\
0,2 \%(\mathrm{v} / \mathrm{v}) 5 \%(\mathrm{w} / \mathrm{v}) \text { Neufuchsin gelöst in } \\
\text { TBS, pH } 8,8\end{array}$ \\
\hline neutral-gepuffertes Formalin & $\begin{array}{l}30 \mathrm{mM} \mathrm{NaH} \mathrm{PO}_{4} \text { und } 50 \mathrm{mM} \mathrm{Na} \mathrm{NaPO}_{4} \text {, } \\
10 \%(\mathrm{v} / \mathrm{v}) \text { Formalin }>35 \% \text {, pH 7,0 }\end{array}$ \\
\hline PBS-Puffer (Phospat-gepufferte NaCl-Lsg.) & $\begin{array}{l}\text { 1x; 1 PBS-Tablette (Invitrogen GmbH, } \\
\text { Karlsruhe) gelöst in } 500 \mathrm{ml} \text { Aqua dest., } \\
\text { danach autoklaviert }\end{array}$ \\
\hline PCR-Puffer & \begin{tabular}{|llll} 
10x, Molzym & GmbH \\
Bremen
\end{tabular} \\
\hline Penicillin / Streptomycin & $\begin{array}{l}\text { Penicillin } 10000 \mathrm{U} / \mathrm{ml} \text {, Streptomycin } 10 \\
\mathrm{mg} / \mathrm{ml} \text {, PAN Biotech } \mathrm{GmbH} \text {, Aidenbach, D }\end{array}$ \\
\hline
\end{tabular}


Fortsetzung Tabelle 6: Stammlösungen

\begin{tabular}{|c|c|}
\hline Lösung & Inhalte (Hersteller) \\
\hline Ponceau-Lösung & $\begin{array}{l}1 \mathrm{x} ; \quad 0,5 \% \quad(\mathrm{w} / \mathrm{v}) \quad \text { Ponceau-S, } 1 \% \quad(\mathrm{v} / \mathrm{v}) \\
\text { Eisessig und } 98,5 \%(\mathrm{v} / \mathrm{v}) \text { Aqua dest. }\end{array}$ \\
\hline Proteinase XXIV & $5000 \mathrm{U} / 1$ Proteinase XXIV \\
\hline Proteinase $\mathrm{K}$ & $\begin{array}{l}150 \mathrm{U} \text { Proteinase } \mathrm{K}, 2 \mathrm{mM} \mathrm{CaCl} \text { in } \mathrm{TBS} \\
\text { (Volumen } 50 \mathrm{ml} \text { ) }\end{array}$ \\
\hline Sammelgel $(4,3 \%)$ & $\begin{array}{l}858 \mu 130 \%(\mathrm{w} / \mathrm{v}) \text { Acrylamid, } 2136 \mu \mathrm{l} 0,5 \mathrm{M} \\
\text { Tris/HCl pH 6,8, } 60 \mu \mathrm{l} 10 \%(\mathrm{w} / \mathrm{v}) \text { SDS, } \\
60 \mu \mathrm{l} 10 \%(\mathrm{w} / \mathrm{v}) \text { APS, } 6 \mu \mathrm{l} \text { TEMED, } 2932 \mu \mathrm{l} \\
\text { Aqua dest. }\end{array}$ \\
\hline SDS-Lösung & $10 \%(\mathrm{w} / \mathrm{v}) \mathrm{SDS}$ \\
\hline TBE-Puffer & $\begin{array}{l}\text { 1x; } 90 \mathrm{mM} \text { Tris, } 90 \mathrm{mM} \text { Borsäure und } 2 \mathrm{mM} \\
\text { EDTA, pH 8,0 }\end{array}$ \\
\hline TBS-Puffer (Tris-gepufferte NaCl-Lsg.) & 1x; $50 \mathrm{mM}$ Tris, $145 \mathrm{mM} \mathrm{NaCl}, \mathrm{pH} 7,5$ \\
\hline TBST-Puffer & $0,1 \%(\mathrm{v} / \mathrm{v})$ Tween 20 und $1 \mathrm{x}$ TBS-Puffer \\
\hline TE-Puffer & 1x; 1 mM Tris, 1 mM EDTA, $\mathrm{pH} 9$ \\
\hline Transferpuffer für Wester Blot & $\begin{array}{l}10 \%(\mathrm{v} / \mathrm{v}) 10 \mathrm{x} \text { Transferlösung, } 15 \%(\mathrm{v} / \mathrm{v}) \\
\text { Methanol, } 75 \%(\mathrm{v} / \mathrm{v}) \text { Aqua dest. }\end{array}$ \\
\hline Transferlösung für Western Blot & $\begin{array}{l}\text { 10x; } 250 \mathrm{mM} \text { Tris, 1,92 M Glycin, 0,2\% } \\
\text { (v/v) } 10 \% \text { SDS-Lösung }\end{array}$ \\
\hline Trenngel (10\%) & 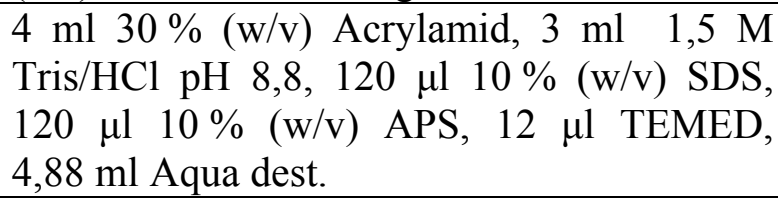 \\
\hline Tris-Lösung & $1 \mathrm{x} ; 100 \mathrm{mM}$ Tris, $\mathrm{pH} 6,8$ \\
\hline Trypsin & $20 \mathrm{U} / 1$ Trypsin und $3,4 \mathrm{mM} \mathrm{CaCl}_{2}$ in TBS \\
\hline
\end{tabular}

\subsection{Synthetische Oligonukleotide}

\subsubsection{Synthetische DNA-Oligonukleotide}

Synthetische DNA-Oligonukleotide wurden von der Firma Operon Biotechnologies GmbH, Köln, bezogen. Die Stammkonzentration von $100 \mu \mathrm{M}$ wurde mit Ampuwa eingestellt. Die für die PCR (Kapitel 2.12.4) eingesetzte Arbeitslösung wurde auf eine Konzentration von $10 \mu \mathrm{M}$ verdünnt.

\subsubsection{DNA-Oligonukleotide zur Genotypisierung von Mäusen}

Die Genotypisierung von Mäusen ist unter 2.16.3 und unter 2.12.4 beschrieben. Hierzu wurde mit den in Tabelle 7 aufgelisteten DNA-Oligonukleotiden gearbeitet. 
Tabelle 7: DNA-Oligonukleotide für Genotypisierung von Mauslinien.

\begin{tabular}{|c|c|c|c|c|}
\hline Name & Sequenz $5^{\prime}->3^{\prime}$ & $\underset{\left[{ }^{\circ} \mathrm{C}\right]^{*}}{\mathbf{T m}}$ & $\begin{array}{l}\text { Länge } \\
\text { [bp]* }\end{array}$ & $\begin{array}{c}\mathrm{GC} \\
{[\mathrm{mol} \%]^{*}}\end{array}$ \\
\hline EIIa-Cre F & $\begin{array}{l}\text { CCT GGA AAA TGC TTC TGT } \\
\text { CCG }\end{array}$ & 63,93 & 21 & 52 \\
\hline EIIa-Cre R & $\begin{array}{l}\text { CAG GGT GTT ATA AGC AAT } \\
\text { CCC }\end{array}$ & 60,81 & 21 & 47 \\
\hline mPTCNx_f & $\begin{array}{l}\text { TGG TAA TTC TGG GCT CCC } \\
\text { GT }\end{array}$ & 65,71 & 20 & 55 \\
\hline mPTCdelNx_f & $\begin{array}{lllll}\text { TTC ATT GAA CCT TGG GGA } \\
\text { ACA TT }\end{array}$ & 63,02 & 23 & 39 \\
\hline mPTCNx_r & 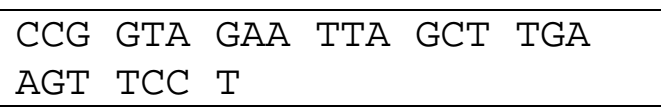 & 64,54 & 25 & 44 \\
\hline mPTCwt_r & TCA AGG AGC AGA GGC CCA A & 65,86 & 19 & 57 \\
\hline p910F.4 & $\begin{array}{l}\text { ACG ACC CTG GAC GAC ATC } \\
\text { CTA AA }\end{array}$ & 67,51 & 23 & 52 \\
\hline p1011R.2 & $\begin{array}{llllll}\text { TCT } & \text { GTC } & \text { CTG } & \text { TTT } & \text { CAC } & \text { TGA } \\
\text { ATG } & \text { CAT } & \text { GG } & & & \\
\end{array}$ & 67,43 & 26 & 46 \\
\hline NeoF & $\begin{array}{lllll}\text { CGT } & \text { GAT ATT GCT GAA GAG } \\
\text { CTT } & \text { GG } & & & \\
\end{array}$ & 64,07 & 23 & 47 \\
\hline NeoR & $\begin{array}{l}\text { GCA TCA GAG CAG CCG ATT } \\
\text { GTC TG }\end{array}$ & 68,28 & 23 & 56 \\
\hline Exon7F & $\begin{array}{llllll}\text { AGG } & \text { AAG } & \text { TAT } & \text { ATG } & \text { CAT } & \text { TGG } \\
\text { CAG } & \text { GAG } & & & & \\
\end{array}$ & 64,58 & 24 & 45 \\
\hline RosCre ER-F & ACC AGC CAG CTA TCA ACT C & 61,67 & 19 & 52 \\
\hline RosCre ER-R & $\begin{array}{llllll}\text { TAT } & \text { ACG } & \text { CGT } & \text { GCT } & \text { AGC } & \text { GAA } \\
\text { GAT } & \text { CTC } & \text { CAT } & \text { CTT } & \text { CCA } & \text { GCA }\end{array}$ & 75,27 & 37 & 51 \\
\hline
\end{tabular}

$\mathrm{m}=$ Maus (murin)

* Berechnungen unter Verwendung des Programms Perl Primer (perlprimer.sourceforge.net)

\subsubsection{DNA-Oligonukleotide für RT-PCR}

Der spezifische Nachweis von Transkripten erfolgte mittels PCR (Kapitel 2.12.4 und 2.12.5) an cDNA (2.12.3) und der in Tabelle 8 und Tabelle 9 aufgelisteten DNA-Oligonukleotide.

Tabelle 8: DNA-Oligonukleotide für RT-PCR (murin)

\begin{tabular}{|c|c|c|c|c|c|}
\hline Name & Sequenz $5^{\prime}->3^{\prime}$ & $\begin{array}{c}\mathbf{T m} \\
{\left[{ }^{\circ} \mathbf{C}\right]^{*}}\end{array}$ & $\begin{array}{l}\text { Länge } \\
\text { [ bp]* }\end{array}$ & $\begin{array}{c}\mathrm{GC} \\
{[\mathrm{mol} \%]} \\
*\end{array}$ & $\begin{array}{c}\text { DNA- } \\
\text { Fragment } \\
{[\text { [bp] }}\end{array}$ \\
\hline 18S-fwd & $\begin{array}{l}\text { CGC AAA TTA CCC ACT } \\
\text { CCC } \mathrm{G}\end{array}$ & 63,64 & 19 & 57 & \multirow[t]{2}{*}{81} \\
\hline 18S-rev2 & $\begin{array}{l}\text { TTC CAA TTA CAG GGC } \\
\text { CTC GAA }\end{array}$ & 63,92 & 21 & 47 & \\
\hline DKK1 F & $\begin{array}{lllll}\text { AGG } & \text { AAG } & \text { CGC } & \text { TGC } & \text { ATG } \\
\text { AGG } & \text { CA }\end{array}$ & 69,27 & 20 & 60 & \multirow[t]{2}{*}{184} \\
\hline DKK1 R & $\begin{array}{l}\text { AAG TCA GTG TGG TTC } \\
\text { TTC TGG }\end{array}$ & 62,27 & 21 & 47 & \\
\hline
\end{tabular}


Fortsetzung Tabelle 8: DNA-Oligonukleotide für RT-PCR (murin)

\begin{tabular}{|c|c|c|c|c|c|}
\hline Name & Sequenz $5^{\prime}->3^{\prime}$ & $\begin{array}{c}\mathbf{T m} \\
{\left[{ }^{\circ} \mathbf{C}\right]^{*}}\end{array}$ & $\begin{array}{l}\text { Länge } \\
\text { [ bp]* }\end{array}$ & $\begin{array}{c}\mathrm{GC} \\
{[\mathrm{mol} \%]} \\
*\end{array}$ & $\begin{array}{c}\text { DNA- } \\
\text { Fragment } \\
\text { [bp] }\end{array}$ \\
\hline mCutl-1F.1 & TGC AGC GAC TCC AGG CC & 67,46 & 17 & 70 & \multirow{2}{*}{132} \\
\hline hsCutl1R.1 & $\begin{array}{lllll}\text { CAG } & \text { CCT } & \text { GGC } & \text { CTT } & \text { TGA } \\
\text { GTT } & \text { TTT } & & & \end{array}$ & 64,07 & 21 & 47 & \\
\hline mFzd2F & $\begin{array}{l}\text { TGG GTA AGC CAG CAC } \\
\text { TGC AAG A }\end{array}$ & 68,87 & 22 & 54 & \multirow[t]{2}{*}{293} \\
\hline mFzd2R & $\begin{array}{lllll}\text { CTC } & \text { CTG } & \text { AGT } & \text { GAA } & \text { GGA } \\
\text { GGG } & \text { CAC } & \text { G } & & \end{array}$ & 68,88 & 22 & 63 & \\
\hline mFzd4F & $\begin{array}{l}\text { CGA GCT GCA GCT GAC } \\
\text { AAC TT }\end{array}$ & 65,79 & 20 & 55 & \multirow[t]{2}{*}{169} \\
\hline mFzd4R & $\begin{array}{ll}\text { GAC } & \text { TGG TTC ACA GCG } \\
\text { TCT } & \text { CT }\end{array}$ & 64,28 & 20 & 55 & \\
\hline mFzd5F & $\begin{array}{l}\text { ACA GGT ACC TAG CTT } \\
\text { GTC GTT }\end{array}$ & 63,26 & 21 & 47 & \multirow[t]{2}{*}{179} \\
\hline mFzd5R & $\begin{array}{lllll}\text { GCA } & \text { GCA } & \text { CTC } & \text { AGT } & \text { TCC } \\
\text { ACA } & \text { C } & & & \end{array}$ & 63,78 & 19 & 57 & \\
\hline mGli1-tq-f & $\begin{array}{l}\text { TAC ATG CTG GTG GTG } \\
\text { CAC } \\
\text { ATG }\end{array}$ & 65,59 & 21 & 52 & \multirow[t]{2}{*}{115} \\
\hline mGli1-tq-r & $\begin{array}{lclll}\text { ACC } & \text { GAA } & \text { GGT } & \text { GCG } & \text { TCT } \\
\text { TGA } & \text { GG } & & & \end{array}$ & 67,06 & 20 & 60 & \\
\hline mK1-F & $\begin{array}{l}\text { TCA ACG TTG AGG TTG } \\
\text { ACC CTC }\end{array}$ & 64,67 & 21 & 52 & \multirow[t]{2}{*}{232} \\
\hline mK1-R & $\begin{array}{lllll}\text { ACC } & \text { TTC } & \text { CTT } & \text { CTG } & \text { AGG } \\
\text { ATG } & \text { CTG } & & & \end{array}$ & 63,98 & 21 & 52 & \\
\hline mK10F & $\begin{array}{llll}\text { GGA } & \text { TGC } & \text { TGA } & \text { AGA } \\
\text { GTT } & \text { CAA }\end{array}$ & 62,68 & 21 & 47 & \multirow[t]{2}{*}{189} \\
\hline mK10R & $\begin{array}{lcccc}\text { TCT } & \text { GTT } & \text { TCT } & \text { GCC } & \text { AAG } \\
\text { GAG } & \text { GCT } & & & \end{array}$ & 66,26 & 21 & 52 & \\
\hline mPcnaF.1 & $\begin{array}{l}\text { AGA } \text { GCA } \\
\text { CTC }\end{array}$ & 62,6 & 19 & 52 & \multirow[t]{2}{*}{136} \\
\hline mPcnaR.1 & 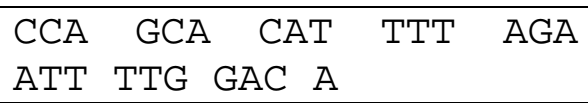 & 62,66 & 25 & 36 & \\
\hline mRor2F & GCG AAC TGC ATG CGC AT & 64,63 & 17 & 58 & \multirow[t]{2}{*}{143} \\
\hline mRor2R & $\begin{array}{lllll}\text { GGG } & \text { TGC } & \text { TGC } & \text { AGA } & \text { GCC } \\
\text { CAA } & & & & \\
\end{array}$ & 67,81 & 18 & 66 & \\
\hline mPtchgesamttq $F$ & $\begin{array}{l}\text { CTG GCA GAG GAC TTA } \\
\text { CGT GGA G }\end{array}$ & 66,63 & 22 & 59 & \multirow[t]{2}{*}{135} \\
\hline mPtchgesamttqR & $\begin{array}{l}\text { GCC ACT CGG ATG ACA } \\
\text { CTG ACA T }\end{array}$ & 66,93 & 22 & 54 & \\
\hline Wnt5aF & $\begin{array}{l}\text { TCC TAT GAG AGC GCA } \\
\text { CGC AT }\end{array}$ & 66,38 & 20 & 55 & \multirow[t]{2}{*}{225} \\
\hline Wnt5aR & $\begin{array}{lclll}\text { CAG } & \text { CTT } & \text { GCC } & \text { CCG } & \text { GCT } \\
\text { GTT } & \text { GA } & & & \end{array}$ & 70,47 & 20 & 65 & \\
\hline
\end{tabular}

$\mathrm{m}=$ Maus (murin); hs = Mensch (Homo sapiens)

* Berechnungen unter Verwendung des Programms Perl Primer (perlprimer.sourceforge.net) 
Tabelle 9: DNA-Oligonukleotide für RT-PCR (human)

\begin{tabular}{|c|c|c|c|c|c|}
\hline Name & Sequenz $5^{\prime}->3^{\prime}$ & $\begin{array}{c}\mathbf{T m} \\
{\left[{ }^{\circ} \mathrm{C}\right]^{*}}\end{array}$ & $\begin{array}{l}\text { Länge } \\
\text { [ bp]* }\end{array}$ & $\begin{array}{c}\mathrm{GC} \\
{[\mathrm{mol} \%]} \\
*\end{array}$ & $\begin{array}{c}\text { DNA- } \\
\text { Fragment } \\
\text { [bp] }\end{array}$ \\
\hline 18S-fwd & CGC AAA TTA CCC ACT CCC G & 63,64 & 19 & 57 & \multirow[t]{2}{*}{81} \\
\hline 18S-rev2 & $\begin{array}{l}\text { TTC CAA TTA CAG GGC CTC } \\
\text { GAA }\end{array}$ & 63,92 & 21 & 47 & \\
\hline $\begin{array}{l}\text { Hsa Gli1 F } \\
\text { tq }\end{array}$ & $\begin{array}{l}\text { AGC TAC ATC AAC TCC GGC } \\
\text { CA }\end{array}$ & 66,0 & 20 & 55 & \multirow[t]{2}{*}{116} \\
\hline $\begin{array}{l}\text { Hsa Gli1 R } \\
\text { tq }\end{array}$ & GCT GCG GCG TTC AAG AGA & 65,66 & 18 & 61 & \\
\hline hsCutl1F.1 & CCA AGC TGC GGG AGA ATT C & 63,66 & 19 & 57 & \multirow[t]{2}{*}{108} \\
\hline hsCutl1R.1 & $\begin{array}{l}\text { CAG CCT GGC CTT TGA GTT } \\
\text { TTT }\end{array}$ & 64,07 & 21 & 47 & \\
\hline hsFZD2F & CAT CAT GCC CAA CCT TCT & 59,58 & 18 & 50 & \multirow[t]{2}{*}{205} \\
\hline hsFZD2R & GGC TTC GCA GCC CT & 61,43 & 14 & 71 & \\
\hline hsFZD4F & $\begin{array}{l}\text { CGA GCT GCA GCT GAC AAC } \\
\text { TT }\end{array}$ & 65,79 & 20 & 55 & \multirow[t]{2}{*}{238} \\
\hline hsFZD4R & $\begin{array}{l}\text { TGG TCG TTC TGT GGT GGG } \\
\text { AA }\end{array}$ & 66,08 & 20 & 55 & \\
\hline hsFzd5-F2 & CCC AGC GTC AAG TCC AT & 61,69 & 17 & 58 & \multirow[t]{2}{*}{200} \\
\hline hsFzd5-R2 & TTG ATG ACG CTG CGG AT & 61,76 & 17 & 52 & \\
\hline hsPCNAF & $\begin{array}{l}\text { CAA CGA GGC CTG CTG GGA } \\
\text { TA }\end{array}$ & 66,67 & 20 & 60 & \multirow[t]{2}{*}{179} \\
\hline hSPCNAR & $\begin{array}{llllll}\text { CGG CGC ATT TTA GTA TTT } \\
\text { TGG A }\end{array}$ & 62,19 & 22 & 40 & \\
\hline hsROR2F & GCT CAT CCT CAT GCG GCT T & 65,35 & 19 & 57 & \multirow[t]{2}{*}{165} \\
\hline hsROR2R & $\begin{array}{l}\text { GTG CTT GCC GTT CCT CTG } \\
\text { TAA }\end{array}$ & 65,31 & 21 & 52 & \\
\hline hsWNT5AF & $\begin{array}{lllll}\text { GCT } & \text { CCT } & \text { ACG AGA } & \text { GTG } \\
\text { CTC } & \text { GCA } & \text { T }\end{array}$ & 68,64 & 22 & 59 & \multirow[t]{2}{*}{225} \\
\hline hsWNT5AR & ACT TGC CCC GGC TGT TGA & 67,06 & 18 & 61 & \\
\hline
\end{tabular}

hs $=$ Mensch (Homo sapiens)

* Berechnungen unter Verwendung des Programms Perl Primer (perlprimer.sourceforge.net) 


\subsection{Antikörper}

\subsubsection{Primäre Antikörper}

Tabelle 10: Primärantikörper

\begin{tabular}{|c|c|c|}
\hline Antikörper & $\begin{array}{l}\text { Herkunft, Klonalität, } \\
\text { Anwendung, Verdünnung }\end{array}$ & Hersteller \\
\hline$\beta$-Catenin & $\begin{array}{l}\text { Kaninchen, polyklonal, } \mathrm{IHC}^{\mathrm{a}} \text {, } \\
1: 1.000, \mathrm{WB}^{\mathrm{b}}, 1: 5.000\end{array}$ & $\begin{array}{l}\text { Zur Verfügung gestellt von } \\
\text { Felix Brembeck, Universität } \\
\text { Göttingen }\end{array}$ \\
\hline HSC 70 (B-6): sc-7298 & $\begin{array}{l}\text { Maus, monoklonal, } \mathrm{WB}^{\mathrm{b}} \text {, } \\
1: 25.000\end{array}$ & $\begin{array}{l}\text { Santa Cruz Biotechnology } \\
\text { INC., Santa Cruz, USA }\end{array}$ \\
\hline $\begin{array}{lll}\text { Phospho-PKC } & \text { (pan) } & (\beta I I \\
\text { Ser660) \#9371 } & & \end{array}$ & $\begin{array}{l}\text { Kaninchen, polyklonal, } \mathrm{IHC}^{\mathrm{a}} \\
1: 100, \mathrm{WB}^{\mathrm{b}}, 1: 1.000\end{array}$ & $\begin{array}{l}\text { Cell Signaling Technology } \\
\text { INC., Beverly, USA }\end{array}$ \\
\hline $\begin{array}{l}\text { Phospho-PKC } \\
\text { (Thr638/641) \#9375 }\end{array}$ & $\begin{array}{l}\text { Kaninchen, polyklonal, } \mathrm{WB}^{\mathrm{b}} \text {, } \\
1: 1.000\end{array}$ & $\begin{array}{l}\text { Cell Signaling Technology } \\
\text { INC., Beverly, USA }\end{array}$ \\
\hline $\begin{array}{l}\text { Phospho-SAPK/JNK } \\
\text { (Thr183/Tyr185)(81E11) } \\
\text { \#4668 }\end{array}$ & $\begin{array}{l}\text { Kaninchen, monoklonal, } \\
\mathrm{WB}^{\mathrm{b}}, 1: 1.000\end{array}$ & $\begin{array}{l}\text { Cell Signaling Technology } \\
\text { INC., Beverly, USA }\end{array}$ \\
\hline Phospho-JNK (G-7): sc-6254 & $\begin{array}{l}\text { Maus, monoklonal, } \mathrm{WB}^{\mathrm{b}} \text {, } \\
1: 1.000\end{array}$ & $\begin{array}{l}\text { Santa Cruz Biotechnology } \\
\text { INC., Santa Cruz, USA }\end{array}$ \\
\hline SAPK/JNK \#9252 & $\begin{array}{l}\text { Kaninchen, polyklonal, } \mathrm{WB}^{\mathrm{b}} \text {, } \\
1: 2.500\end{array}$ & $\begin{array}{l}\text { Cell Signaling Technology } \\
\text { INC., Beverly, USA }\end{array}$ \\
\hline
\end{tabular}

${ }^{\mathrm{a}}$ Immunhistochemie (Kapitel 2.14), ${ }^{\mathrm{b}}$ Western Blot (2.15)

\subsubsection{Sekundäre Antikörper}

Tabelle 11: Sekundärantikörper

\begin{tabular}{|l|l|l|}
\hline Antikörper & $\begin{array}{l}\text { Herkunft, Klonalität, } \\
\text { Anwendung, Verdünnung, } \\
\text { Konjugat }\end{array}$ & Hersteller \\
\hline Anti-Kaninchen & $\begin{array}{l}\text { Ziege, polyklonal, IHC } \\
1: 50, \text { alkalische Phospha- } \\
\text { tase (AP) }\end{array}$ & $\begin{array}{l}\text { Dako Deutschland GmbH, } \\
\text { Hamburg, D }\end{array}$ \\
\hline Anti-Kaninchen & $\begin{array}{l}\text { Ziege, polyklonal, WB } \\
1: 5.000 \text { Meerrettichperoxi- } \\
\text { dase (HRP) }\end{array}$ & Sigma, Saint Louis, USA \\
\hline Anti-Maus & $\begin{array}{l}\text { Ziege, polyklonal, IHC } \\
1: 500, \text { alkalische Phospha- } \\
\text { tase (AP) }\end{array}$ & $\begin{array}{l}\text { Dako Deutschland GmbH, } \\
\text { Hamburg, D }\end{array}$ \\
\hline Anti-Maus & $\begin{array}{l}\text { Kaninchen, polyklonal, WB } \\
1: 10.000 \text { Meerrettichperoxi- } \\
\text { dase (HRP) }\end{array}$ & Dianova GmbH, Hamburg, D \\
\hline
\end{tabular}

\footnotetext{
${ }^{\mathrm{a}}$ Immunhistochemie (Kapitel 2.14), ${ }^{\mathrm{b}}$ Western Blot (2.15)
} 


\subsection{Proteine}

Tabelle 12: Proteine

\begin{tabular}{|l|l|}
\hline Protein & Hersteller \\
\hline Leupeptin & Carl Roth GmbH \& Co. KG, Karlsruhe, D \\
\hline MolTaq & Molzym GmbH und Co KG, Bremen, D \\
\hline Pepstatin & Sigma-Aldrich Chemie GmbH, Steinheim, D \\
\hline Proteinase XXIV & Sigma-Aldrich Chemie GmbH, Steinheim, D \\
\hline Proteinase K & Carl Roth GmbH \& Co. KG, Karlsruhe, D \\
\hline $\begin{array}{l}\text { Precision Plus Protein, } \\
\text { Proteingrößenmarker }\end{array}$ & Bio-Rad Laboratories GmbH, München, D \\
\hline rmWnt-5a & R \& D Systems, Minneapolis, USA \\
\hline Trypsin & Sigma-Aldrich Chemie GmbH, Steinheim, D \\
\hline
\end{tabular}

\subsection{Medien}

\subsubsection{Medien für die Kultur eukaryotischer Zellen}

Die eukaryotischen Zellen (Tabelle 15, S. 23) wurden in Dulbecco's Modified Eagle Medium (DMEM) mit $10 \%$ fötalem Kälberserum (FCS, fetal calf serum) und Antibiotika kultiviert. Die ASZ001-Zellen wurden in 154CF, einem Wachstumsmedium speziell für Keratinozyten, welches nur eine geringe Menge an $\mathrm{Ca}^{2+}$ enthält, zusammen mit chelatiertem $2 \%$ FCS und Antibiotika kultiviert (So et al., 2006). Die Wachstumsmedien und ihre genaue Zusammensetzung sind in Tabelle 13 und Tabelle 14 aufgelistet.

Für bestimmte Experimente wurden die Konzentrationen der Bestandteile der Medien verändert. Diese Veränderungen sind direkt in der Beschreibung der Experimente angegeben. Die Herkunft und der Zelltyp der verschiedenen Zelllinien sind in Tabelle 15 aufgeführt.

Tabelle 13: Inhaltsstoffe der Zellkulturmedien

\begin{tabular}{|l|l|}
\hline Medien und Zusätze & Hersteller \\
\hline 154CF & Cascade Biologics, Mansfield, GB \\
\hline DMEM & Gibco, Invitrogen GmbH, Karlsruhe, D \\
\hline FCS & Gibco, Invitrogen GmbH, Karlsruhe, D \\
\hline Geneticinsulfat (G418) & Carl Roth GmbH \& Co. KG, Karlsruhe, D \\
\hline Penicillin / Streptomycin & PAN Biotech GmbH, Aidenbach, D \\
\hline
\end{tabular}


Tabelle 14: Zusammensetzung der Wachstumsmedien

\begin{tabular}{|c|c|c|c|c|c|c|}
\hline $\begin{array}{l}\text { Medien und } \\
\text { Zusätze }\end{array}$ & HaCaT & C5N & ASZ001 & $\begin{array}{c}\text { Mausfibro } \\
\text {-blasten }\end{array}$ & HEK293 & HEK293Shh \\
\hline $\begin{array}{l}\text { DMEM (1x) } \\
\text { + Glukose 4,5g/L; } \\
\text { + L-Glutamin } \\
\text { + Pyruvat }\end{array}$ & + & - & - & + & + & + \\
\hline $\begin{array}{l}\text { DMEM (1x) } \\
\text { + Glukose 4,5g/L } \\
\text { + L-Glutamin } \\
\text { - Pyruvat } \\
\end{array}$ & - & + & - & - & - & - \\
\hline $154 \mathrm{CF}$ & - & - & + & - & - & - \\
\hline $10 \%$ FCS & + & + & - & + & + & + \\
\hline $2 \%$ FCS & - & - & + & - & - & - \\
\hline 1\% Pen / Strep & + & + & + & + & + & + \\
\hline G418 $[400 \mu \mathrm{g} / \mathrm{ml}]$ & - & - & - & - & - & + \\
\hline
\end{tabular}

\subsubsection{Herstellung von Shh-konditioniertem Medium}

Zur Herstellung von Shh-konditioniertem Medium wurde die Zelllinie HEK293Shh verwendet, welche stabil mit Shh und dem Neomycinresistenzgen transfiziert ist und Shh produziert. Die Zellen wurden in Wachstumsmedium bestehend aus DMEM (+Pyruvat), $10 \%$ FCS, $1 \%$ Penicillin / Streptomycin (Pen/Strep) und $400 \mu \mathrm{g} / \mathrm{ml}$ Geneticinsulfat (G418) kultiviert. Nachdem die Zellen zu ca. 80 \% konfluent waren, wurde Medium zugegeben, welches DMEM (+Pyruvat), $2 \%$ FCS und $1 \%$ Pen/Strep enthielt. G418 wurde nicht mehr appliziert. Nach einer Inkubationszeit von $24 \mathrm{~h}$ wurde das Medium mit einer Pipette abgenommen und steril filtriert (Porengröße: 0,2 $\mu \mathrm{m}$ ).

Als Kontrolle diente Medium von HEK293-Zellen, welche nicht transfiziert waren. Das Medium wurde nach dem gleichen Protokoll wie bei den HEK293Shh gewonnen. Der einzige Unterschied bestand darin, dass dem Medium der HEK293-Zellen zu keiner Zeit G418 zugegeben wurde.

Beide Medien wurden nach Gewinnung im Verhältnis 1:1 mit DMEM, 0,5 \% (v/v) FCS und $1 \%(v / v)$ Pen/Strep verdünnt. 


\subsection{Biologisches Material}

\subsubsection{Eukaryotische Zelllinien}

Eukaryotische Zelllinien wurden mit den unter 2.10.1 beschriebenen Medien in speziellen $10 \mathrm{~cm}$ Zellkulturschalen bei $37^{\circ} \mathrm{C}$ in einer konstanten $\mathrm{CO}_{2}$-haltigen Atmosphäre $\left(5 \% \mathrm{CO}_{2}\right)$ mit $95 \%$ Luftfeuchtigkeit kultiviert.

Für die durchgeführten Versuche wurden insgesamt sechs verschiedene Zelllinien verwendet. Dabei handelte es sich um die humane Keratinozytenzelllinie HaCaT (Boukamp et al., 1988), die murine Keratinozytenzelllinie C5N (Kulesz-Martin et al., 1983; Holden et al., 1997), und die murine BCC-Zelllinie ASZ001 (So et al., 2006), in der Ptch mutiert ist. Des Weiteren wurden murine Fibroblasten, die aus der Dermis von Mäusen gewonnen wurden (Ptch flox/flox $)$, sowie die humane embryonale Nierenzelllinie HEK293 (aus dem Englischen „Human Embryonal Kidney“ cells) eingesetzt. Die HEK293Shh-Zellen überexprimieren aufgrund einer stabilen Transfektion mit einem Plasmid den aktiven Shh N-Terminus und das Gen für Neomyzinresistenz. In Tabelle 15 finden sich alle verwendeten Zelllinien.

Da es sich bei allen Linien um immortalisierte Zellen handelt, die möglicherweise wichtige physiologische Eigenschaften verloren haben, sind die Ergebnisse kritisch zu betrachten und eine Übertragung auf normale Zellen ist nicht immer möglich. Beispielsweise lässt sich laut Literturangaben durch Erhöhung der Kalziumkonzentration keine Differenzierung von C5N hervorrufen (Kulesz-Martin et al., 1983; Holden et al., 1997), während dies sonst bei Keratinozyten in vitro möglich ist (Hennings et al., 1980).

Tabelle 15: Auflistung der verwendeten eukaryotischen Zelllinien.

\begin{tabular}{|l|l|}
\hline Zelllinie & Spezies, Zelltyp \\
\hline ASZ001 & Mus musculus, Ptch-defizientes BCC \\
\hline C5N & Mus musculus, Keratinozyten \\
\hline HaCaT & Homo sapiens, Keratinozyten \\
\hline HEK293 & Homo sapiens, embryonale Nierenzellen \\
\hline HEK293Shh & Homo sapiens, embryonale Nierenzellen \\
\hline Murine Fibroblasten & $\begin{array}{l}\text { Mus musculus, dermale Fibroblasten aus } \text { Ptch }^{\text {flox/lox }}- \\
\text { Mäusen }\end{array}$ \\
\hline
\end{tabular}




\subsubsection{Mauslinien}

Zur Induktion von BCC wurden Mäuse des Genotyps $P t c h^{\text {floxflox }}$ ERT2 ${ }^{+-}$verwendet. Hierzu wurden konditionelle Ptch-knock-out-Mäuse $\left(P t c h^{\text {flox/flox }}\right)$ mit CreERT2 transgenen Mäusen verpaart. In den Ptch flox/flox -Mäusen sind Exon 8 und 9 von loxP-Sequenzen flankiert, welche somit durch das Enzym Cre-Rekombinase entfernt werden können (Uhmann et al., 2007). CreERT2 transgene Mäuse exprimieren ubiquitär eine Tamoxifen-induzierbare CreRekombinase (Hameyer et al., 2007). Durch intramuskuläre Applikation von $100 \mu \mathrm{g}$ Tamoxifen entwickeln die Tiere zunächst BCC-Vorläuferläsionen und später manifeste BCC. Die Präparation der BCC erfolgte zu zwei definierten Zeitpunkten. Entweder wurden die BCC als frühes Stadium nach 24 d nach der Tamoxifeninjektion oder als spätes Stadium nach 300 d präpariert.

\subsection{Molekularbiologische Methoden}

\subsubsection{Isolierung und Aufreinigung von Nukleinsäuren}

\subsubsection{Isolierung von genomischer DNA aus Gewebeproben}

Die Gewebeproben wurden mit $25 \mu$ Proteinase K und $500 \mu$ STE-Puffer kräftig vermischt und über Nacht bei $55^{\circ} \mathrm{C}$ inkubiert. Im Anschluss daran wurden Gewebereste durch Zentrifugation der Reaktionsansätze bei $13.000 \mathrm{Rpm}$ für 10 min pelettiert und $400 \mu 1$ des Überstands vorsichtig in $1 \mathrm{ml}$ kaltes $99 \%$-iges (v/v) Ethanol überführt. Die Reaktionsansätze wurden wieder kräftig gemischt und die genomische DNA durch 15-minütige Inkubation bei $-80^{\circ} \mathrm{C}$ und Zentrifugation (13.000 Rpm, $30 \mathrm{~min}, 4{ }^{\circ} \mathrm{C}$ ) gefällt. Der Überstand wurde anschließend vorsichtig dekantiert und das Nukleinsäurepellet in $500 \mu 1$ Ethanol (70\%, v/v) gewaschen (13.000 Rpm, $10 \mathrm{~min}, 4^{\circ} \mathrm{C}$ ). Der Überstand wurde vorsichtig dekantiert, das Nukleinsäurepellet getrocknet und die DNA in 30-60 $\mu 1$ Ampuwa vollständig bei $42{ }^{\circ} \mathrm{C}$ unter Schütteln (1.400 Rpm) resuspendiert.

\subsubsection{Isolierung von RNA}

\subsection{Isolierung von RNA aus Zellen}

Die Zellen, die in 6-Loch-Platten gehalten wurden, wurden mit $1 \mathrm{ml}$ kaltem 1x PBS gewaschen und anschließend mit $1 \mathrm{ml}$ TriFast $^{\mathrm{TM}}$ für $5 \mathrm{~min}$ auf Eis inkubiert. Durch das wiederholte Auf- und Abpipettieren von TriFast ${ }^{\mathrm{TM}}$ wurden die Zellen von der Platte gelöst. Die Reaktionsansätze wurden vollständig in je ein 2-ml-Reaktionsgefäß überführt, 2 min 
kräftig gemischt (auf dem Vortexer) und 5 min bei Raumtemperatur (RT) inkubiert. Nach Zugabe von $200 \mu$ l Chloroform wurden die Reaktionsansätze 1 min kräftig gemischt (Vortex) und für 3 min bei RT inkubiert. Durch Zentrifugation für 30 min bei $12.000 \mathrm{Rpm}$ und $4{ }^{\circ} \mathrm{C}$ wurden wässrige und organische Phase voneinander vollständig getrennt. Die obere wässrige Phase wurde in ein 2-ml-Reaktionsgefäß überführt, $500 \mu$ Isopropanol wurden zugegeben, kräftig gemischt und die RNA wurde bei $-20^{\circ} \mathrm{C}$ für mindestens $15 \mathrm{~min}$ und anschließender Zentrifugation (30 min bei $12.000 \mathrm{Rpm}$ und $4{ }^{\circ} \mathrm{C}$ ) gefällt. Der Überstand wurde vorsichtig dekantiert, das RNA-Pellet mit $1 \mathrm{ml} 70 \%$ (v/v) Ethanol zwei Mal gewaschen und anschließend bei $4{ }^{\circ} \mathrm{C}$ und $12.000 \mathrm{Rpm}$ für $10 \mathrm{~min}$ zentrifugiert. Nach vorsichtigem Dekantieren des Überstandes wurde das Pellet bei RT getrocknet. Die RNA wurde schließlich in $30 \mu \mathrm{l}$ RNAse-freiem destilliertem Wasser vollständig resuspendiert und bis zur Weiterverarbeitung bei $-80{ }^{\circ} \mathrm{C}$ gelagert.

\subsection{Isolierung von RNA aus Gewebe}

Die auf Trockeneis gelagerten oder frischen Gewebe wurden mit einem sterilen Skalpell zerkleinert und in ein steriles 13-ml-Röhrchen mit $2 \mathrm{ml}$ TriFast ${ }^{\mathrm{TM}}$ überführt. Bei Schwanzhautproben wurden zuvor die Epidermis und Anteile der Dermis von den Knochen vorsichtig abpräpariert. Das Gewebe wurde für 30 bis $60 \mathrm{sec}$ auf Eis homogenisiert (Homogenisator). Nach einer Inkubation von $5 \mathrm{~min}$ bei RT wurden $400 \mu \mathrm{l}$ Chloroform zugegeben und der Ansatz, wie unter 2.12.1.2.1 beschrieben, weiterbehandelt.

\subsubsection{Konzentrationsbestimmung von Nukleinsäurelösungen}

Die Konzentration von Nukleinsäurelösungen wurde photometrisch bei einer Wellenlänge von $260 \mathrm{~nm}$ ermittelt. Bei einer Optischen Dichte (O.D.) von 1,0 wird von folgenden Konzentrationen ausgegangen (Sambrook, 1989):

- doppelsträngige DNA (dsDNA) $50 \mu \mathrm{g} / \mathrm{ml}$

- RNA $40 \mu \mathrm{g} / \mathrm{ml}$

- Oligonukleotide $20 \mu \mathrm{g} / \mathrm{ml}$.

Das Verhältnis O.D.260/280 ist ein Maß für die Reinheit der Nukleinsäurelösung. Bei reinen RNA- bzw. DNA-Lösungen liegt dieser Wert bei 1,8-2,0 (Sambrook, 1989). Niedrigere Werte 
weisen auf eine Verunreinigung mit z.B. Phenol oder Protein hin. Für die Messung wurden 2 $\mu \mathrm{l}$ einer Probe in $98 \mu \mathrm{l}$ Ampuwa gelöst.

\subsubsection{Synthese von cDNA}

Ausgehend von Gesamt-RNA wurde cDNA mit der SuperScript II Reverse Transkriptase (Invitrogen $\mathrm{GmbH}$, Karlsruhe, D) synthetisiert. Hierzu wurden zunächst die folgenden Komponenten vermengt:

$\begin{array}{lcc}\text { Gesamt-RNA } & 2 & \mu \mathrm{g} \\ \text { Random Hexamer }(50 \mathrm{ng} / \mu \mathrm{l}) & 5 & \mu \mathrm{l} \\ \mathrm{H}_{2} \mathrm{O}_{\text {deion. }} \text { (RNase-frei) } & 7 & \mu \mathrm{l}\end{array}$

Der Reaktionsansatz wurde zur Denaturierung bei $70^{\circ} \mathrm{C}$ für $10 \mathrm{~min}$ inkubiert. Anschließend wurden dem Reaktionsansatz die folgenden Komponenten zugegeben:

$\begin{array}{lcc}\text { First Strand Buffer (5-fach) } & 4 & \mu \mathrm{l} \\ \text { DTT }(0,1 \mathrm{M}) & 2 & \mu \mathrm{l} \\ \text { dNTP-Mix }(10 \mathrm{mM}) & 1 & \mu \mathrm{l}\end{array}$

Der Reaktionsansatz wurde erst für 10 min bei RT und dann für 2 min bei $42{ }^{\circ} \mathrm{C}$ inkubiert. Nach Zugabe von 40 Units Enzym (SuperScript II Reverse Transkriptase) wurde der Reaktionsansatz für weitere $60 \mathrm{~min}$ bei $42{ }^{\circ} \mathrm{C}$ inkubiert. Die Reaktion wurde durch Inkubation bei $70{ }^{\circ} \mathrm{C}$ für 10 min gestoppt. Die synthetisierte cDNA wurde bis zur Weiterverarbeitung bei $-20{ }^{\circ} \mathrm{C}$ gelagert. 


\subsubsection{Polymerase-Kettenreaktion (PCR)}

DNA-Fragmente aus genomischer DNA oder cDNA wurden in einer Standardreaktion in einem Endvolumen von $10 \mu 1$ mittels PCR amplifiziert:

\begin{tabular}{|c|c|}
\hline Matrize $(100 \mathrm{ng} / \mu \mathrm{l})$ & 1 \\
\hline Polymerase-Puffer (10-fach) & 1 \\
\hline Cresol $(0,1 \%(w / v))$ & 1 \\
\hline $\mathrm{dNTP}(10 \mathrm{mM})$ & 0,2 \\
\hline Primer forw. $(10 \mu \mathrm{M})$ & 0,5 \\
\hline Primer rev. $(10 \mu \mathrm{M})$ & 0,5 \\
\hline MolTaq Polymerase (5 U/ $\mu \mathrm{l})$ & 0,1 \\
\hline $\mathrm{H}_{2} \mathrm{O}_{\text {deion. }}$ & 10 \\
\hline
\end{tabular}

Der durch den Hersteller (Molzym GmbH \& Co.KG, Bremen) mitgelieferte PolymerasePuffer enthielt $\mathrm{MgCl}_{2}$ in einer Endkonzentration von 1,5 mM. Bis auf die Matrize und das Enzym wurden alle Komponenten des Reaktionsansatzes der Reihe nach in einem sog. Master Mix zusammengegeben und kräftig gemischt. Um unspezifische Amplifikationsprodukte zu minimieren, wurde dem Reaktionsansatz die Polymerase als letzte Komponente zugegeben und noch einmal kräftig gemischt.

Der Reaktionsansatz wurde zur vollständigen Denaturierung der DNA für wenigstens 2 min bei $94{ }^{\circ} \mathrm{C}$ inkubiert. An diese Denaturierungsphase schloss sich im Standardansatz ein Temperaturzyklus an, der routinemäßig 33x wiederholt wurde: $20 \mathrm{sec}$ Denaturierungsphase bei $94{ }^{\circ} \mathrm{C}, 20 \mathrm{sec}$ Hybridisierungsphase bei $60{ }^{\circ} \mathrm{C}$ und $30 \mathrm{sec}$ Polymerisationsphase bei $72{ }^{\circ} \mathrm{C}$. Die Dauer der Polymerisationsphase wurde bei größeren Fragmenten entsprechend verlängert (ca. $1 \mathrm{~min} / \mathrm{kb}$ ). Dauer und Temperatur der Hybridisierungsphase wurden bei Bedarf entsprechend angepasst und richteten sich nach der theoretischen Schmelztemperatur $\left(T_{m}\right)$ der eingesetzten sequenzspezifischen Oligonukleotide, die mit Hilfe des Programms Perl Primer (perlprimer.sourceforge.net) auf Basis des Nearest-Neighborhood-Algorithmus berechnet worden war. In Tabelle 16 finden sich die genauen PCR-Profile für die Genotypisierung von Mäusen. Die Eigenschaften der PCR-Primer finden sich in Kapitel 2.7.2 in Tabelle 7.

Nach Ablauf der Zyklen wurden die Reaktionsansätze entweder direkt weiterverarbeitet oder bei $8{ }^{\circ} \mathrm{C}$ für $24 \mathrm{Std}$. bzw. $-20^{\circ} \mathrm{C}$ gelagert. 
Tabelle 16: PCR-Profile für die Genotypisierung von Mäusen

\begin{tabular}{|c|c|c|c|}
\hline \multicolumn{2}{|c|}{$\begin{array}{l}\text { p910F.4 - p1011R.2 } \\
\text { NeoF - p1011R.2 }\end{array}$} & \multicolumn{2}{|l|}{$\begin{array}{l}\text { p910F.4-NeoR } \\
\text { Exon7F-NeoR }\end{array}$} \\
\hline \multicolumn{2}{|l|}{$5 \min 94{ }^{\circ} \mathrm{C}$} & \multicolumn{2}{|l|}{$4 \min 94{ }^{\circ} \mathrm{C}$} \\
\hline $1 \mathrm{~min}$ & $94^{\circ} \mathrm{C}$ & $1 \mathrm{~min}$ & $94^{\circ} \mathrm{C}$ \\
\hline $1 \mathrm{~min}$ & $62^{\circ} \mathrm{C}$ & $1 \mathrm{~min}$ & $60{ }^{\circ} \mathrm{C}$ \\
\hline $3 \mathrm{~min}$ & $72{ }^{\circ} \mathrm{C}$ & $3 \mathrm{~min}$ & $72{ }^{\circ} \mathrm{C}$ \\
\hline & \multicolumn{2}{|l|}{$5 \min \quad 72{ }^{\circ} \mathrm{C}$} \\
\hline \multicolumn{4}{|c|}{ mPTCNx_f - mPTCNx_r } \\
\hline \multicolumn{4}{|c|}{ mPTCdelNx_f - mPTCNx_r } \\
\hline \multicolumn{2}{|c|}{ mPTCNx_f - mPTCwt_r } & \multicolumn{2}{|c|}{ EIIa-Cre F - EIIa-Cre R } \\
\hline \multicolumn{2}{|l|}{$2 \min \quad 95^{\circ} \mathrm{C}$} & \multicolumn{2}{|l|}{$4 \min \quad 95^{\circ} \mathrm{C}$} \\
\hline $30 \mathrm{sec}$ & $95^{\circ} \mathrm{C}$ & \multirow{3}{*}{$\begin{array}{l}1 \mathrm{~min} \\
1 \mathrm{~min} \\
1 \mathrm{~min}\end{array}$} & $95^{\circ} \mathrm{C}$ \\
\hline $34 \mathrm{x}$ & $60^{\circ} \mathrm{C}$ & & $67^{\circ} \mathrm{C}$ \\
\hline $45 \mathrm{sec}$ & $72{ }^{\circ} \mathrm{C}$ & & $72{ }^{\circ} \mathrm{C}$ \\
\hline $5 \min \quad 72^{\circ} \mathrm{C}$ & & $10 \min 72^{\circ} \mathrm{C}$ & \\
\hline \multicolumn{2}{|c|}{ RosCre ER-F - RosCre ER-R } & & \\
\hline \multicolumn{2}{|l|}{$3 \min \quad 95^{\circ} \mathrm{C}$} & & \\
\hline \multirow[b]{2}{*}{$35 x$} & $95^{\circ} \mathrm{C}$ & & \\
\hline & $56^{\circ} \mathrm{C}$ & & \\
\hline $50 \mathrm{sec}$ & $72^{\circ} \mathrm{C}$ & & \\
\hline $10 \min 72^{\circ} \mathrm{C}$ & & & \\
\hline
\end{tabular}

\subsubsection{Quantitative Real Time PCR (qRT-PCR)}

Die Quantifizierung von DNA oder RNA ist durch die quantitative Real Time PCR möglich. Die Methode basiert auf der Messung eines emittierten Fluoreszenzsignals innerhalb jedes Zyklus im Verlauf der PCR. Die Intensität des Fluoreszenzsignals innerhalb des Reaktionsverlaufes kann mit der Menge der als Matrize eingesetzten DNA oder cDNA korreliert werden. 


\subsubsection{Prinzip der qRT-PCR}

Im Reaktionsverlauf einer PCR nimmt die Menge an amplifiziertem Produkt zu. Ab einer bestimmten Zyklenzahl folgt der Reaktionsverlauf einem exponentiellen Profil, bis eine Komponente der PCR limitierend wirkt (i.d.R. das Enzym).

Für die qRT-PCR können grundsätzlich zwei methodische Ansätze unterschieden werden: (i) Zugabe eines interkalierenden Fluoreszenzfarbstoffes (SYBR ${ }^{\circledR}$ Green) und (ii) Zugabe von einer Sonde, die mit einem entsprechenden Fluoreszenzfarbstoff gekoppelt ist.

In beiden Fällen ist die Zunahme des Fluoreszenzsignals $\left(R_{n}\right)$ im Reaktionsverlauf direkt korreliert mit der Zunahme von PCR Produkt. Durch Normalisierung des gemessenen Signals mit einem Referenzfarbstoff (z.B. 6-Carboxy-X-rhodamin) kann das normalisierte Fluoreszenzsignal $\left(\Delta \mathrm{R}_{\mathrm{n}}\right)$ halblogarithmisch gegen die Zyklenzahl in einer Kurve dargestellt werden (Abbildung 3). In der exponentiellen Phase des Reaktionsverlaufes folgt die resultierende Kurve der Gleichung:

(Formel 1)

$$
y=m x+b
$$

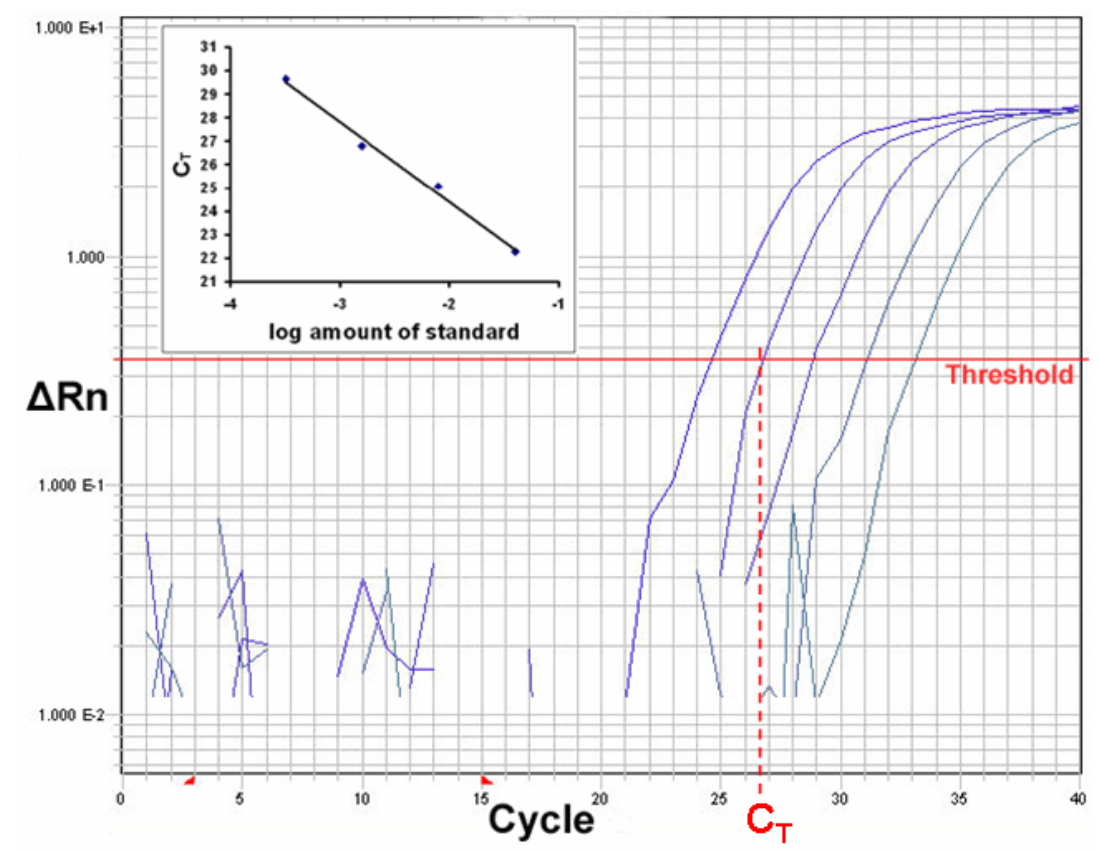

Abbildung 3 : $\mathrm{C}_{\mathrm{T}}$ Wert und Standardkurve.

Der $\mathrm{C}_{\mathrm{T}}$ Wert kennzeichnet den Punkt des Reaktionsverlaufes, an dem das gemessene Fluoreszenzsignal einen definierten Schwellenwert erreicht. Bei den dargestellten Kurven handelt es sich um eine Standardkurve mit cDNA bekannter Konzentration als Matrize. Die halblogarithmische Auftragung der ermittelten $\mathrm{C}_{\mathrm{T}}$-Werte gegen den Logarithmus der Konzentrationswerte ermöglicht die Berechnung der Menge eingesetzter Matrize einer Probe.

Der Punkt der Kurve, an dem das gemessene Fluoreszenzsignal einen definierten Schwellenwert erreicht, wird als Threshold Cycle $\left(\mathrm{C}_{\mathrm{T}}\right)$ bezeichnet (Abbildung 3). In diesem Punkt liegt das gemessene Fluoreszenzsignal signifikant über dem Hintergrundrauschen. Der 
$\mathrm{C}_{\mathrm{T}}$ Wert ist umgekehrt proportional $\mathrm{zu}$ dem logarithmischen Wert der Konzentration der Matrize, die für die PCR eingesetzt wurde. Anhand einer zuvor erstellten Standardkurve und der o.g. Formel 1 kann so der $\mathrm{C}_{\mathrm{T}}$-Wert in einen Konzentrationswert umgerechnet werden.

\subsubsection{Relative Quantifizierung}

Für den Vergleich des Expressionsniveaus eines Genes in unterschiedlichen Proben wurde in dieser Arbeit SYBR ${ }^{\circledR}$ Green (QuantiTect ${ }^{\circledR}$ SYBR green PCR Kit, Fa. Qiagen, Hilden) verwendet. Die mit dem Sequence Detection System HT7900 (Applied Biosystems, Darmstadt) ermittelten Daten wurden anhand der Standardkurvenmethode für die relative Quantifizierung verrechnet.

Für die Standardkurve wurde $18 \mathrm{~S}$ rRNA als endogene Kontrolle mit sequenzspezifischen Oligonukleotiden an cDNA eines Mausembryos (12,5 dpc) bzw. eines humanen BCC eingesetzt. Die Konzentration der eingesetzten cDNA lag in beiden Fällen zwischen 80 - 0,03 pg (serielle 1:5 Verdünnungen über sechs Stufen). Typischerweise betrugen die ermittelten Werte für die Amplifikationseffizienz zwischen 97 - $103 \%$. Die ermittelten $\mathrm{C}_{\mathrm{T}}$-Werte der Proben wurden auf der Basis einer Standardkurve verrechnet. Nach Normalisierung der berechneten Konzentrationswerte der Proben mit den entsprechenden Werten der endogenen Kontrolle wurde die relative Expression der eingesetzten Proben anhand eines geeigneten Kalibrators berechnet und graphisch dargestellt

\subsubsection{Auswertung}

Für die Auswertung wurden die ermittelten Daten zunächst mit dem Programm SDS 2.1 (Applied Biosystems, Darmstadt) prozessiert und anschließend mit Microsoft Excel (Microsoft Co., Redmond, USA) verrechnet.

\subsubsection{Agarose-Gelelektrophorese}

Die Agarose-Gelelektrophorese dient der Untersuchung von PCR-Produkten. Da DNA negativ geladen ist, läuft sie bei Gleichstrom im elektrischen Feld von der Kathode in Richtung der Anode. Kleinere DNA-Moleküle können die Gelmatrix besser passieren als größere, sodass es zu einer Auftrennung der Moleküle nach der Größe kommt. Die kleinsten DNA-Moleküle werden dabei am dichtesten an der Anode gefunden. 
Für die Elektrophorese wurden 1,5-prozentige Gele verwendet (1,5 mg Agarose wurden in $100 \mathrm{ml}$ 1x TBE-Puffer mit Hilfe einer Mikrowelle gelöst, danach wurden der Lösung 2 Tropfen Ethidiumbromid zugegeben). Ethidiumbromid interkaliert in DNA und kann durch UV-Licht zur Fluoreszenz angeregt werden. Auf diese Weise kann die untersuchte DNA im Gel nachgewiesen werden. Für die Größenzuordnung wurde jedem Ansatz ein Größenmarker beigefügt.

\subsection{Zellbiologische Methoden}

\subsubsection{Zellkultur eukaryotischer Zellen}

Die Zellen wurden routinemäßig in 10-cm-Petrischalen kultiviert. Das Nährmedium wurde alle 2 bis 3 Tage gewechselt. Nach etwa einer Woche oder wenn die Zellen zu ungefähr 80 \% konfluent waren, wurden die Zellen in neue Zellkulturschalen überführt. Dazu wurden die Zellen in 1x PBS gewaschen, dann wurde $2 \mathrm{ml}$ Trypsin zugegeben und für 2 bis 5 min inkubiert. Durch die Zugabe von $10 \mathrm{ml}$ DMEM, welches $10 \%$ FCS und $1 \%$ Pen/Strep enthielt, wurde die Reaktion durch die Verdünnung verlangsamt. Ein Milliliter dieser Suspension wurde in $10 \mathrm{ml}$ Wachstumsmedium einer neuen 10-cm-Platte überführt.

Für die Experimente wurden 60.000 Zellen in jede Vertiefung einer 6-Loch-Platte gegeben. Hierzu wurden nach der Trypsinierung $10 \mathrm{ml}$ der Zellsuspension für $5 \mathrm{~min}$ bei $300 \mathrm{xg}$ zentrifugiert. Nach Absaugen des Mediums wurde das Zellpellet in $1 \mathrm{ml}$ Nährmedium resuspendiert und die Zellkonzentration mittels Neubauer-Zählkammer bestimmt. Die Konzentration wurde nach folgender Gleichung berechnet.

(Formel 2)

$$
\begin{aligned}
& \mathrm{c}=\mathrm{Z} /\left(\mathrm{Q} \times 4 \times 10^{-6} \times \text { [Verdünnung] }\right) \\
& \mathrm{c}=\text { Zellkonzentration [Zellen/ml] } \\
& \mathrm{Z}=\text { Anzahl der gezählten Zellen } \\
& \mathrm{Q}=\text { Anzahl der ausgezählten Kleinquadrate }
\end{aligned}
$$

\subsubsection{Stimulation von Zellen mit Shh}

Nach dem Aussäen von je 60.000 der Zielzellen in jede Vertiefung einer 6-Loch-Platte wurden die Zellen zunächst für $24 \mathrm{~h}$ mit Wachstumsmedium kultiviert (Tabelle 14, S. 22). Dann wurde das Medium abgenommen und durch Medium mit einem Anteil von $2 \%$ FCS ersetzt und für $24 \mathrm{~h}$ synchronisiert (durch den geringen Anteil von FCS am Medium wird das Wachstum der Zellen gestoppt, die sich gerade im Zellzyklus befindliche Zellen können aber 
in den $24 \mathrm{~h}$ Inkubationszeit ihr Wachstum noch abschließen). Danach wurde in die entsprechenden Positionen entweder HEK-Medium oder Shh-konditioniertes Medium (Kapitel 2.10.2, S. 22; Abbildung 4) gegeben. Nach 24 h wurde das entsprechende Medium noch einmal erneuert. Nach weiteren $24 \mathrm{~h}$ wurden die Zellen mit PBS gewaschen und die RNA isoliert (Kapitel 2.12.1.2.1, S. 24f.). Als zusätzliche Kontrolle wurden Zellen mitgeführt, bei denen die Zellen nach dem Aussäen und dem Anwachsen in Wachstumsmedium für $72 \mathrm{~h}$ in DMEM $+2 \%$ FCS belassen wurden. Auch hier erfolgte nach Abschluss der Inkubationszeit die RNA-Isolierung.

Abbildung 4 zeigt den genauen Versuchsaufbau.

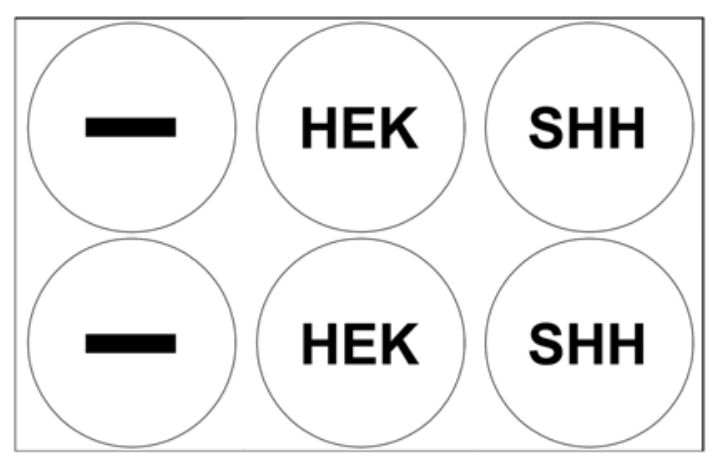

Abbildung 4: Schema der 6-Loch-Platte bei der Shh-Stimulation. In jeder Vertiefung befanden sich 60.000 Zielzellen. Nach 24 h Kultivierung in Wachstumsmedium wurden die Zellen für $24 \mathrm{~h}$ mit DMEM, $2 \%$ FCS und $1 \%$ Pen/Strep kultiviert. Danach erfolgte für $48 \mathrm{~h}$ die Stimulation mit dem Shh-konditioniertem Medium (Shh) und dem von HEK293-Zellen gewonnenem Kontrollmedium (HEK). Als weitere Kontrolle wurden Zellen unbehandelt (-) belassen.

\subsubsection{Stimulation von Zellen mit rWnt5a}

Nach Ausbringung von 60.000 Zellen pro Vertiefung wurden die Zellen zunächst für $24 \mathrm{~h}$ mit Wachstumsmedium (Tabelle 14, S. 22), danach für insgesamt 48 h mit DMEM, 2 \% FCS und $1 \%$ Pen/Strep kultiviert. Während der letzten $24 \mathrm{~h}$ wurden je $10 \mu \mathrm{l}$ PBS als Lösungsmittelkontrolle oder verschiedene Konzentrationen an rekombinantem Wnt5a gelöst in $10 \mu \mathrm{l}$ PBS (Kapitel 2.6, S. 15) zugegeben. Eine Position wurde unbehandelt belassen. Nach Abschluss der Inkubationszeit wurde die RNA der Zellen isoliert (Kapitel 2.12.1.2.1, S. 24f.).

Der Versuchsaufbau ist in Abbildung 5 gezeigt. 


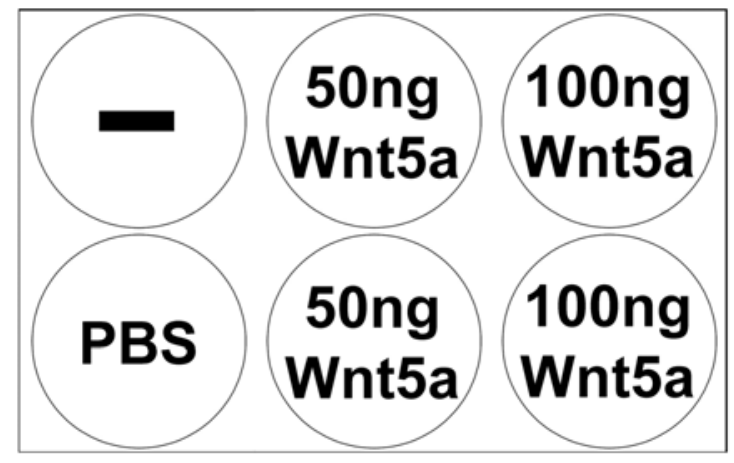

Abbildung 5: Schema der 6-Loch-Platte bei rWnt5a-Stimulation. In jeder Vertiefung befanden sich 60.000 Zellen. Nach $24 \mathrm{~h}$ Wachstum der Zellen in Wachstumsmedium wurden die Zellen für $48 \mathrm{~h}$ mit DMEM, $2 \%$ FCS und $1 \%$ Pen/Strep kultiviert. Die Stimulation der Zellen erfolgte für die letzten $24 \mathrm{~h}$ mit $50 \mathrm{ng}$ oder $100 \mathrm{ng}$ rekombinantem Wnt5a, gelöst in PBS, oder $10 \mu \mathrm{l}$ PBS (Lösungsmittelkontrolle). Als weitere Kontrolle wurden Zellen unbehandelt (-) belassen.

\subsection{Immunhistochemie (IHC)}

\subsubsection{Gewebeeinbettung zum Anfertigen von Paraffinschnitten}

$\mathrm{Zu}$ analysierende Organe und Gewebe wurden 24 bis $30 \mathrm{~h}$ bei RT in neutral-gepuffertem Formalin (Kapitel 2.6, S. 15) fixiert und danach direkt mit Hilfe eines Gewebeeinbett- und Gewebeentwässerungs-Automaten entwässert und maschinell in Paraffin eingegossen (Paraffinspender und Ausgießstation Tissue Block Dispenser PAG 12).

\subsubsection{Anfertigung von Paraffinschnitten und Entparaffinierung}

Paraffinschnitte wurden am Schlittenmikrotom angefertigt, auf SuperFrost ${ }^{\mathrm{TM}}$ Plus Objektträger aufgezogen und über Nacht bei $37^{\circ} \mathrm{C}$ getrocknet. Für immunhistologische Antikörperfärbungen (Kapitel 2.14.3) wurden die Paraffinschnitte entparaffiniert. Hierzu wurden die Schnitte 3x für $10 \mathrm{~min}$ in separaten $100 \%$ (v/v) Xylollösungen inkubiert. Dann wurden sie für je $30 \sec 2 \mathrm{x}$ in $99 \%$ (v/v) Ethanol und jeweils $1 \mathrm{x}$ in $95 \%$ (v/v), $90 \%$ (v/v), 70 $\%(\mathrm{v} / \mathrm{v})$ und $50 \%(\mathrm{v} / \mathrm{v})$ Ethanol geschwenkt, bevor sie dann gründlich in destilliertem Wasser gespült wurden. 


\subsubsection{Immunhistologische Antikörperfärbungen an Paraffinschnitten}

Paraffinschnitte wurden wie unter 2.14 .2 beschrieben angefertigt und entparaffiniert. Die Demaskierung der Epitope erfolgte in einem von insgesamt sieben verschiedenen Ansätzen. Dabei wurden die Schnitte bei 600 Watt 1x 4 min und 4x 3 min in der Mikrowelle in Citratpuffer mit pH 6 oder TE-Puffer aufgekocht. In anderen Ansätzen wurden die Schnitte bei $37^{\circ} \mathrm{C}$ in Citratpuffer mit pH 3 oder mit Trypsin für je 30 min, mit Proteinase $\mathrm{K}$ für 15 min oder mit Proteinase XXIV für 10 min inkubiert. Eine andere Möglichkeit bestand darin, die Schnitte für $30 \mathrm{~min}$ bei $58^{\circ} \mathrm{C}$ in Borsäure zu inkubieren. Die Schnitte aus der Mikrowelle bzw. aus dem $58{ }^{\circ} \mathrm{C}$ Inkubator wurden mit Aqua dest. langsam abgekühlt. Die jeweilige Vorbehandlung für die einzelnen Antikörper findet sich in der Versuchsbeschreibung im Ergebnissteil (Kapitel 3.4.1, S. 51). Danach wurden alle Schnitte für ca. 5 min in TBS mit $0,1 \%(\mathrm{v} / \mathrm{v})$ Triton- X 100 inkubiert. Bei allen nun folgenden Schritten wurden die Schnitte in einer feuchten Kammer inkubiert. Zunächst wurden mit 0,2\% I-Block/PBS 15 min Antikörperbindungsstellen blockiert. Dann wurde der Primärantikörper, in neun Teilen TBS und einem Teil I-Block/PBS gelöst, für 90 min auf die Schnitte gegeben. Eine Auflistung der verwendeten Primärantikörper findet sich in Tabelle 10 (S. 20). Um einer Verdunstung vorzubeugen, wurden die Schnitte für diese Zeit eingedeckt. Danach wurde 3x mit TBS gespült, der mit alkalischer Phosphatase konjugierte Sekundärantikörper (Tabelle 11, S. 20) für $60 \mathrm{~min}$ aufgebracht und erneut eingedeckt. Der anti-Kaninchen-Antikörper wurde ebenfalls in neun Teilen TBS und einem Teil I-Block/PBS gelöst, der anti-Maus-Antikörper hingegen in purem I-Block/PBS. Nach erneutem dreimaligem Waschen in TBS wurden die Schnitte 30 min auf einem Schwenktisch in der Neufuchsin-Entwicklerlösung (immer frisch angesetzt) inkubiert. Die Schnitte wurden anschließend mit Aqua dest. gespült und mit Mayers Hämalaunlösung $6 \mathrm{sec}$ (nukleäre Färbung) oder $17 \mathrm{sec}$ (zytoplasmatische Färbung) gegengefärbt. Nun wurde erneut mit Aqua dest. und dann mit Leitungswasser gespült. Am Ende wurden die Schnitte mit Immu-Mount (Kapitel 2.4, S. 13) und Menzel-Deckgläschen eingedeckt.

Alle genannten Puffer finden sich, soweit nicht anders angegeben, in Kapitel 2.6 (S. 15f.). 


\subsection{Western Blot (WB)}

\subsubsection{Isolierung von Gesamtprotein}

Die auf Trockeneis gelagerten oder frischen Gewebe wurden mit einem sterilen Skalpell zerkleinert und in ein steriles 2-ml-Röhrchen mit Lysepuffer (Tris $\mathrm{pH}$ 7,4 und Proteinaseinhibitoren; Tabelle 6, S. 15f.; Tabelle 4, S. 13f. und Tabelle 12, S. 21) überführt. Bei Schwanzhautproben wurden zuvor die Epidermis und Anteile der Dermis von den Knochen vorsichtig abpräpariert.

Das Gewebe wurde für 30 bis $60 \mathrm{sec}$ auf Eis homogenisiert (Homogenisator). Um das Aufschäumen der Probe zu verhindern, wurde 1\% (w/v) SDS erst nach Beendigung des Homogenisierens dazugegeben. Nun wurde die Suspension 15 min bei $99{ }^{\circ} \mathrm{C}$ und $1.200 \mathrm{rpm}$ auf dem Heizblock inkubiert und danach 10 min bei 10.000 rpm zentrifugiert. Der Überstand, welcher die Proteine enthält, wurde in ein neues Gefäß übertragen und bei $-80{ }^{\circ} \mathrm{C}$ gelagert.

\subsubsection{Quantifizierung der Proteinmenge}

Die Konzentration von Proteinextrakten wurde mit der Nanoquant-Reagenz bestimmt. Zur Herstellung einer Arbeitslösung wurde das Reagenz im Verhältnis 1:5 mit Ampuwa verdünnt und bei $4^{\circ} \mathrm{C}$ gelagert. Die Proteinproben wurden 1:100 mit Aqua dest. verdünnt. Durch Zugabe von $200 \mu \mathrm{l}$ Nanoquant auf $50 \mu \mathrm{l}$ Proteinlösung wurde eine Farbreaktion hervorgerufen. Die O.D. der Proben wurde mit dem Microplate-Reader EL800 bei den Wellenlänge $590 \mathrm{~nm}$ und $450 \mathrm{~nm}$ ermittelt.

Mit Hilfe einer Standardkurve, erstellt mit 10 Verdünnungsstufen BSA-Lösung bekannter Konzentration, kann über den Quotienten $\mathrm{E}_{590} / \mathrm{E}_{450}$ auf die Proteinkonzentration der Proben geschlossen werden.

Alternativ erfolgte die Messung der Proteinmenge photometrisch durch das BioPhotometer 6131. Dazu wurden unterschiedliche Konzentrationen (1:50, 1:100, 1:200) der Proteinlösung vermessen. Das Gerät ermittelt die Konzentrationen auf Grundlage der Warburg-Formel:

$$
\begin{aligned}
& \mathrm{c}=1,55 \times \mathrm{E}_{280}-0,76 \times \mathrm{E}_{260} \\
& \mathrm{c}=\text { Proteinkonzentration }[\mathrm{mg} / \mathrm{ml}] \\
& \mathrm{E}=\text { Extinktion } \\
& \text { 260/280 }
\end{aligned}
$$




\subsubsection{Polyacrylamidgelelektrophorese (PAGE)}

Die Auftrennung der Proteine erfolgte in $10 \%$-igen Polyacrylamidgelen, bestehend aus Trenngel und Sammelgel (Zusammensetzung Tabelle 17).

Tabelle 17: Lösungen für zwei $10 \%$-ige SDS-Polyacrylamidgele

\begin{tabular}{|l|l|l|l|l|l|l|}
\hline Sammelgel & AA $^{\mathrm{a}}$ & SGP $^{\mathrm{b}}$ & SDS $^{\mathrm{d}}$ & APS $^{\mathrm{e}}$ & TEMED $^{\mathrm{f}}$ & Aqua dest. \\
\hline $4,3 \%$ & $858 \mu \mathrm{l}$ & $2136 \mu \mathrm{l}$ & $60 \mu \mathrm{l}$ & $60 \mu \mathrm{l}$ & $6 \mu \mathrm{l}$ & $2932 \mu \mathrm{l}$ \\
\hline
\end{tabular}

\begin{tabular}{|l|l|l|l|l|l|l|}
\hline Trenngel & AA $^{\mathrm{a}}$ & TGP $^{\mathrm{c}}$ & SDS $^{\mathrm{d}}$ & APS $^{\mathrm{e}}$ & TEMED $^{\mathrm{f}}$ & Aqua dest. \\
\hline $10 \%$ & $4000 \mu \mathrm{l}$ & $3000 \mu \mathrm{l}$ & $120 \mu \mathrm{l}$ & $120 \mu \mathrm{l}$ & $12 \mu \mathrm{l}$ & $4880 \mu \mathrm{l}$ \\
\hline
\end{tabular}

a: $30 \%(w / v)$ Rotiphorese Acrylamid/Bisacrylamidlösung (Gewichtsverhältnis $29: 1$ ), ${ }^{\text {b}}$ : Sammelgelpuffer $(0,5 \mathrm{M}$ Tris/ $/ \mathrm{HCl}, \mathrm{pH} 6,8),{ }^{c}$ : Trenngelpuffer $(1,5 \mathrm{M}$ Tris/HCl, $\mathrm{pH} 8,8),{ }^{\mathrm{d}}: 10 \%(\mathrm{w} / \mathrm{v})$ SDS, ${ }^{\mathrm{e}}: 10 \%(\mathrm{w} / \mathrm{v})$ Ammoniumperoxodisulfat, ${ }^{\mathrm{f}}: \mathrm{N}, \mathrm{N}, \mathrm{N}^{\prime}, \mathrm{N}^{\prime}-$ Tetramethylethylendiamin; siehe auch Kapitel 2.4 und 2.6

Als Molekulargewichtsstandard wurde $10 \mu \mathrm{l}$ Precision Plus Protein (Tabelle 12, S. 21) eingesetzt. $15 \mu \mathrm{g}$ der Proben wurden mit $5 \mathrm{x}$ Laemmli-Puffer und Proteinaseinhibitoren (Tabelle 6, S. 15f.) versetzt und vor der Elektrophorese bei $95{ }^{\circ} \mathrm{C} 5 \mathrm{~min}$ denaturiert. Die Auftrennung erfolgte in Laufpuffer zunächst bei $15 \mathrm{~mA}$, bis die Proteinfront am Übergang Sammelgel-Trenngel angekommen war (ca. 1,5 h). Danach wurden die Proteine etwa 2,5 h bei $100 \mathrm{~V}$ aufgetrennt. Angaben über die Zusammensetzung der Puffer finden sich in Tabelle 6 (S. 15f.).

\subsubsection{Western Blot}

Das Polyacrylamidgel (Kapitel 2.15.3) und die Nitrozellulosemembran (Kapitel 2.1) wurden für 10 min in Transferpuffer (Kapitel 2.6, S. 16) äquilibriert. Danach wurde die Kammer für den Transfer wie vom Hersteller beschrieben unter Transferpuffer blasenfrei zusammengesetzt. Die Proteine wurden dann über Nacht bei $4{ }^{\circ} \mathrm{C}$ und konstant $30 \mathrm{~V}$ auf die Membran transferiert. Die Effizient des Proteintransfers wurde durch Anfärben der Membran mit einer Ponceau-S-Färbung sowie einer Coomassie-Blau-Färbung des Polyacrylamidgels überprüft. Hierzu wurde die Nitrozellulosemembran für $10 \mathrm{~min}$ in Ponceau-S-Lösung (Tabelle 6, S. 15f.) inkubiert und mit Aqua dest. langsam entfärbt, bis die Proteinbanden sichtbar wurden. Die vollständige Entfärbung der Membran wurde durch Waschen mit TBSTPuffer (Tabelle 6, S. 15f.) erreicht. Das Polyacrylamidgel wurde mindestens $1 \mathrm{~h}$ bis über Nacht unter gleichmäßigem Schwenken in Coomassie-Blau-Lösung (Tabelle 6, S. 15f.) 
inkubiert. Danach wurde das Gel in Wasser bei 1000 Watt jeweils 1,5 min wiederholt aufgekocht, bis auch hier die Proteinbanden sichtbar wurden.

Zum Blockieren unspezifischer Bindungen wurde die Membran in M-TBST Puffer (Tabelle 6, S. 15f.) unter Schwenken für mindestens $1 \mathrm{~h}$ bei Raumtemperatur inkubiert. Die Bindung des primären Antikörpers erfolgte in M-TBST Puffer unter Schwenken über Nacht bei $4^{\circ} \mathrm{C}$. Als Standard wurde der HSC 70 (B-6): sc-7298 Antikörper von Santa Cruz in der Verdünnung 1:25.000 verwendet (Tabelle 10, S. 20). Danach wurde die Membran für 3x 10 min in M-TBST Puffer gewaschen und mit dem sekundären Meerrettich-Peroxidasegekoppelten Antikörper in M-TBST Puffer für $2 \mathrm{~h}$ bei Raumtemperatur unter Schwenken inkubiert. Der anti-Maus-Antikörper wurde dabei im Verhältnis 1:10.000 in M-TBST verdünnt, der anti-Kaninchen-Antikörper im Verhältnis 1:5.000.

Nach erneutem Waschen der Membran (3x 10 min in M-TBST Puffer und 1x 10 min in 1x TBST) wurde die Bindung der Sekundärantikörper mit Hilfe des ECL plus-Kits auf ECLFilmen sichtbar gemacht. Dazu wurde die Membran mit der Proteinseite nach oben in eine Röntgenkassette übertragen. Die Komponenten des ECL plus-Kits wurden wie vom Hersteller angegeben vermengt und ein Volumen von 1,5 ml wurde auf die Membran pipettiert. Nach 5 min Inkubation wurde die Flüssigkeit wieder entfernt und die Membran in eine Folie eingeschlagen. Zur Visualisierung wurden Röntgenfilme auf der Membran liegend unter Rotlicht inkubiert und anschließend mit dem CURIX 60 von Agfa entwickelt.

Die eingesetzten Verdünnungen der verwendeten primären und sekundären Antikörper sind in Tabelle 10 und Tabelle 11 (S. 20) aufgelistet.

\subsubsection{Antikörper-,,Stripping“}

Bei möglicher Antikörperinkompatibilität wurde, um mögliche Kreuzreaktionen auszuschließen, das Verfahren des sogenannten Antikörper-,,Stripping“ durchgeführt. Dabei wurden alle an Proteine der Nitrozellulosemembran gebundenen Antikörper entfernt. Die Membran wurde dazu $30 \mathrm{~min}$ in mindestens $100 \mathrm{ml}$ Stripping-Puffer (Tabelle 6, S. 15f.) bei $50^{\circ} \mathrm{C}$ unter Schwenken inkubiert, danach noch zweimal jeweils $10 \mathrm{~min}$ bei RT in $100 \mathrm{ml}$ TBST (Tabelle 6). Nach Kontrolle der Antikörper-Entfernung mittels ECL-Kit wurde die Membran, wie in Kapitel 2.15.4 beschrieben, erneut mit einem Antikörper inkubiert. 


\subsubsection{Densitometrie und Auswertung}

Nach der Entwicklung der Röntgenfilme erfolgte die Auswertung. Dabei wurde den detektierten Banden zunächst ihr Molekulargewicht mittels des Größenmarkers Precision Plus Protein (Tabelle 12, S. 21) zugeordnet. Der Größenmarker ist in den Abbildungen nicht zu erkennen, da es sich um einen Größenmarker handelt, der nur auf der Nitrozellulosemembran sichtbar ist. Die Größenzuordnung erfolgte durch Vergleich der Membran mit dem Röntgenfilm.

Die eigentliche Auswertung wurde mit Hilfe des Programms Quantity One durchgeführt. Dazu wurden die Röntgenfilme der Western Blots eingescannt und durch das genannte Programm densitometrisch ausgewertet. Die ermittelten Dichtewerte der unterschiedlichen Banden einer Membran wurden auf die Dichtewerte der HSC-70-Messung derselben Membran kalibriert. Durch diese Art der Auswertung kann eine Aussage über die relative Menge des Zielproteins in den einzelnen Proben getroffen werden. Die Haut-oder BCC-Probe mit dem höchsten Wert wurde auf den Wert $=1$ gesetzt.

\subsection{Tierexperimentelle Methoden}

\subsubsection{Zucht und Haltung von Mus musculus}

Die verwendeten Mauslinien (Kapitel 2.11.2, S. 24) wurden im institutseigenen Tierstall (Institut für Humangenetik, Universität Göttingen) gezüchtet. Die Tierhaltung erfolgte in Makrolonkäfigen Typ II und III, bei einem zwölfstündigen Hell-Dunkel-Rhythmus (HellPeriode: 6.00-18.00 Uhr), einer Temperatur von $20 \pm 2^{\circ} \mathrm{C}$ und einer relativen Luftfeuchtigkeit von $50 \pm 10 \%$. Pelletierte Zuchtdiät (Alleinfutter für Mäuse-Zucht, Ssniff Spezialdiäten GmbH, Soest) und Wasser (Leitungswasser) standen den Tieren ad libitum zur Verfügung.

\subsubsection{Schwanzbiopsie und Ohrlochmarkierung}

Schwanzbiopsien (ca. 0,5 cm der Schwanzspitze) und gleichzeitige Ohrlochmarkierungen (Nummerierung der Mäuse) von 4 Wochen alten Mäusen wurden vom Personal im institutseigenen Tierstall vorgenommen. 


\subsubsection{Genotypisierung von Mäusen}

Für die Genotypisierung der in den Experimenten eingesetzten Mauslinien (Kapitel 2.11.2, S. 24) wurden Schwanzbiopsien der Tiere genommen und die genomische DNA isoliert und auf $100 \mathrm{ng} / \mu \mathrm{l}$ eingestellt. Für die Genotypisierung wurden die unter 2.12.4 (S. 27) angegebenen Primerkombinationen und PCR-Profile verwendet. Die PCR-Produkte wurden schließlich in einer Agarosegelelektrophorese (Kapitel 2.12.6, S. 30) getrennt und ausgewertet.

\subsubsection{Applikation von Tamoxifen}

Zur Induktion der Cre-Rekombinase in der Mauslinie Ptch flox/flox $; E R T 2^{+/-}$wurde Tamoxifen (Tabelle 4, S. 13f.) in $96 \%$ Ethanol hergestellt und diese in sterilem Sonnenblumenöl (Tabelle 4) 1:10 verdünnt. Die Emulsion wurde bis zur Verwendung bei $-20{ }^{\circ} \mathrm{C}$ gelagert.

Die eigentliche Induktion erfolgte durch Applikation von 1 x $100 \mu \mathrm{g}$ Tamoxifen intramuskulär bei Tieren mit dem Genotyp Ptch ${ }^{\text {floxflox }} ; E R T 2^{+/-}$. Als Kontrolle dienten Tiere mit dem Genotyp Ptch ${ }^{\text {flox/flox }}$, denen ebenfalls Tamoxifen verabreicht wurde. 


\section{Ergebnisse}

\subsection{Expressionsanalyse von Gli1 und Wnt5a in murinen und humanen BCC}

Murine BCC wurden in Mäusen mit dem Genotyp Ptch ${ }^{\text {floxflox }}$; ERT2 ${ }^{+/}$durch Applikation von Tamoxifen induziert. Untersucht wurden frühe $(24 \mathrm{~d}$ BCC, Präparation der Proben 24 Tage nach Behandlung mit Tamoxifen; Maus 5 und 6) und späte BCC (300d BCC, Präparation der Proben 300 Tage nach Behandlung mit Tamoxifen; Maus 7 bis 9). Als Kontrolle dienten mit Lösungsmitteln behandelte Tiere des Genotyps Ptch ${ }^{\text {floxflox }}$; ERT2 ${ }^{+/-}$(Maus 1 und 4) bzw. Tiere mit dem Genotyp Ptch flox/flox (Maus 2 und 3) (Kapitel 2.11.2, S. 24; Kapitel 2.16.4 und 2.16.3, S. 39).

Als Ausgangsmaterial für murine BCC wurde von allen Tieren eine Schwanzbiopsie gewonnen, aus welcher zunächst die RNA isoliert wurde (Kapitel 2.12.1.2.2, S. 25). Diese wurde in cDNA umgeschrieben (Kapitel 2.12.3, S. 26) und für die Versuche eingesetzt. Bei den humanen Proben wurde die RNA aus Tumorstanzen und Stanzen normaler Haut isoliert. Die cDNA wurde wie im Methodenteil beschrieben synthetisiert. Für die Analysen wurden die in Tabelle 8 und Tabelle 9 (S. 17ff.) aufgelisteten Oligonukleotide eingesetzt.

Als Bezugswert (Kalibrator) wurde jeweils der niedrigste ermittelte Wert einer Kontrolle festgelegt.

Zunächst wurde die Expression von Gli1 und Wnt5a in murinen BCC und normaler Haut untersucht. In humanen Proben wurde nur die Expression von Wnt5a gemessen, da die Überexpression von Gli1 schon mehrmals in der Literatur gezeigt worden ist (Ghali et al., 1999; Bonifas et al., 2001; Asplund et al., 2008). 


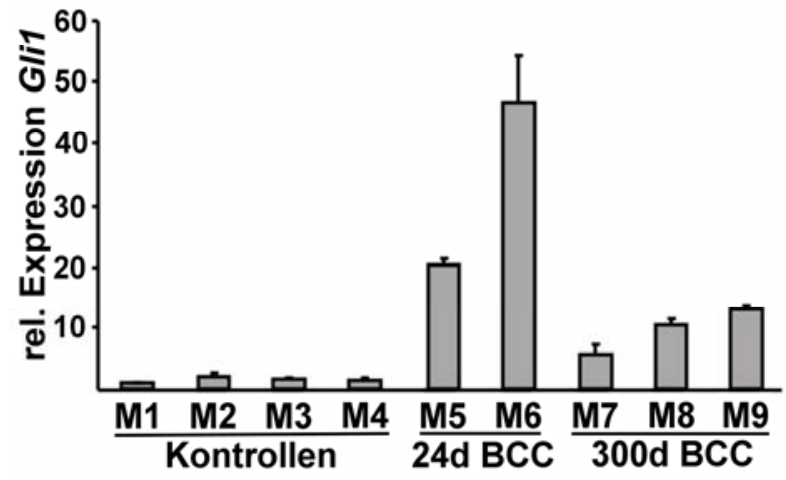

Abbildung 6: Quantifizierung der Gli1-Expression in murinen BCC

Für die Analyse der Expression von Gli1 wurde murine Schwanzhaut-cDNA in eine qRT-PCR mit jeweils sequenzspezifischen Oligonukleotiden eingesetzt (siehe Text). Jede Probe wurde in Triplikaten analysiert. Die ermittelten Werte wurden gegen die Werte der Expression von 18S rRNA als endogener Standard normalisiert.

Maus 1 bis Maus 4 (M1-M4): Haut von Kontrollmäusen

Maus 5 und Maus 6 (M5-M6): BCC, Gruppe 24d

Maus 7 bis Maus 9 (M7-M9): BCC, Gruppe 300d

Der Wert M1 diente als Kalibrator und wurde auf den Wert = 1 gesetzt.

Die Expression von Gli1 war in allen untersuchten murinen BCC-Proben gegenüber normaler Haut deutlich erhöht (Abbildung 6). Dabei zeigten die frühen BCC (19,8- bis 46-fach) wiederum eine deutlich höhere Expression als die späten Tumore (5,5- bis 12,8-fach). Innerhalb beider Gruppen wurde eine große interindividuelle Variabilität in der Expression deutlich.
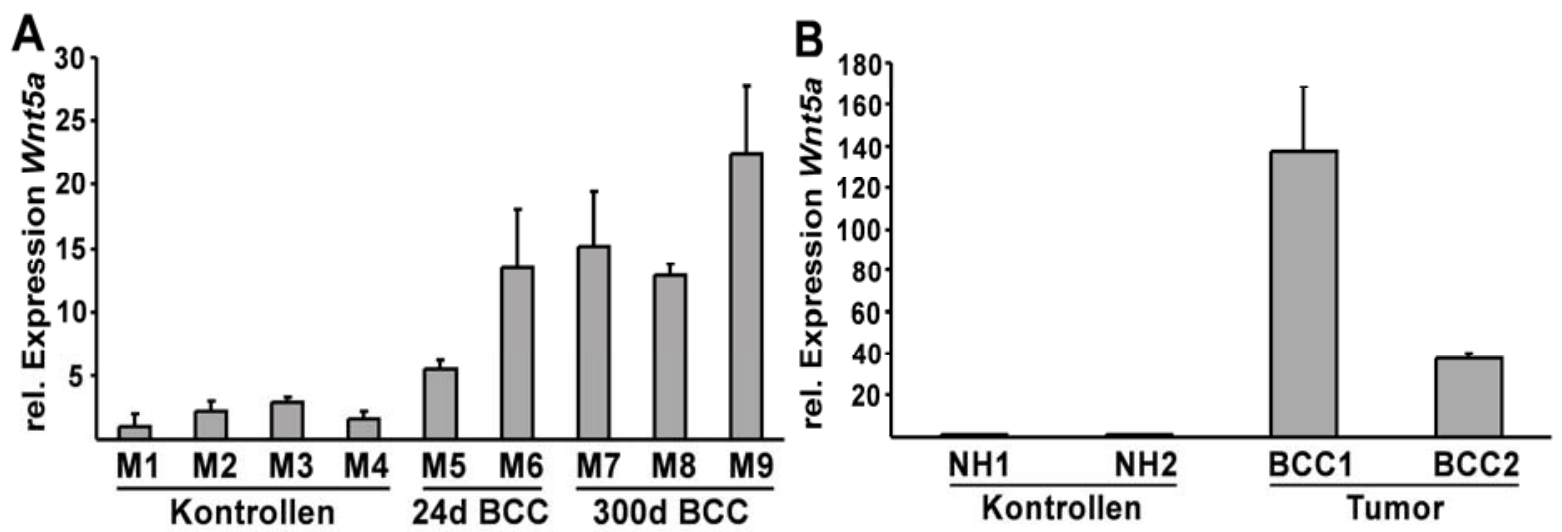

Abbildung 7: Quantifizierung der Wnt5a-Expression in murinen und humanen BCC.

Für die Analyse der Expression von Wnt5a wurde murine Schwanzhaut-cDNA (A) bzw. humane ausgestanzte Tumor- und Haut-cDNA (B) in eine qRT-PCR mit jeweils sequenzspezifischen Oligonukleotiden eingesetzt (siehe Text). Jede Probe wurde in Triplikaten analysiert. Die ermittelten Werte wurden gegen die Werte der Expression von 18S rRNA als endogener Standard normalisiert.
A: murine BCC
Maus 1 bis Maus 4 (M1-M4): Haut von Kontrollmäusen
Maus 5 und Maus 6 (M5-M6): BCC, Gruppe 24d
Maus 7 bis Maus 9 (M7-M9): BCC, Gruppe 300d
B: humane BCC
NH: normale humane Haut

Der Wert M1 bzw. NH1 diente als Kalibrator und wurde auf den Wert = 1 gesetzt. 
Ebenso wie bei Gli1 fand sich auch für Wnt5a eine erhöhte Expression in allen untersuchten BCC-Proben gegenüber der normalen Haut. In den BCCs, die 24d und 300d nach ihrer Induktion isoliert worden sind, konnte ebenfalls eine interindividuelle Variabilität der Expression von Wnt5a nachgewiesen werden. Jedoch war erkennbar, dass 300d Tumoren eine höhere Wht5a-Expression als 24d Tumoren zeigten (Abbildung 7A).

Eine solche interindividuelle Variabilität der Expression von Wnt5a zeigte sich auch in den analysierten humanen BCC (Abbildung 7B). Analog zu den murinen BCC-Proben konnte auch hier eine eindeutige Überexpression von Wnt5a im Vergleich zu normaler Haut ermittelt werden.

Die Expressionsanalysen wurden auch an den Keratinozytenzelllinien $\mathrm{C} 5 \mathrm{~N}$ und $\mathrm{HaCaT}$ sowie der BCC-Zelllinie ASZ001 durchgeführt und mit der Expression von normaler Haut verglichen (Kapitel 2.11.1, S. 23).
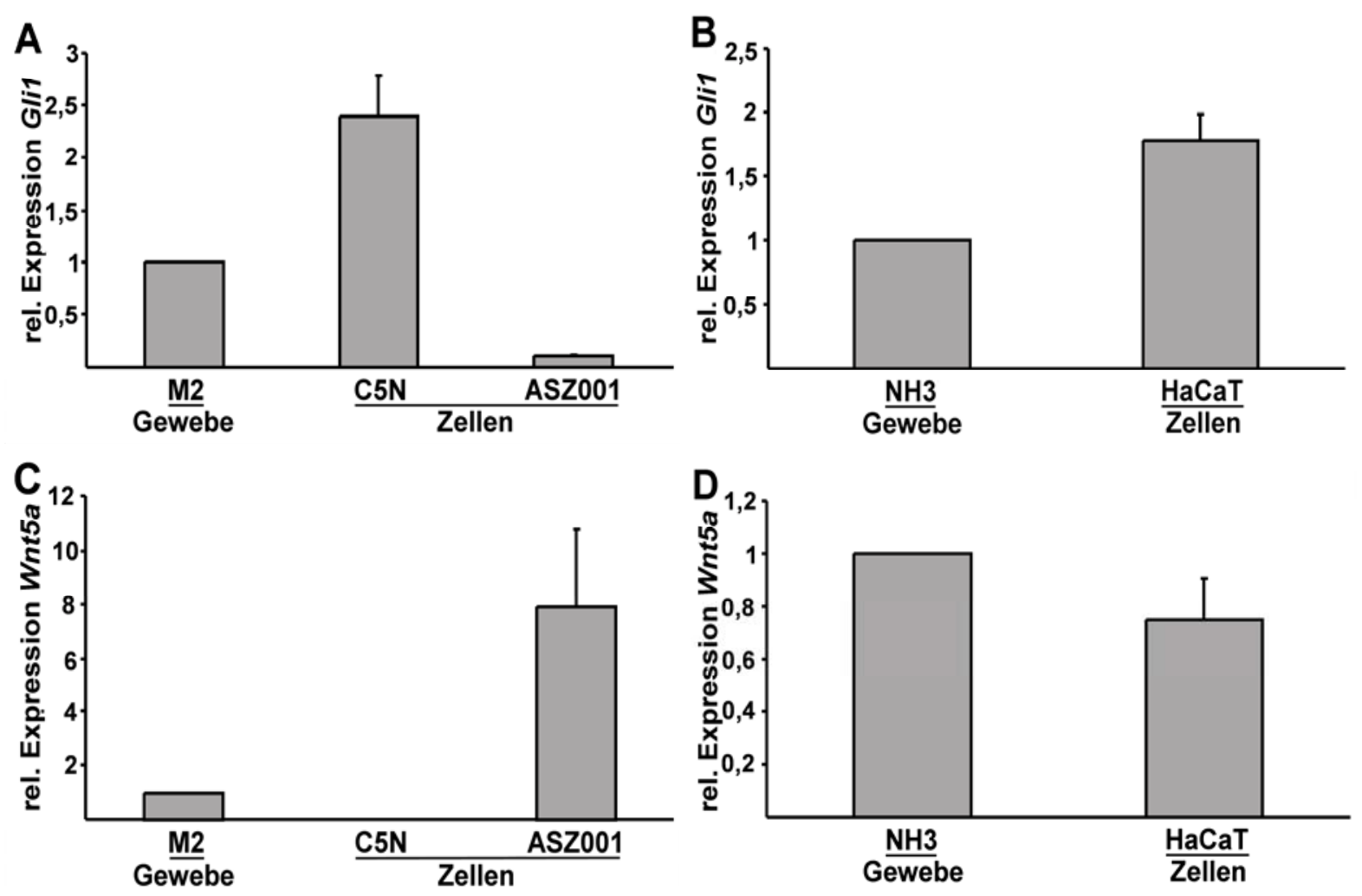

Abbildung 8: Quantifizierung der Gli1- und Wnt5a-Expression in den Zelllinien C5N, ASZ001 und HaCaT im Vergleich zu normaler Haut.

Für die Expressionsanalyse wurde cDNA aus C5N und ASZ001 und murine Schwanzhaut-cDNA (A, C) bzw. cDNA aus HaCaT und humane ausgestanzte Haut-cDNA (B, D) in eine qRT-PCR mit jeweils sequenzspezifischen Oligonukleotiden eingesetzt. Jede Probe wurde in Triplikaten analysiert. Die ermittelten Werte wurden gegen die Werte der Expression von 18S rRNA als endogener Standard normalisiert.

Maus 2 (M2): Haut von Kontrollmäusen

NH3: normale humane Haut

Der Wert M2 bzw. NH3 diente als Kalibrator und wurde auf den Wert = 1 gesetzt. 
Wie auch in normaler muriner Haut wurde Gli1 in C5N-Zellen exprimiert, Wht5a wurde nicht detektiert (Abbildung 8A und 8C). HaCaT-Zellen zeigten eine ähnliche Gli1- (Abbildung 8B) und Wnt5a-Expression (Abbildung 8D) wie normale humane Haut. Die Expression von Gli1 und eingeschränkt auch von Wnt5a der untersuchten Keratinozytenzelllinien war somit mit derjenigen von normaler Haut vergleichbar.

ASZ001 hingegen exprimierten nur sehr wenig Gli1 (Abbildung 8C), obwohl man in diesen Zellen aufgrund der Ptch $^{-/}$-Defizienz eine Aktivierung der Hh-Signalkaskade ähnlich wie in nativen BCC-Proben erwartet hätte. Die Expression von Wnt5a hingegen war in ASZ001 stark erhöht und zeigte ähnliche Werte wie murine BCC (Abbildung 8C; Abbildung 7A).

Zusammengefasst zeigten diese Daten, dass BCC Gli1 überexprimierten und die HhSignalkaskade aktiv war. Dies war sowohl für humane BCC als auch für andere murine BCCTiermodelle bereits mehrfach gezeigt worden (Gailani und Bale, 1997; Rubin et al., 2005; Mancuso et al., 2004; Zibat et al., 2009). Des Weiteren bestätigten diese Daten die in der Literatur beschriebene Überexpression von Wnt5a in humanen BCC (Bonifas et al., 2001; O’Driscoll et al., 2006). Darüberhinaus wurde deutlich, dass Wnt5a auch in murinen BCC hochreguliert war.

\subsection{Untersuchung der Wnt5a-Expression in den Keratinozytenzelllinien HaCaT und C5N nach Stimulation mit Shh}

In der Literatur ist beschrieben, dass die Wnt5a-Expression im Haarfollikel positiv durch den Hh-Signalweg reguliert wird (Reddy et al., 2001; Kapitel 1.3.4, S. 8). Daher war es möglich, dass die Wnt5a-Expression in BCC ebenfalls durch den Hh-Signalweg reguliert wird.

Um dies zu untersuchen, wurden die Zelllinien HaCaT und C5N (Kapitel 2.11.1, S. 23) mit Shh stimuliert. Mittels quantitativer RT-PCR wurde die Expression von Gli1 (Aktivität der Hh-Signalkaskade) und von Wnt5a bestimmt.

Zudem wurde die Expression von ,proliferating cell nuclear antigen“ (Pcna) untersucht. Dieses Gen wird in der Synthesephase (S-Phase) des Zellzyklus am stärksten exprimiert (Celis et al., 1987) und seine Expression gibt daher Hinweise auf das Proliferationsverhalten der untersuchten Zellen.

Zur Versuchsdurchführung siehe Kapitel 2.12.5 und 2.13.2 (S. 28 bzw. S. 31f.). Jeder Versuch wurde in Doppelansätzen durchgeführt, d.h. zwei Proben blieben unbehandelt, zwei Proben wurden mit dem HEK-Kontrollmedium (von nicht-transfizierten HEK-Zellen) und 
zwei mit dem Shh-konditionierten Medium (von HEK-Zellen, die stabil mit dem Shhexprimierenden Plasmid transfiziert sind; Kapitel 2.10.2, S. 22) behandelt,. Bei der Auswertung wurden die Werte der beiden unbehandelten und der beiden mit dem HEKMedium inkubierten Proben gemittelt (Kapitel 2.13.2). Die Werte der beiden mit Shh stimulierten Zellen wurden einzeln betrachtet. Als Kalibrator diente der Wert der mit dem HEK-Medium inkubierten Zellen.

\subsubsection{Test des Shh-konditionierten Mediums}

Vorversuche der AG Hahn zeigten, dass sich der Hh-Signalweg in murinen Fibroblasten (isoliert von $P t c h^{\text {flox/flox }}$-Mäusen) durch Shh-konditioniertes Medium stimulieren lässt, was in einer reproduzierbaren Erhöhung der Gli1-Expression deutlich wurde. Daher wurde das neu hergestellte Shh-konditionierte Medium vor der Verwendung zunächst an Fibroblasten getestet und die Gli1-Expression mittels quantitativer RT-PCR gemessen. Zusätzlich wurde an diesen Zellen der Effekt auf die Expression von Ptch (ein weiterer Marker für die Aktivität des Hh-Signalweges; Kapitel 1.2 und Abbildung 1, S. 2ff.) und Wnt5a ermittelt.
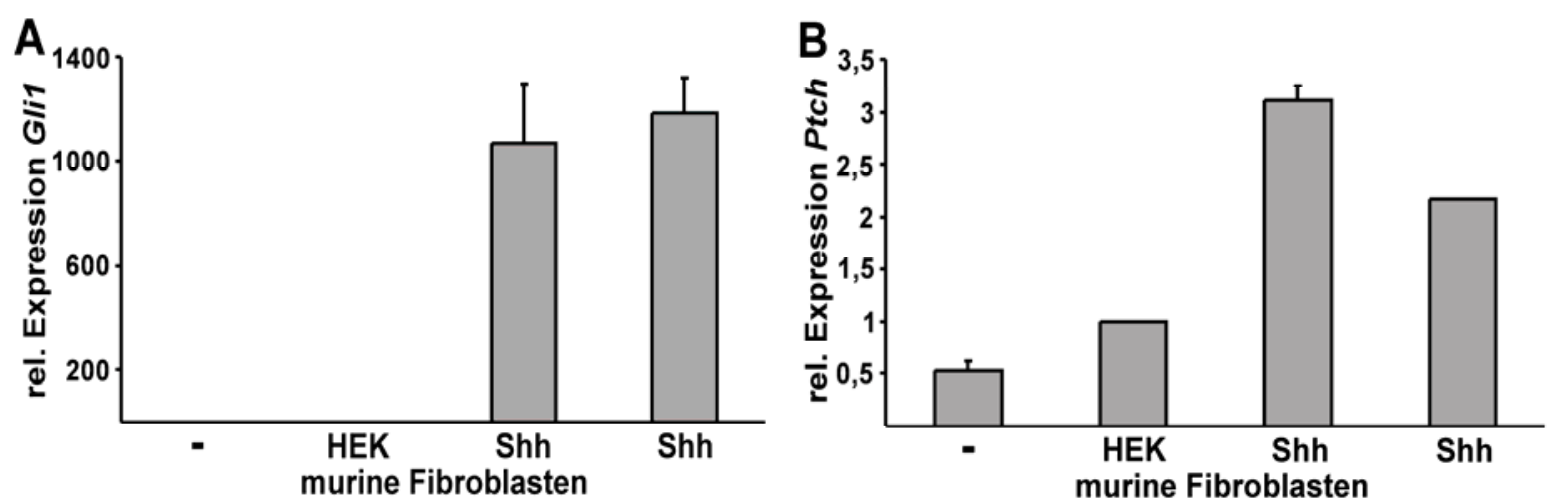

Abbildung 9: Quantifizierung der Gli1- und Ptch-Expression in Shh-stimulierten Fibroblasten.

Für die Analyse der Expression von Gli1 und Ptch wurde cDNA aus Fibroblasten in eine qRT-PCR mit jeweils sequenzspezifischen Oligonukleotiden eingesetzt. Jede Probe wurde in Triplikaten analysiert. Die ermittelten Werte wurden gegen die Werte der Expression von 18S rRNA als endogener Standard normalisiert.

$\begin{array}{ll}\text { HEK } & \text { Znbehandelte Zellen } \\ \text { Shh } & \text { Zellen mit HEK-Kontrollmedium inkubiert } \\ & \text { mit Shh-konditioniertem Medium inkubiert }\end{array}$

Der Wert der mit dem HEK-Medium inkubierten Zellen diente als Kalibrator und wurde auf den Wert $=1$ gesetzt.

Der Test der verwendeten Shh-konditionierten Medien und der HEK-Kontrollmedien, hier an einem der Ergebnisse exemplarisch gezeigt, führte in jedem der durchgeführten Versuche zu einer Induktion der Gli1-Expression in den mit Shh-konditioniertem Medium behandelten Zellen. Die Werte waren zwischen 200- und 1200-fach höher als diejenigen, die durch das Kontrollmedium hervorgerufen wurden (Abbildung 9A). Gleichzeitig kam es durch die 
Stimulation zur Steigerung in der Expression von Ptch (Abbildung 9B). Diese ist in den stimulierten Zellen zwischen 2,2- und 3,1-fach erhöht.

Die Ergebnisse zeigten, dass das hergestellte Shh-konditionierte Medium funktionsfähig war. In den mit dem Shh-konditioniertem Medium inkubierten Zellen kam es weiterhin zu einer Steigerung der Expression von Wnt5a (Abbildung 10). Alle Messwerte waren zwischen 1,35und 3,26-fach gegenüber dem Kontrollwert erhöht.

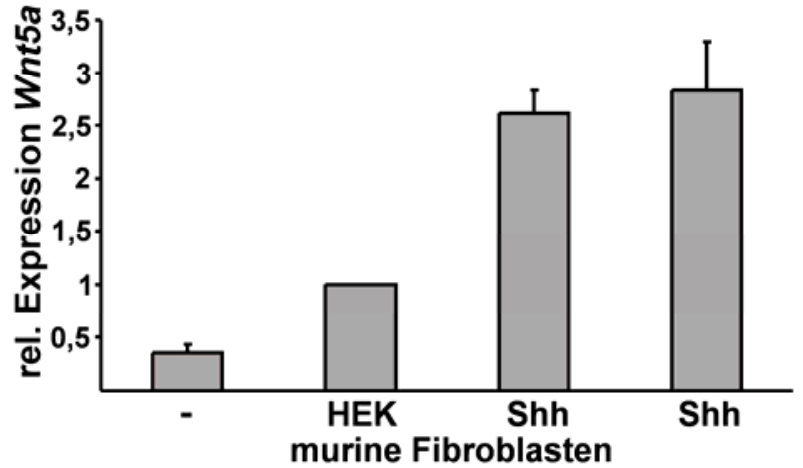

\section{Abbildung 10: Quantifizierung der Wnt5a-Expression in Shh-stimulierten Fibroblasten.}

Für die Analyse der Expression von Wnt5a wurde cDNA aus Fibroblasten in eine qRT PCR mit jeweils sequenzspezifischen Oligonukleotiden eingesetzt. Jede Probe wurde in Triplikaten analysiert. Die ermittelten Werte wurden gegen die Werte der Expression von 18S rRNA als endogener Standard normalisiert.

$\begin{array}{ll}\text { HEK } & \text { unbehandelte Zellen } \\ \text { Shh } & \text { Zellen mit HEK-Kontrollmedium inkubiert } \\ & \text { Zellen mit Shh-Medium inkubiert }\end{array}$

Der Wert der mit dem HEK-Medium inkubierten Zellen diente als Kalibrator und wurde auf den Wert $=1$ gesetzt.

\subsubsection{Shh-Stimulation von C5N-Zellen}

Ausgehend von den unter 3.2 beschriebenen Vorüberlegungen, wurden murine Keratinozyten der Zelllinie C5N mit dem Shh-konditionierten Medium stimuliert.

Abbildung 11 zeigt ein ausgewähltes Ergebnis von drei unabhängig voneinander durchgeführten Versuchen, die jeweils in Duplikaten durchgeführt wurden. In keinem der Experimente kam es zu einer Steigerung der Gli1-Expression. Fünf der insgesamt sechs ermittelten Werte lagen im Bereich des Kontrollwertes. In einem Experiment zeigte Gli1 gegenüber dem Kontrollwert sogar eine verminderte Expression (Faktor 0,48; Abbildung 11A). Ähnliches gilt für die Expression von Wnt5a. Alle Messwerte lagen im Bereich des Kontrollwertes. 

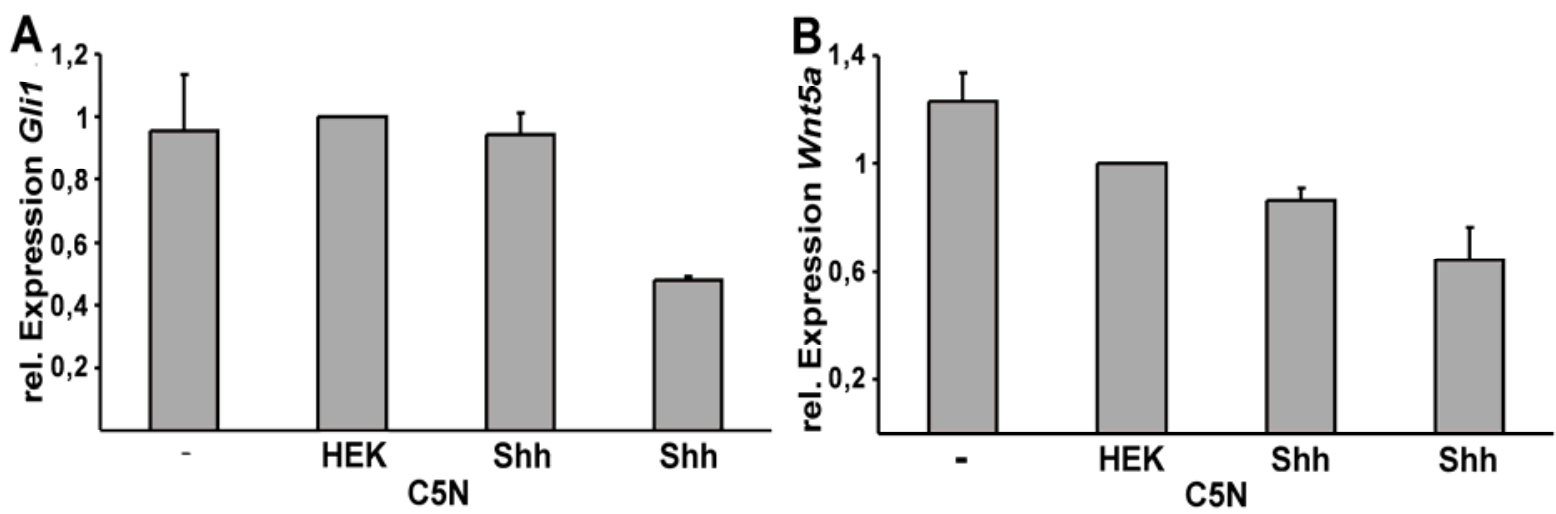

Abbildung 11: Quantifizierung der Gli1- und Wnt5a-Expression in Shh-stimulierten C5N-Zellen.

Für die Analyse der Expression von Gli1 und Wnt5a wurde cDNA aus C5N-Zellen in eine qRT-PCR mit jeweils sequenzspezifischen Oligonukleotiden eingesetzt. Jede Probe wurde in Triplikaten analysiert. Die ermittelten Werte wurden gegen die Werte der Expression von 18S rRNA als endogener Standard normalisiert.

unbehandelte Zellen

HEK Zellen mit HEK-Kontrollmedium inkubiert

Shh Zellen mit Shh-Medium inkubiert

Der Wert der mit dem HEK-Medium inkubierten Zellen diente als Kalibrator und wurde auf den Wert $=1$ gesetzt.

Die Daten zeigten, dass es bei dieser Versuchsdurchführung in $\mathrm{C} 5 \mathrm{~N}-Z$ ellen zu keiner Aktivierung des Hh-Signalweges und zu keiner Steigerung der Wnt5a-Expression kam.

Auf die Expression des Proliferationsmarkers Pcna hatte Shh in diesem Versuchsaufbau ebenfalls keinen sichtbaren Effekt. Abbildung 12 zeigt exemplarisch die Daten einer von insgesamt zwei unabhängigen Versuchsdurchführungen. Der Wert für die Shh-stimulierten C5N-Zellen lag in allen Fällen im Breich des HEK-Kontrollmediums.

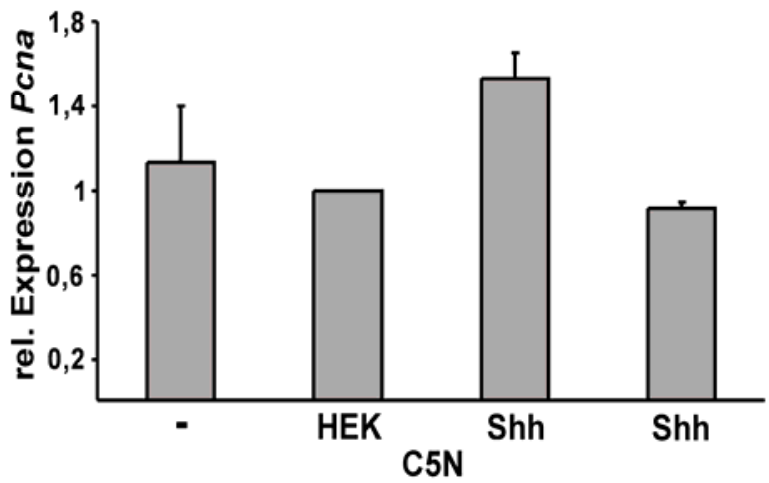

Abbildung 12: Quantifizierung der Pcna-Expression in Shh-stimulierten C5N-Zellen.

Für die Analyse der Expression von Pcna wurde cDNA aus C5N-Zellen in eine qRT PCR mit jeweils sequenzspezifischen Oligonukleotiden eingesetzt. Jede Probe wurde in Triplikaten analysiert. Die ermittelten Werte wurden gegen die Werte der Expression von 18S rRNA als endogener Standard normalisiert.

$$
\begin{array}{ll}
\text { - } & \text { unbehandelte Zellen } \\
\text { HEK } & \text { Zellen mit HEK-Kontrollmedium inkubiert } \\
\text { Shh } & \text { Zellen mit Shh-Medium inkubiert }
\end{array}
$$

Der Wert der mit dem HEK-Medium inkubierten Zellen diente als Kalibrator und wurde auf den Wert $=1$ gesetzt. 


\subsubsection{Shh-Stimulation von HaCaT-Zellen}

Für diesen Versuch wurden humane Keratinozyten der Zelllinie HaCaT wie in Kapitel 3.2 beschrieben mit Shh-konditioniertem Medium stimuliert.
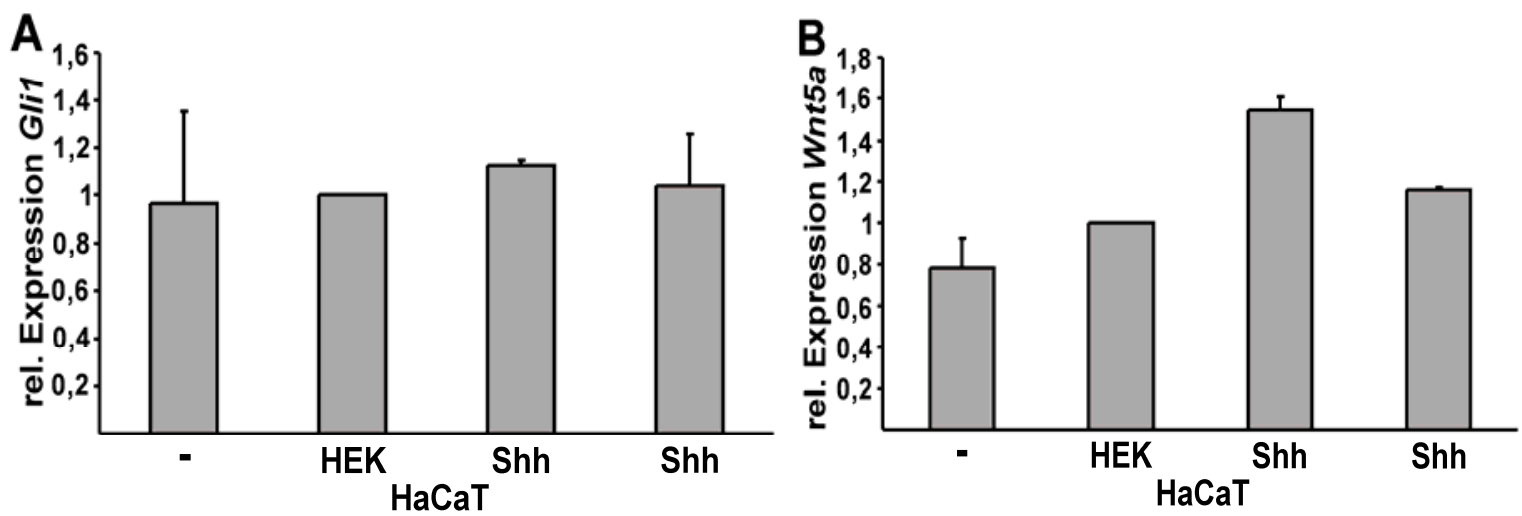

Abbildung 13: Quantifizierung der Gli1-und Wnt5a-Expression in Shh-stimulierten HaCaT-Zellen.

Für die Analyse der Expression von Gli1 und Wnt5a wurde cDNA aus HaCaT-Zellen in eine qRT-PCR mit jeweils sequenzspezifischen Oligonukleotiden eingesetzt. Jede Probe wurde in Triplikaten analysiert. Die ermittelten Werte wurden gegen die Werte der Expression von 18S rRNA als endogener Standard normalisiert.
- $\quad$ unbehandelte Zellen
HEK Zellen mit HEK-Kontrollmedium inkubiert
Shh Zellen mit Shh-Medium inkubiert

Der Wert der mit dem HEK-Medium inkubierten Zellen diente als Kalibrator und wurde auf den Wert $=1$ gesetzt.

Die Auswertung von drei voneinander unabhängig durchgeführten Versuchen zeigte, dass Shh auch in humanen Keratinozyten keinen eindeutigen Einfluss auf die Expression von Gli1 hat. Alle Messwerte lagen im Bereich der Kontrollen. Die Expression von Wnt5a war bei vier der sechs Messungen im Bereich der Kontrollwerte, zwei Werte waren leicht erhöht $(1,54-$ und 2,38-fach; Abbildung 13B).

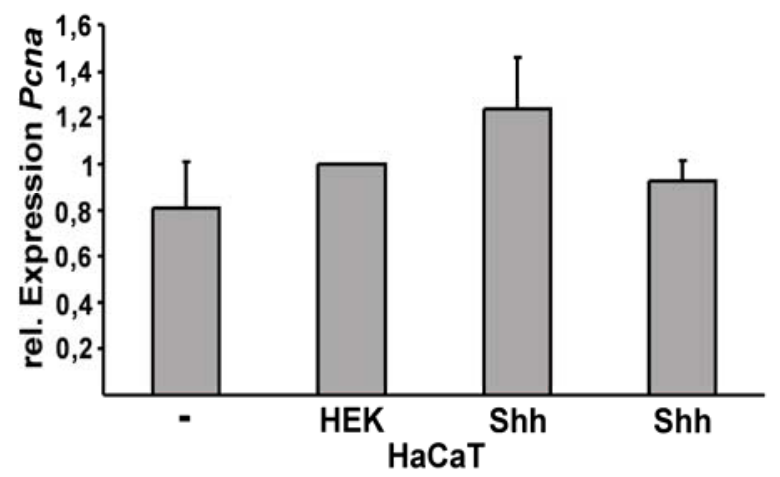

Abbildung 14: Quantifizierung der Pcna-Expression in Shh-stimulierten HaCaT-Zellen.

Für die Analyse der Expression von Pcna wurde cDNA aus HaCaT-Zellen in eine qRT-PCR mit jeweils sequenzspezifischen Oligonukleotiden eingesetzt. Jede Probe wurde in Triplikaten analysiert. Die ermittelten Werte wurden gegen die Werte der Expression von 18S rRNA als endogener Standard normalisiert.

unbehandelte Zellen

HEK Zellen mit HEK-Kontrollmedium inkubiert

Shh Zellen mit Shh-Medium inkubiert

Der Wert der mit dem HEK-Medium inkubierten Zellen diente als Kalibrator und wurde auf den Wert $=1$ gesetzt. 
Abbildung 14 zeigt den Effekt von Shh auf die Proliferation von HaCaT-Zellen. Alle gemessenen Werte schwankten um den Wert des Kontrollmediums, eine deutliche Differenz konnte bei keiner der Proben gemessen werden. Eine unabhängige Wiederholung des Versuches erbrachte ein ähnliches Ergebnis.

Zusammenfassend zeigten diese Experimente, dass sich in Keratinozyten weder die HhSignalkaskade noch die Wnt5a-Expression durch konditioniertes Shh-Medium stimulieren ließ.

An dieser Stelle muss nun folgendes festgehalten werden: Weiterführende Experimente anderer Labormitglieder (Gli-transfizierte Keratinozyten oder ASZ001 sowie Untersuchungen an murinen BCC) haben während der Durchführung der oben beschriebenen Experimente gezeigt, dass die Expression von Wnt5a tatsächlich nicht durch die Hh-Signalkaskade in Keratinozyten oder BCC die reguliert wird. Zusätzlich wurde mittels in situ Hybridisierungen gezeigt, dass Wnt5a ausschließlich im Tumorstroma von BCC exprimiert wird und dabei mit der Expression der Differenzierungsmarker Keratin 1 (K1) und Keratin 10 (K10) im Tumor korreliert.

\subsection{Untersuchung der Effekte von Wnt5a auf die Proliferation und/oder Differenzierung der BCC-Zelllinie ASZ001}

Aufgrund dieser Datenlage konnte man erwarten, dass potentielle Effekte von Wnt5a auf BCC-Zellen parakrin und nicht tumor-intrinsisch vermittelt werden. Daher wurden Analysen an der BCC-Zelllinie ASZ001 durchgeführt, die exogen mit rekombinantem Wnt5a (rWnt5a) behandelt wurde. Untersucht wurden die Effekte auf das Proliferations- und Differenzierungsverhalten dieser Zellen.

K1 und K10 sind bekannte Differenzierungsmarker für Keratinozyten, deren Transkription früh in der Differenzierung der Zellen gesteigert wird (Yuspa et al., 1989). Neben den beiden Differenzierungsmarkern wurde die Expression des Proliferationsmarkers Pcna gemessen (Celis et al., 1987).

Dazu wurden jeweils 60.000 ASZ001-Zellen in jede Vertiefung einer 6-Loch-Platte ausgebracht und mit unterschiedlichen Konzentrationen von rWnt5a (50 ng oder $100 \mathrm{ng}$ ) inkubiert. Als Kontrolle dienten unbehandelte sowie mit Lösungsmittel behandelte ASZ001. Zusätzlich wurde die Genexpression in normaler Haut sowie in BCC mituntersucht. Die Genexpression wurde mittels qRT-PCR ermittelt (Kapitel 2.12.5). Die genaue Versuchsdurchführung findet sich in Kapitel 2.13.3 (S. 32f.). 
Die Messwerte aus den ASZ001 wurden auf den Wert der mit PBS behandelten Zellen kalibriert. Bei den Gewebeproben diente die normale Haut als Kalibrator.
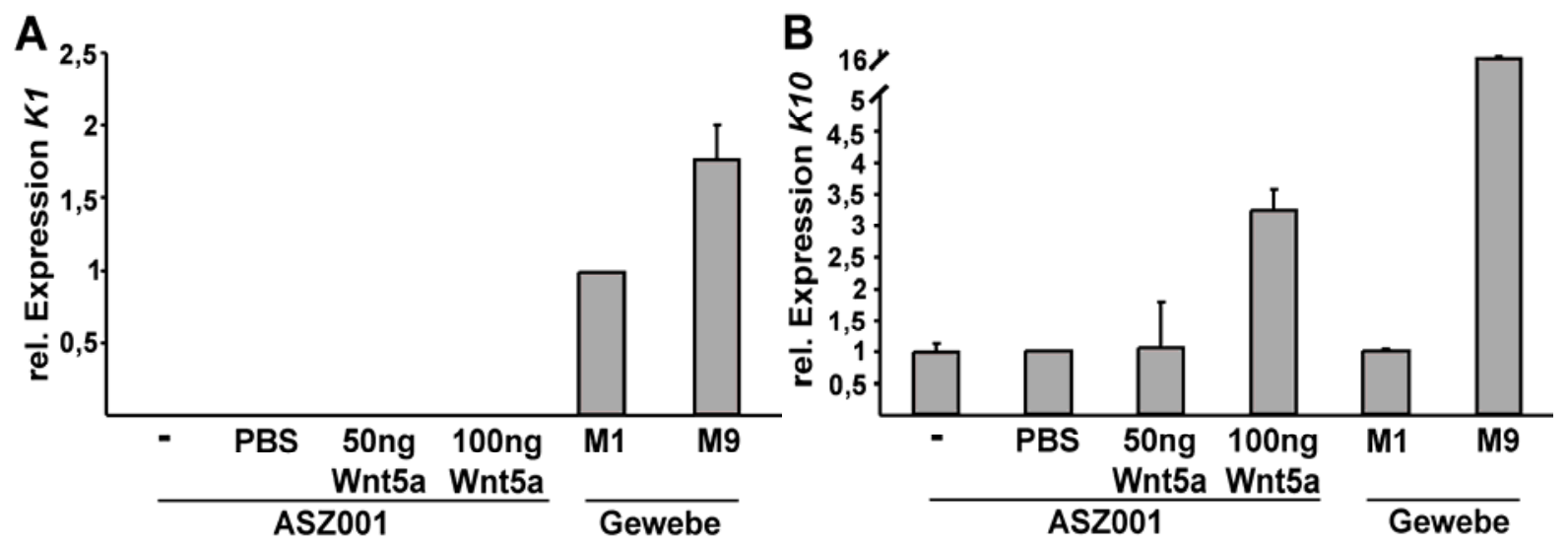

Abbildung 15: Quantifizierung der K1- und K10-Expression in rWnt5a-stimulierten ASZ001.

Für die Analyse der Expression von K1 und K10 wurde cDNA aus ASZ001, normaler Haut und BCC in eine qRT-PCR mit jeweils sequenzspezifischen Oligonukleotiden eingesetzt. Jede Probe wurde in Triplikaten analysiert. Die ermittelten Werte wurden gegen die Werte der Expression von 18S rRNA als endogener Standard normalisiert.

$\begin{array}{ll}- & \text { unbehandelte Zellen } \\ \text { PBS } & \text { Lösungsmittelkontrolle } \\ \text { Wnt5a } & \text { Stimulation mit der entsprechenden Menge rWnt5a } \\ \text { Maus 1 (M1) } & \text { normale Haut, Lösungsmittelkontrolle } \\ \text { Maus 9 (M9) } & \text { BCC, Gruppe 300d }\end{array}$

Der Wert M1 bzw.der Wert der mit PBS inkubierten Zellen diente als Kalibrator und wurde auf den Wert $=1$ gesetzt.

In Abbildung 15A ist die Expression von $K 1$ in normaler Haut und in einem BCC gezeigt, welche im BCC etwa um den Faktor 1,8 erhöht war. Die Expression von K1 in den ASZ001Zellen war zu gering, um ein detektierbares Signal zu liefern. Möglicherweise wird K1 in den ASZ001 nicht exprimiert.

Abbildung 15B zeigt den Effekt von rWnt5a auf die Expression von K10. Die Zugabe von 50 ng rWnt5a zu den ASZ001 zeigte keinen Effekt, das Expressionniveau lag auf dem der beiden Kontrollen. Bei Applikation von 100 ng rWnt5a hingegen stieg die Expression von K10 um den Faktor 3,2 an. In den Gewebeproben war die K10-Expression in den BCC gegenüber der Haut um den Faktor 18 erhöht.

Auf die Expression von Pcna in ASZ001 schien Wnt5a dagegen keinen Einfluss zu haben. Der Wert für die mit $50 \mathrm{ng}$ rWnt5a stimulierten Zellen lag auf dem Niveau der PBSKontrolle, der Wert der 100 ng Gruppe lag auf dem Niveau der unbehandelten ASZ001 (Abbildung 16). Hierzu ist jedoch zu sagen, dass dieses Experiment nur einmal durchgeführt worden ist. In den BCC-Proben wurde Pcna etwa 9,5-fach höher exprimiert, als in normaler Haut. Dies korreliert mit der Wnt5a-Expression in beiden Proben. So wurde Wnt5a im BCC etwa 10-fach stärker exprimiert als in Haut (Abbildung 7A, S. 41). 


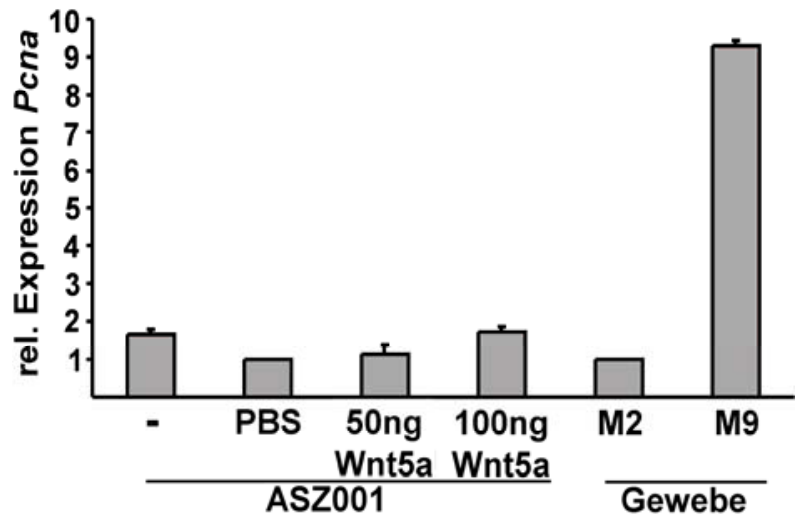

Abbildung 16: Quantifizierung der Pcna-Expression in rWnt5a-stimulierten ASZ001.

Für die Analyse der Expression von Pcna wurde cDNA aus ASZ001, normaler Haut und BCC in eine qRT-PCR mit jeweils sequenzspezifischen Oligonukleotiden eingesetzt. Jede Probe wurde in Triplikaten analysiert. Die ermittelten Werte wurden gegen die Werte der Expression von 18S rRNA als endogener Standard normalisiert.

$\begin{array}{ll}\text { PBS } & \text { unbehandelte Zellen } \\ \text { Wnt5a } & \text { Lösungsmittelkontrolle } \\ \text { Maus 2 (M2) } & \text { Stimulation mit der entsprechenden Menge rWnt5a } \\ \text { Maus 9 (M9) } & \text { normale Haut, Lösungsmittelkontrolle }\end{array}$

Der Wert der mit PBS inkubierten Zellen diente als Kalibrator und wurde auf den Wert = 1 gesetzt.

Zusammenfassend lässt sich festhalten, dass exogenes Wnt5a in der BCC-Zelllinie ASZ001 die Expression von K10 und damit die Differenzierung induzierte. Auf die Proliferation dieser Zellen schien Wnt5a hingegen keinen Einfluss zu haben.

\subsection{Untersuchung der Aktivität der Wnt-Signalwege im murinen BCC}

Die Daten aus Kapitel 3.3 zeigten, dass exogen zugeführtes Wnt5a in BCC einen Anstieg der Expression von K10 bewirkt. Da angenommen werden konnte, dass dieser Effekt durch einen der Wnt5a-Signalwege hervorgerufen wurde, wurde die Aktivität von Schlüsselproteinen der einzelnen Signalwege in murinen BCC untersucht. Bei diesen Schlüsselproteine handelte es sich um $\beta$-Catenin ( $\beta$ Cat) für den kanonischen Signalweg (Kapitel 1.3.2, S. 5f.), um die Proteinkinase C (PKC) für den $\mathrm{Wnt} / \mathrm{Ca}^{2+}-\mathrm{Weg}$ (Kapitel 1.3.3.1, S. 7) und um die Jun Nterminale Kinase (JNK) für den Wnt/JNK/AP1-Weg (Kapitel 1.3.3.2, S. 8).

In einem ersten Schritt wurde versucht, immunhistochemische Färbungen (IHC) für diese Proteine $\mathrm{zu}$ etablieren, da auch die zelluläre Lokalisation der Proteine Hinweise auf ihren Aktivierungsstatus liefern kann. Eine IHC war jedoch nur für $\beta C$ at möglich. Daher wurde die Aktivität von PKC und JNK im Western Blot (WB) untersucht.

Sowohl vor IHC als auch vor der Proteinisolation aus Geweben für die Western-BlotAnalysen, wurden die Diagnosen BCC bzw. normale Haut durch die Abteilung Pathologie der Universität Göttingen bestätigt (das entsprechende Gewebe für WB-Analysen wurde bis zur Diagnose tiefgefroren). 
Exemplarisch ist in Abbildung 17 die HE-Färbung einer der verwendeten BCC- und einer der Hautproben zu sehen.

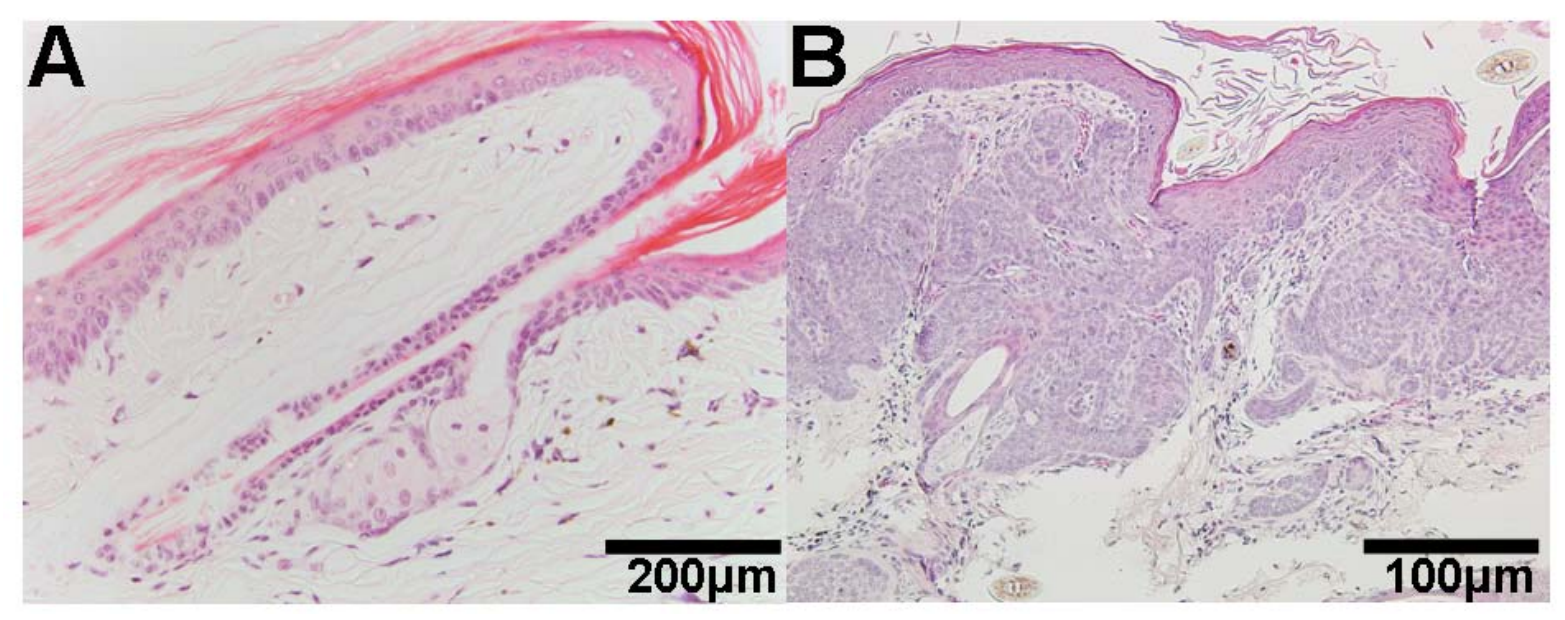

Abbildung 17: HE-Färbung von BCC und normaler Haut.

Histologische Bilder einer Hautprobe und eines BCC, aus denen die Proteine für den Western Blot isoliert wurden. Die Diagnosen normale „Haut“ bzw. „BCC“ wurden vor Verwendung der Proben durch die Abteilung Pathologie der Universität Göttingen bestätigt. Bilder erstellt in Kollaboration mit PD Dr. W. Schulz-Schaefer, Universität Göttingen.

A: $\quad$ normale Haut, HE gefärbt, Vergrößerung $200 \mathrm{x}$

B: $\quad$ BCC 90 d nach Applikation von Tamoxifen, HE gefärbt, Vergrößerung 100 x

\subsubsection{Untersuchung der Aktivität des kanonischen Signalweges im BCC}

Im Zentrum der Aktivität des kanonischen Signalweges steht das $\beta$ Cat, welches als Transkriptionsfaktor nur im Zellkern seine Funktion ausüben kann. Aus diesem Grund ist die subzelluläre Lokalisation von $\beta$ Cat für eine Aussage über die Aktivität des kanonischen Signalweges von essentieller Bedeutung. Einige Studien zeigten, dass $\beta C a t$ in BCCTumorzellen im Zellkern akkumuliert (Yamazaki et al., 2001; El-Bahrawy et al., 2003; Saldanha et al., 2004; Salto-Tellez et al., 2006). Andere Studien dagegen beschrieben nur zytoplasmatisch- bzw. membranständig-exprimiertes $\beta$ Cat (Boonchai et al., 2000; Lo Muzio et al., 2002; Asplund et al., 2008).

Zur Untersuchung der Expression von $\beta C$ at in murinen BCC wurden Schnitte von Tumoren und normaler Haut mit dem $\beta$-Catenin-Antikörper, wie in Kapitel 2.14.3 (S. 34) beschrieben, gefärbt. Als Vorbehandlung wurden die Schnitte in TE-Puffer (Tabelle 6, S. 15f.) mit einem pH-Wert von 9 in der Mikrowelle aufgekocht. Genauere Informationen über den Antikörper wie die eingesetzte Konzentration etc. können Tabelle 10 (S. 20) entnommen werden. 


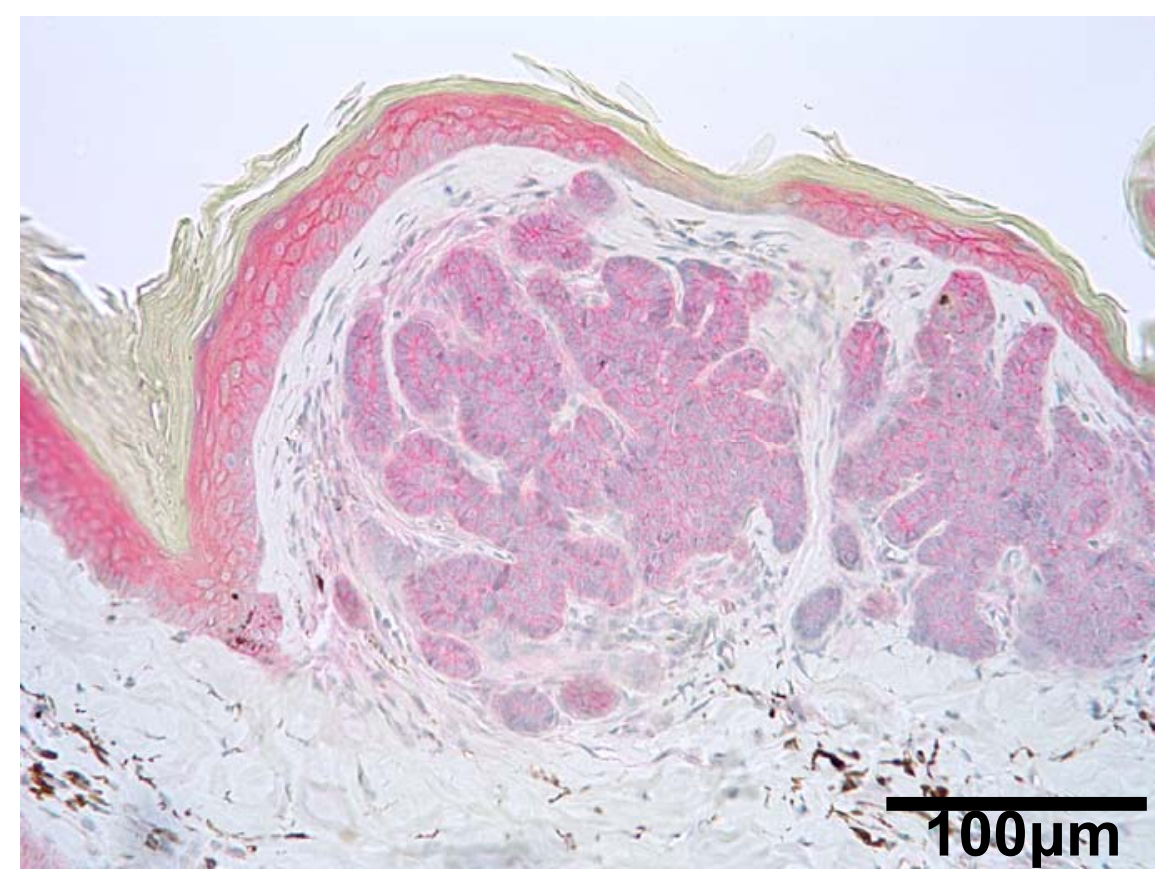

\section{Abbildung 18: Lokalisation von $\beta C$ at in BCC und Haut}

Immunhistochemische Färbung für $\beta$-Catenin ( $\beta$ Cat) an einem murinen BCC. Vergrößerung 200 x. Expression von $\beta C$ at in BCC zytoplasmatisch und membranassoziiert. Bestätigung der Ergebnisse durch die Abteilung Pathologie der Universität Göttingen. Bild erstellt in Kollaboration mit PD Dr. W. Schulz-Schaefer, Universität Göttingen.

Wie in Abbildung 18 gezeigt, bindet der Antikörper zytoplasmatisch bzw. membranassoziiert an Zellen der Epidermis, der Haarfollikel und des BCC. Eine nukleäre Lokalisation von $\beta C$ at konnte in keinem der untersuchten BCC eindeutig nachgewiesen werden. Der Befund wurde durch die Abteilung Pathologie der Universität Göttingen bestätigt. Dieses Ergebnis deckt sich mit den Ergebnissen von Boonchai et al. (2000), Lo Muzio et al. (2002) und Asplund et al. (2008).

Auch die Western-Blot-Analyse zeigte, dass $\beta C$ at in BCC- und Hautproben in etwa gleichen Mengen exprimiert wird (Abbildung 19).

Zusammengefasst zeigten diese Ergebnisse, dass die Aktivierung des kanonischen WntSignalweges keine große Rolle beim BCC zu spielen scheint. 


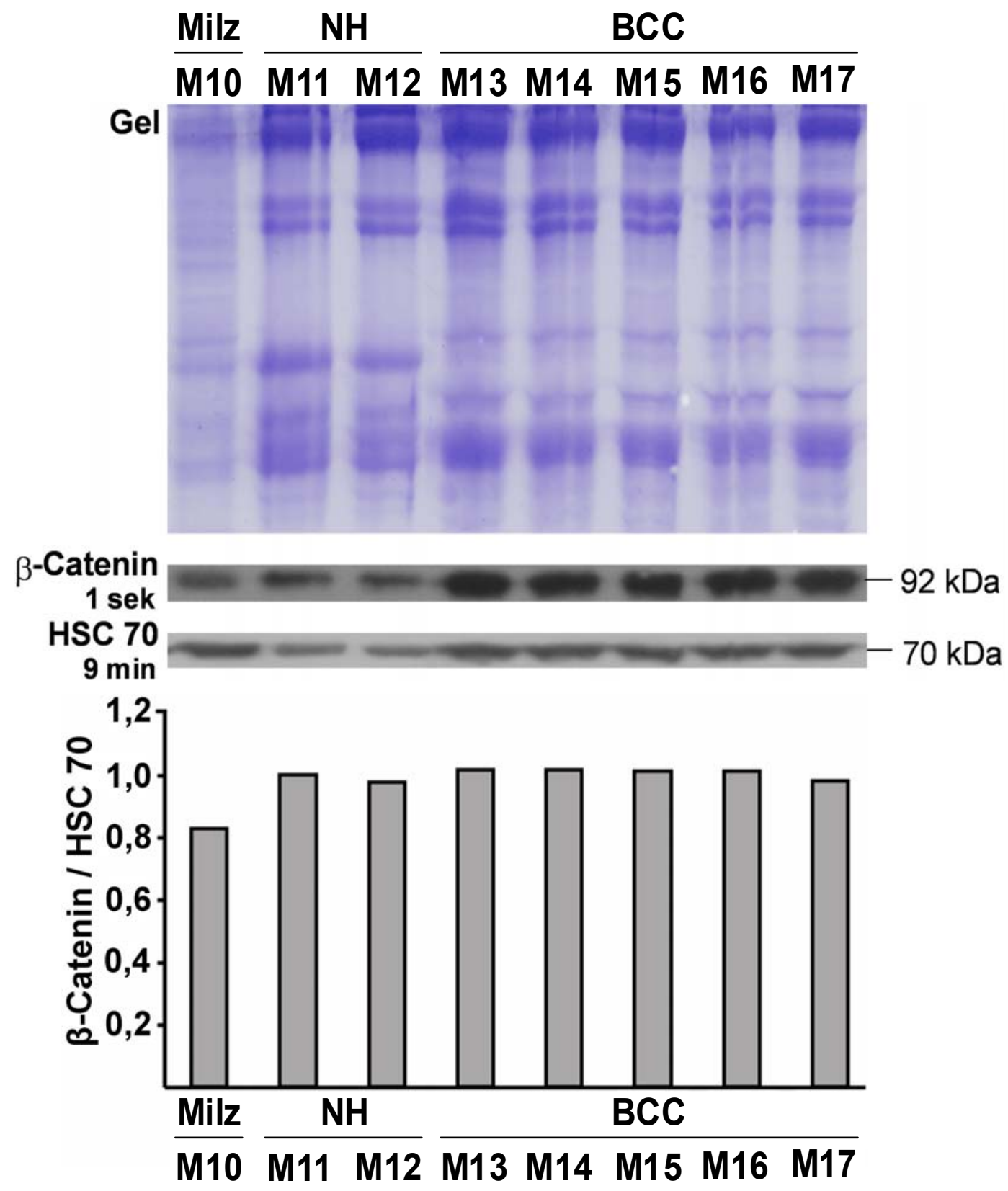

Abbildung 19: Western-Blot-Analyse der Expression von $\beta$ Cat in BCC- und Hautproben.

Für die Analyse wurde Protein aus der Schwanzhaut von Mäusen bzw. der Milz isoliert. Das oberste Bild zeigt das Gel nach Färbung mit Coomassie-Blau. Im mittleren Abschnitt finden sich der Blot mit Angabe der verwendeten Antikörper sowie die Belichtungszeit. Unten ist das Ergebnis der densitometrischen Auswertung der 92 kDa-Bande abgebildet. Zur Kalibration wurden die ermittelten Werte für $\beta$ Cat auf die Werte der Ladekontrolle HSC 70 bezogen. Der Wert für die Probe M11 wurde dabei auf den Wert = 1 gesetzt.

Maus 10 (M10): Milz, Positivkontrolle

Maus 11 und Maus 12 (M11-M12): Haut von Kontrollmäusen

Maus 13 bis Maus 17 (M13-M17): BCC 


\subsubsection{Untersuchung der Aktivität des Wnt/Ca ${ }^{2+}$-Weges im BCC}

Die Familie der PKC besteht aus mindestens 12 Serin-Threonin-Kinasen (Koivunen et al., 2006). In Keratinozyten der Epidermis kommen die Isoformen $\mathrm{PKC} \alpha, \mathrm{PKC} \beta, \mathrm{PKC} \delta, \mathrm{PKC} \eta$, $\mathrm{PKC} \varepsilon$ und $\mathrm{PKC} \zeta$ vor. Die beiden $\mathrm{PKC} \beta$-Isoformen werden nur schwach exprimiert (Breitkreuz et al., 2007).

Um eine Aussage über die Aktivität der PKC in BCC und normaler Haut machen zu können, wurde der phospho-PKC pan-Antikörper (Tabelle 10, S. 20) eingesetzt. Dieser Antikörper detektiert laut Hersteller die PKC-Isoformen $\alpha, \beta \mathrm{I}, \beta \mathrm{II}, \delta, \varepsilon, \eta$ und $\theta$, wenn sie am Serinrest 660 phosphoryliert sind. Nur die Detektion von $\mathrm{PKC} \zeta$ wird ausdrücklich verneint. Des Weiteren wurde zur genaueren Spezifizierung der gefundenen Banden der phospho-PKC $\alpha / \beta_{\text {II }}$-Antikörper (Tabelle 10) verwendet. Dieser weist v.a. die Isoformen $\alpha$ und $\beta_{\text {II, }}$ in geringerem Maße auch $\beta_{\mathrm{I}}$ und $\gamma$, nach. Die Durchführung des Western Blots ist in Kapitel 2.15 (S. 35ff.) beschrieben.

Eine Etablierung des phospho-PKC (pan)-Antikörpers in der IHC war nicht möglich. Alle Vorbehandlungen der Gewebeschnitte (Kapitel 2.14.3, S. 34) erbrachten kein eindeutiges Ergebnis.

Die Western-Blot-Analyse der Gewebe mit dem phospho-PKC (pan)-Antikörper ist in Abbildung 20 gezeigt. Als Positivkontrolle diente dabei ein Proteinlysat aus einer murinen Milz (Wetsel et al., 1992). Da der phospho-PKC (pan)-Antikörper verschiedene Isoformen der PKC-Familie nachweist, zeigten sich bei der Auswertung auf dem Röntgenfilm auch mehrere Banden, deren Zuordnung zu einzelnen Isoformen der PKC im Folgenden versucht wird.

Die größte Bande wies ein Molekulargewicht von etwa $80 \mathrm{kDa}$ auf und lag somit im Größenbereich der PKC-Isoformen $\alpha, \beta_{\mathrm{I}}, \beta_{\mathrm{II}}, \delta, \varepsilon, \zeta$ und $\theta$ (Smith et al., 2007). Diese Bande war in allen Proben nachweisbar, wobei sie in den Hautproben deutlich schwächer war als in den BCC (Abbildung 20).

Die mögliche Zuordnung der Bande zu einer speziellen Isoform erfolgte nach gründlicher Literaturrecherche und soll an dieser Stelle erläutert werden. In der Milz können die PKCIsoformen $\alpha, \beta_{\mathrm{I}}, \beta_{\mathrm{II}}, \delta$ und $\zeta$ nachgewiesen werden (Wetsel et al., 1992). Im BCC sind die Isoformen $\alpha$ und $\delta$ nicht oder nur sehr gering exprimiert (Neill et al., 2003) und PKC $\zeta$ wird laut Hersteller vom Antikörper nicht detektiert. Daraus folgt, dass es sich bei der in den BCC nachgewiesenen PKC-Isoform nur um eine oder beide $\beta$-Isoformen handeln kann. Dieses 
Ergebnis ist sehr interessant, da die $\beta$-Isoformen in Keratinozyten normalerweise nur sehr schwach exprimiert werden (Breitkreuz et al., 2007).

Bei den in normalen Hautproben detektierten Banden könnte es sich um PKC $\alpha$ handeln, welches laut Literatur in Keratinozyten stark exprimiert wird (Breitkreuz et al., 2007). Das Molekulargewicht von PKC $\alpha$ und $\beta_{\mathrm{II}}$ ist mit $80 \mathrm{kDa}$, das von PKC $\beta_{\mathrm{I}}$ mit $79 \mathrm{kDa}$ angegeben (Smith et al., 2007), sodass die Banden wie hier gefunden etwa auf einer Höhe laufen müssten.

Um diese Vermutungen zu überprüfen, wurde in einem zweiten Schritt auf dieselbe Membran der phospho-PKC $\alpha / \beta_{\text {II }}$-Antikörper aufgebracht (Abbildung 20). Auf dem Film zeigte sich ebenfalls eine deutliche Bande im Bereich von etwa $80 \mathrm{kDa}$ in allen Proben, die mit der Bande des p-PKC (pan)-Antikörpers deckungsgleich war. Auch die Intensität der Banden war vergleichbar. Sie war in den BCC deutlich stärker als in den Hautproben. Allerdings zeigte die Densitometrie geringe Abweichungen in der Signalintensität der einzelnen Proben bei Verwendung der unterschiedlichen Antikörper.

Das Ergebnis legte nahe, dass in den normalen Hautproben tatsächlich PKC $\alpha$ und in den BCC wahrscheinlich PKC $\beta_{\text {II }}$ exprimiert wurde. Da der Antikörper, wenn auch nur schwach, ebenfalls mit $\beta_{\mathrm{I}}$ reagiert, könnte auch dieses Protein vorliegen. Die endgültige Bestätigung des Ergebnisses durch Verwendung von spezifischen, nur gegen eine einzelne PKC-Isoform gerichtete, Antikörper steht noch aus.

Die densitometrische Auswertung der 80 kDa-Bande zeigte, dass die Intensität des Signals in der Haut etwas geringer war als in den BCC (Abbildung 20; für alle weiter unten aufgeführten Signale wurde auf die densitometrische Zuordnung verzichtet). Da es sich jedoch wie oben ausgeführt wahrscheinlich um zwei verschiedene PKC-Isoformen handelte, war dieser Vergleich nicht sehr aussagekräftig. Das interessante an diesem Versuch war also nicht nur die unterschiedliche Signalintensität, sondern der mögliche Expressionsnachweis der unterschiedlichen PKC-Isoformen in Haut und BCC.

Bei etwa $75 \mathrm{kDa}$ erkennt man weitere Banden, die in Milz und BCC-Proben deutlich sichtbar waren. In den normalen Hautproben war die Bande nur sehr schwach oder gar nicht nachweisbar. Aufgrund des Molekulargewichts könnte es sich dabei um PKC $\gamma(75 \mathrm{kDa}$; Smith et al., 2007), PKC $\delta$ (75 kDa; Birkenfeld et al., 1996) oder PKC $\lambda$ (74 kDa, Akimoto et al., 1994) handeln. Da der Antikörper nach Angaben des Herstellers von den genannten Möglichen nur die PKC $\delta$ erkennt, handelte es sich bei der Bande aller Wahrscheinlichkeit nach um diese Isoform. Des Weiteren wird in der Milz von diesen drei Isoformen ebenfalls 
nur PKC $\delta$ gefunden (Wetsel et al., 1992). Dem entgegen steht das Ergebnis von Neill et al., die in $\mathrm{BCC}$ eine verminderte Expression von $\mathrm{PKC} \delta$ beobachteten (Neill et al., 2003). Eine eindeutige Zuordnung der Bande zu einer PKC-Isoform kann anhand der Ergebnisse und der Literaturlage somit noch nicht getroffen werden. Daher wurde auch auf die densitometrische Auswertung verzichtet.

Bei etwa $60 \mathrm{kDa}$ konnte in den normalen Hautproben eine weitere Bande nachgewiesen werden, die weder in Milz noch in BCC auftritt. Möglicherweise findet sich dort PKC 1 (65$70 \mathrm{kDA}$ ) oder $\lambda$ (60 kDA; Smith et al., 2007).

Die Detektion dieser beiden PKC-Isoformen mit phospho-PKC (pan)-Antikörper wird vom Hersteller nicht beschrieben. Daher ist es fraglich, ob es sich bei den gefundenen Banden um eine dieser Isoformen handelte. Ein Versuch zur Zuordnung dieser Banden mit anderen PKCAntikörpern wurde bisher noch nicht vorgenommen.

Schließlich konnte sowohl mit dem phospho-PKC (pan)- als auch mit dem phospho-PKC $\alpha / \beta_{\mathrm{II}}$-Antikörper eine weitere Bande von weniger als $50 \mathrm{kDa}$ Größe detektiert werden, die von der Signalintensität her vergleichbar war. In den BCC-Proben war das Signal deutlich stärker als in den normalen Hautproben. Eine PKC-Isoform dieser Größe wird in der Literatur nicht beschrieben.

Zusammenfassend kann gesagt werden, dass BCC und normale Haut möglicherweise verschiedene Isoformen von PKC exprimieren. Allerdings ist die abschließende Zuordnung der gefundenen Banden zu den PKC-Isoformen bisher noch nicht erfolgt. Nichtsdestotrotz scheinen BCC vermehrt phospho-PKC-Isoformen zu exprimieren. 


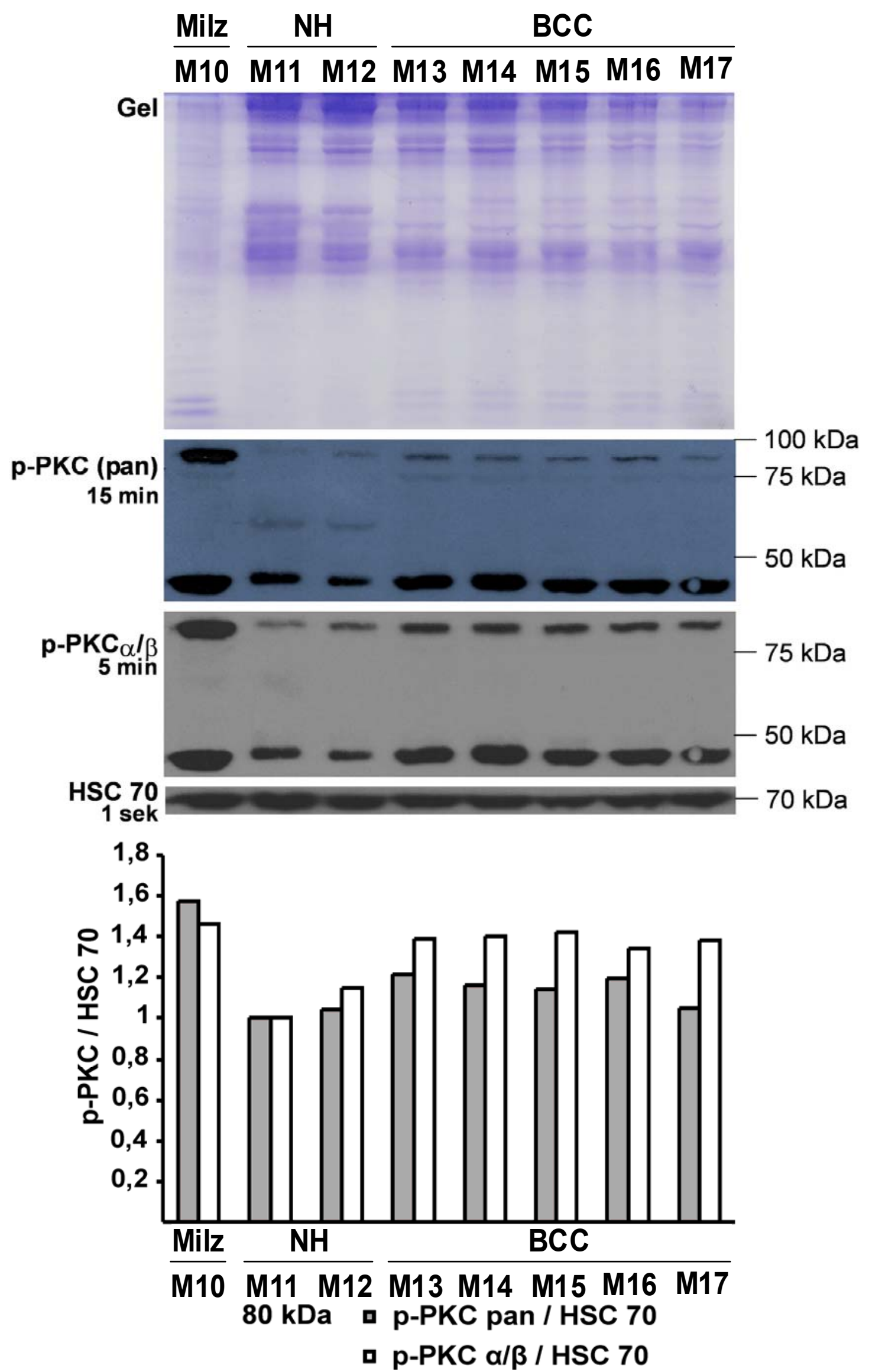

Abbildung 20: Western-Blot-Analyse der Expression von phosphorylierten PKC-Isoformen in BCC- und Hautproben. 
Für die Analyse wurde Protein aus der Schwanzhaut von Mäusen bzw. der Milz isoliert. Das oberste Bild zeigt das Gel nach Färbung mit Coomassie-Blau. Im mittleren Abschnitt finden sich der Blot mit Angabe der verwendeten Antikörper sowie die Belichtungszeit. Der phospho-PKC (pan)-Antikörper detektiert den Großteil der PKC-Isoformen (siehe Text), der phospho-PKC $\alpha / \beta_{\mathrm{II}}$-Antikörper ist relativ spezifisch für die Isoformen $\alpha$ und $\beta_{\mathrm{II}}$. Unten ist das Ergebnis der densitometrischen Auswertung der Bande bei $80 \mathrm{kDa}$ mit beiden Antikörpern abgebildet. Zur Kalibration wurden die ermittelten Werte für phospho-PKC auf die Werte der Ladekontrolle HSC 70 bezogen. Der Wert für M11 wurde dabei auf den Wert = 1 gesetzt.

Maus 10 (M10): Milz, Positivkontrolle

Maus 11 und Maus 12 (M11-M12): Haut von Kontrollmäusen

Maus 13 bis Maus 17 (M13-M17): BCC

\subsubsection{Untersuchung der Aktivität des Wnt/JNK/AP1-Weges im BCC}

Insgesamt werden drei Isoformen des JNK-Proteins beschrieben (Barr und Bogoyevitch, 2001). Die Isoformen JNK1 (46 kDa) und JNK2 (54 kDa) werden ubiquitär, JNK3 (54 kDa) hingegen selektiv in Herz, Gehirn und Hoden exprimiert (Conze et al., 2002). Eine Expression von JNK in Keratinozyten konnte ohne genauere Spezifizierung der Isoform bereits nachgewiesen werden (Yu et al., 2007).

Der in dieser Arbeit eingesetzte SAPK/JNK-Antikörper detektiert das JNK-Gesamtprotein mit einer Größe von 46 bzw. 54 kDa, während der phospho-SAPK/JNK (Thr183/Tyr185)(81E11)- und der phospho-JNK (G-7)-Antikörper (Tabelle 10, S. 20) nur phosphoryliertes JNK der gleichen Größe nachweisen.

Als Positivkontrolle beim Western Blot diente Proteinlysat der Milz, da JNK1 und JNK2 in T- und B-Zellen exprimiert wird (Dong et al., 2001).

Wie in Abbildung 21 dargestellt ist, wurde mit dem SAPK/JNK-Antikörper in BCC deutlich mehr JNK 2 und/oder JNK3 (beide 54 kDa) detektiert als in normaler Haut. Dagegen konnte JNK1 (46 kDa) nicht eindeutig detektiert werden. Auch bindet der Antikörper nach längerer Inkubationszeit wahrscheinlich unspezifisch, wodurch die verschiedenen Banden auf dem Film erklärt werden können. Daher wurde nur die 54 kDa-Bande densitometrisch ausgewertet. 


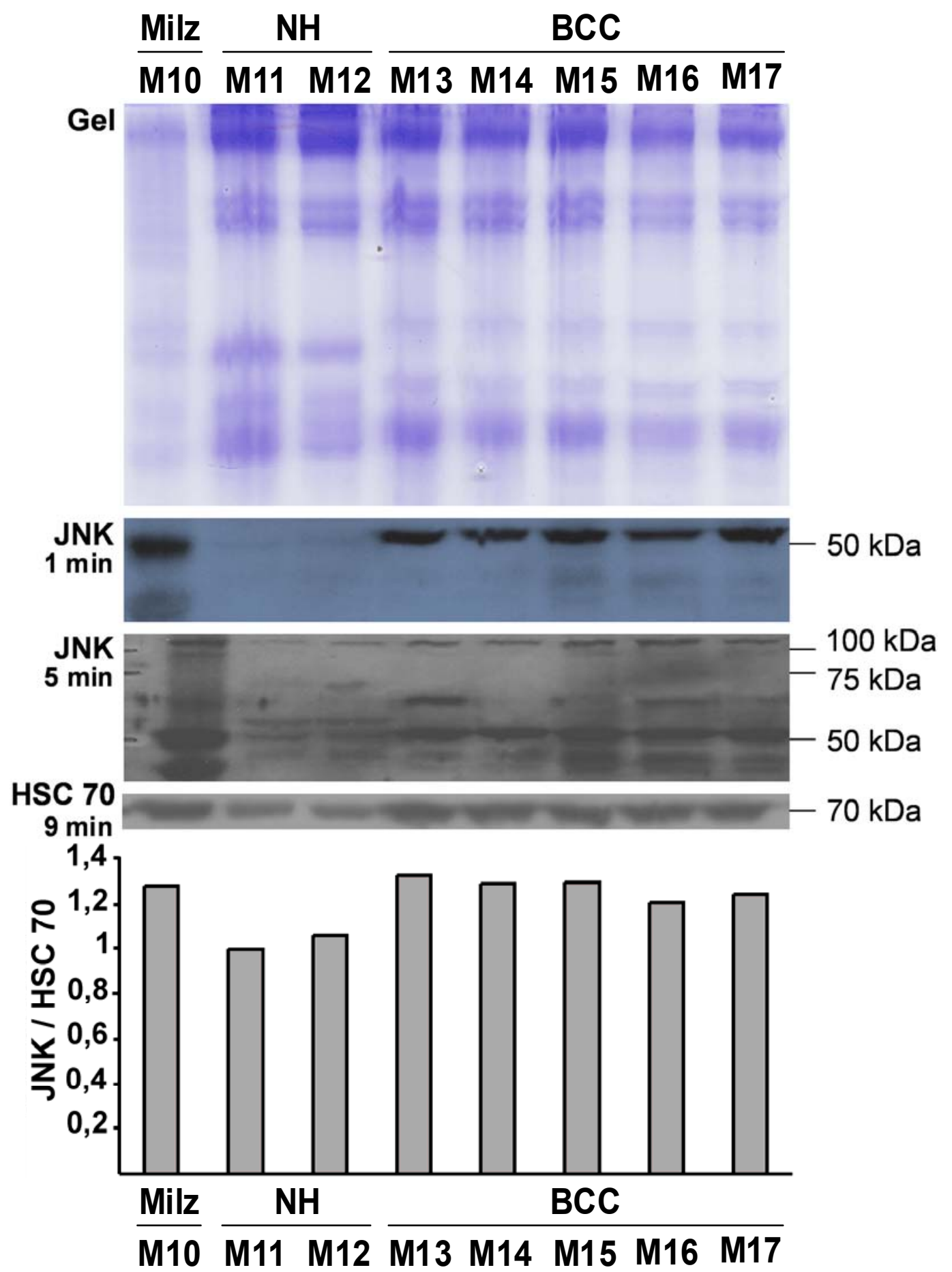

Abbildung 21: Western-Blot-Analyse der Expression von JNK-Isoformen in BCC- und Hautproben.

Für die Analyse wurde Protein aus der Schwanzhaut von Mäusen bzw. der Milz isoliert. Die Isoform JNK1 hat ein Molekulargewicht von $46 \mathrm{kDa}$, die Isoformen JNK2 und JNK3 eines von $54 \mathrm{kDa}$. Das oberste Bild zeigt das Gel nach Färbung mit Coomassie-Blau. Im mittleren Abschnitt finden sich der Blot mit Angabe der verwendeten Antikörper sowie die Belichtungszeit. Wie man sieht war eine genaue Zuordnung der $46 \mathrm{kDa}-\mathrm{Bande}$ nicht möglich, die daher densitometrisch nicht ausgewertet wurde. Unten ist das Ergebnis der densitometrischen Auswertung der 54 kDa-Bande abgebildet. Zur Kalibration wurden die ermittelten Werte für JNK auf die Werte der Ladekontrolle HSC 70 bezogen. Der Wert für M11 wurde dabei auf den Wert = 1 gesetzt.

Maus 10 (M10): Milz, Positivkontrolle

Maus 11 und Maus 12 (M11-M12): Haut von Kontrollmäusen

Maus 13 bis Maus 17 (M13-M17): BCC 


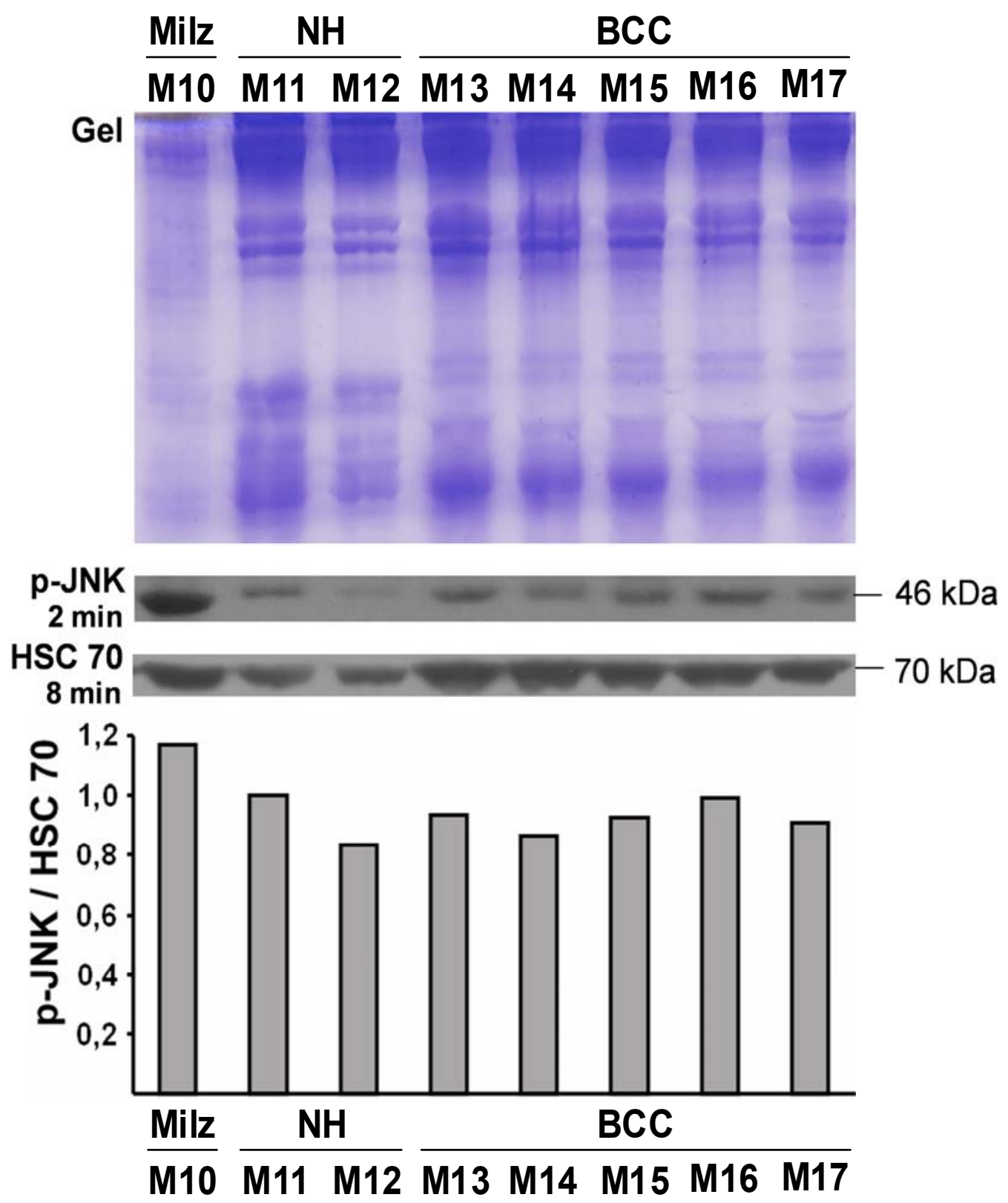

Abbildung 22: Western -Blot-Analyse der Expression von phosphorylierten JNK-Isoformen in BCC- und Hautproben mittels eines phospho-JNK-Antikörpers von Santa Cruz.

Für die Analyse wurde Protein aus der Schwanzhaut von Mäusen bzw. der Milz isoliert. Das oberste Bild zeigt das Gel nach Färbung mit Coomassie-Blau. Im mittleren Abschnitt finden sich der Blot mit Angabe der verwendeten Antikörper sowie die Belichtungszeit. Es ist nur die 46 kDa-Bande (phospho-JNK1) abgebildet, da die 54 kDa-Bande (phospho-JNK 2 und phospho-JNK3) durch unspezifische Bindung des Sekundär-Antikörpers verdeckt wird. Unten ist das Ergebnis der densitometrischen Auswertung der 46 kDa-Bande abgebildet. Zur Kalibration wurden die ermittelten Werte für phospho-JNK auf die Werte der Ladekontrolle HSC 70 bezogen. Der Wert für M11 wurde dabei auf den Wert = 1 gesetzt.

Maus 10 (M10): Milz, Positivkontrolle

Maus 11 und Maus 12 (M11-M12): Haut von Kontrollmäusen

Maus 13 bis Maus 17 (M13-M17): BCC 
Mit dem phospho-JNK-Antikörper der Firma Santa Cruz, welcher sowohl das 46 kDa große phosphorylierte JNK1 als auch das 54 kDa große phosphorylierte JNK2 detektiert, zeigte die densitometrische Auswertung für JNK1 keine eindeutigen Unterschiede in der Expression zwischen normaler Haut und Tumor (Abbildung 22). Wie man der Abbildung entnehmen kann, zeigten sich Expressionsschwankungen. So zeigte die Hautprobe M11 den höchsten Messwert, die zweite Hautprobe M12 hingegen den Geringsten. Die Werte der fünf BCC lagen im Bereich dazwischen. Leider konnte die Bande für das phosphorylierte JNK2 nicht ausgewertet werden, da die Bande durch unspezifische Bindung des Sekundarantikörpers verdeckt wurde (Daten nicht gezeigt).

Der WB (Abbildung 23) mit dem phospho-JNK-Antikörper der Firma Cell Signaling, welcher alle drei JNK-Proteine im phosphorylierten Zustand detektiert, zeigte kaum ein Signal in den normalen Hautproben M11 und M12. Die BCC-Probe M14 hatte nur eine geringfügig höhere Signalintensität. Beim BCC M13 lag der Wert der 54 kDa-Bande, bei M17 der Wert der 46 kDa-Bande nur gering über den Werten der beiden Hautproben. Lediglich die Messwerte von M15 und M16 waren beide deutlich gegenüber der Haut erhöht.

Insgesamt ergab die Analyse, dass BCC deutlich mehr JNK-Gesamtprotein exprimieren als Hautproben. Aktives phospho-JNK hingegen schien in Haut und BCC etwa gleich stark exprimiert zu sein. 


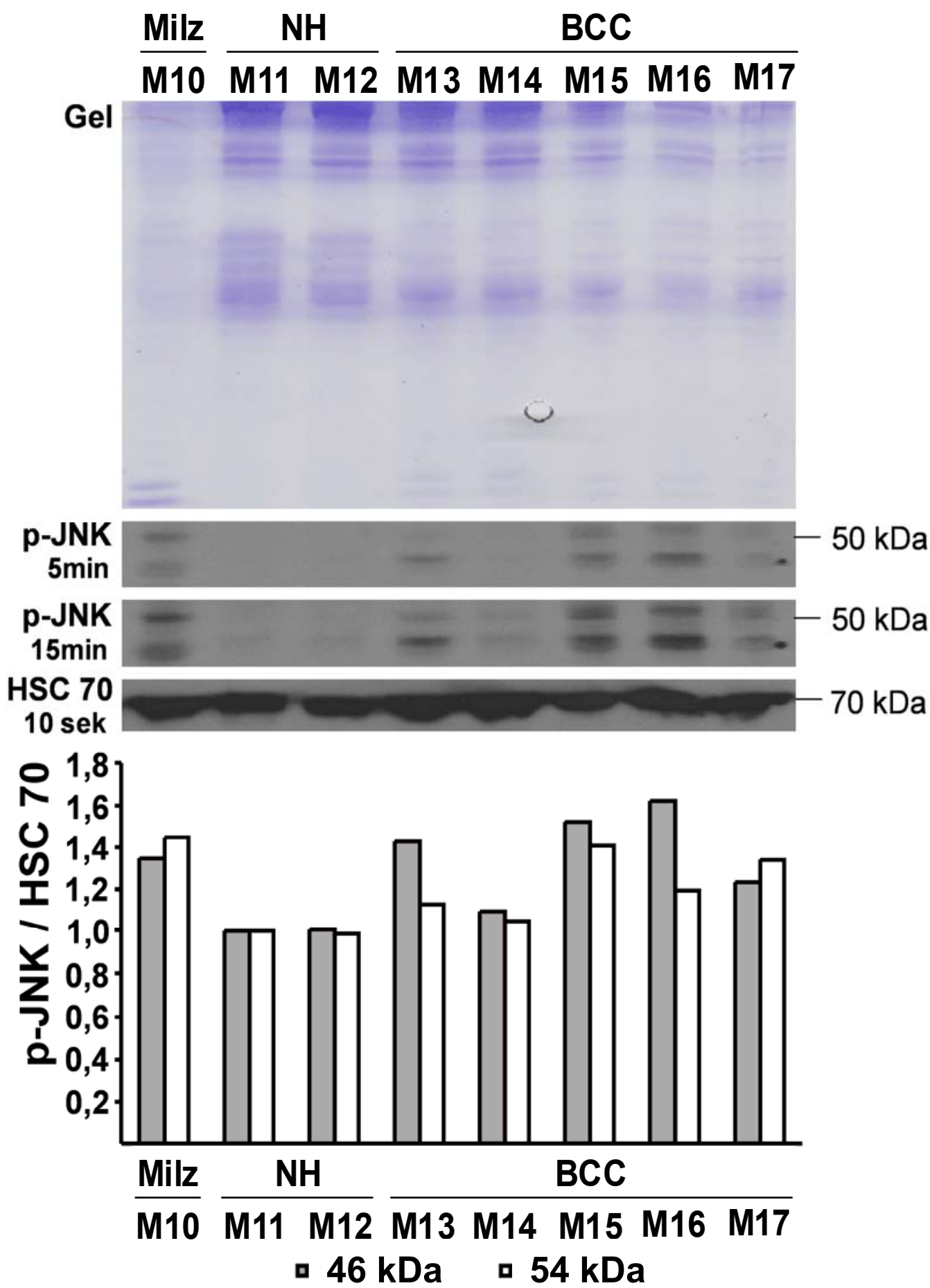

Abbildung 23: Western-Blot-Analyse der Expression von phosphorylierten JNK-Isoformen in BCC- und Hautproben mittels eines phospho-JNK-Antikörpers von Cell Signaling.

Für die Analyse wurde Protein aus der Schwanzhaut von Mäusen bzw. der Milz isoliert. Das oberste Bild zeigt das Gel nach Färbung mit Coomassie-Blau. Im mittleren Abschnitt finden sich der Blot mit Angabe der verwendeten Antikörper und die Belichtungszeit. Unten ist das Ergebnis der densitometrischen Auswertung der Banden bei 54 (phospho-JNK 2 und phospho-JNK3) bzw. bei $46 \mathrm{kDa}$ (phospho-JNK1) abgebildet. Zur Kalibration wurden die ermittelten Werte für phospho-JNK auf die Werte der Ladekontrolle HSC 70 bezogen. Der Wert für M11 wurde dabei auf den Wert = 1 gesetzt.

Maus 10 (M10): Milz, Positivkontrolle

Maus 11 und Maus 12 (M11-M12): Haut von Kontrollmäusen

Maus 13 bis Maus 17 (M13-M17): BCC 


\subsection{Expressionsanalyse von potentiellen Wnt5a-Rezeptoren in murinen und humanen BCC sowie in den Keratinozytenzelllinien HaCaT und C5N und der BCC-Zelllinie ASZ001}

Wie die Western Blots gezeigt haben, sind in BCC v.a. die beiden nicht-kanonischen WntSignalwege aktiviert (Kapitel 3.4). Wnt5a - aber auch andere Wnt - können beide Signalwege aktivieren (Katoh, 2005). Die Aktivierung hängt hierbei jedoch vom Rezeptorkontext ab (Mikels und Nusse, 2006). Daher wurde im Folgenden sowohl in humanen als auch in murinen BCC die Expression verschiedener Wnt5a-Rezeptoren untersucht. Die Rezeptorexpression wurde auch an Keratinozyten und in der BCC-Zelllinie ASZ001 analysiert.

Die Auswahl der Rezeptoren Ror2, Fzd2, Fzd4 und Fzd5 erfolgte nach gründlicher Sichtung der Literatur. Von allen ausgewählten Rezeptoren ist bekannt, dass sie Wnt5a binden können. Laut Literatur aktiviert Wnt5a über die Rezeptoren Fzd2 und Fzd5 den Wnt/Ca ${ }^{2+}-\mathrm{Weg}$. Vermessen wurde auch die Expression des Rezeptors Ror2, über den Wnt5a u.a. den Wnt/JNK/AP1-Weg aktiviert. Außerdem wurde die Expression des Rezeptors Fzd4 analysiert, der über Wnt5a den kanonischen Signalweg (Wnt/ßCat-Signalweg) aktiviert (Abbildung 2, S. 7). Auf eine Expressionsanalyse des Rezeptors Fzd7, welcher ebenfalls Wnt5a binden kann und den kanonischen Signalweg stimuliert (Umbhauer et al., 2000), wurde verzichtet, da die bisherigen Ergebnisse dem kanonischen Signalweg keine wichtige Funktion im BCC zuschreiben (Kapitel 3.4.1). 

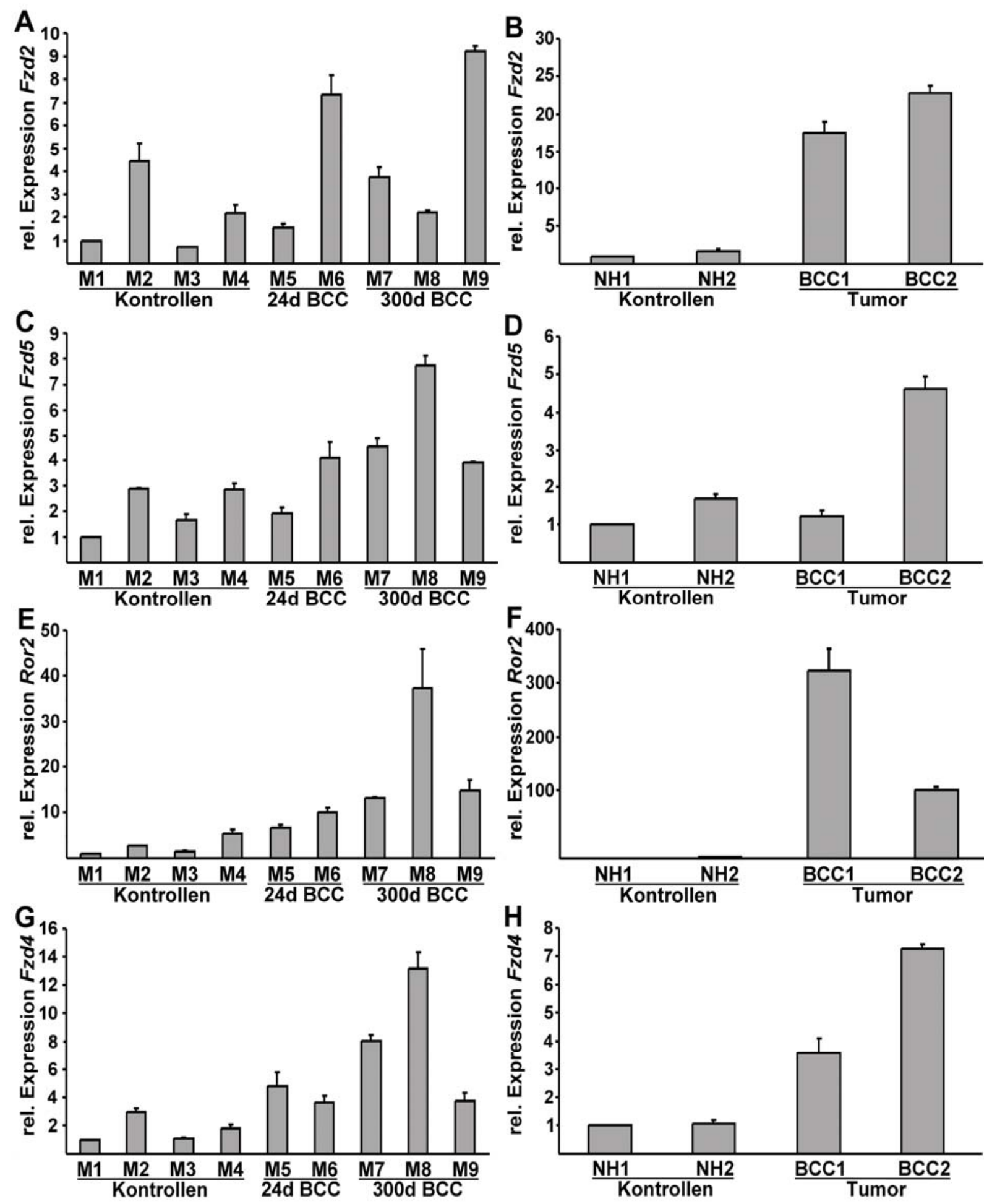

Abbildung 24: Quantifizierung der Expression unterschiedlicher Wnt5a-Rezeptoren in murinen und humanen BCC.

Für die Analyse der Expression von Fzd2, Fzd5, Ror2 und Fzd4 wurde murine Schwanzhaut-cDNA (A,C,E,G) bzw. humane ausgestanzte Tumor- und Haut-cDNA (B,D,F,H) in eine qRT-PCR mit jeweils sequenzspezifischen Oligonukleotiden eingesetzt (siehe Text). Jede Probe wurde in Triplikaten analysiert. Die ermittelten Werte wurden gegen die Werte der Expression von 18S rRNA als endogener Standard normalisiert. Die Werte M1 $(\mathrm{A}, \mathrm{C}, \mathrm{E}, \mathrm{G})$ bzw. NH2 (B,D) und NH1 $(\mathrm{F}, \mathrm{H})$ dienten als Kalibratoren und wurden auf den Wert $=1$ gesetzt

A,C,E,G: Maus 1 bis Maus 4 (M1-M4): Haut von Kontrollmäusen

Maus 5 und Maus 6 (M5-M6): BCC, Gruppe 24d

Maus 7 bis Maus 9 (M7-M9): BCC, Gruppe 300d

B,D,F,H: NH: normale humane Haut 
Für Fzd2 konnte in den murinen BCC keine eindeutige Überexpression gegenüber normaler Haut nachgewiesen werden (Abbildung 24A). Zwei Tiere (M6 und M9) zeigten zwar eine 7bzw. 9-fache Überexpression von Fzd2, die ermittelten Werte lagen für die restlichen untersuchten Tiere aber nur geringfügig über bzw. auf dem Niveau der Werte der Kontrollen. Die Expression von Fzd2 schien anhand der ermittelten Daten individuell sehr starken Schwankungen unterworfen zu sein.

Im Gegensatz dazu konnte für die beiden humanen Tumorproben eine eindeutige Überexpression von Fzd2 nachgewiesen werden (Abbildung 24B). Die für die Tumorproben (BCC1 und BCC2) ermittelten Werte von 17,46 bzw. 22,84 lagen dabei deutlich über den Werten, die für normale Haut ermittelt werden konnten.

In den murinen Proben wurde Fzd5 in Tumoren verglichen mit den eingesetzten Kontrollen stärker exprimiert als in den Kontrollen (Abbildung 24C). Dabei zeigten die 300d BCC eine eindeutige Überexpression, während diese bei den 24d BCC nur für M6 bestanden. Der Wert für M5 lag im Bereich der Kontrollen.

Bei den humanen BCC zeigte nur die Probe BCC2 eine Überexpression von Fzd5 (4,63-fach), während die Probe BCC1 auf dem Expressionsniveau der Kontrollen lag (1,21-fach, Abbildung 24D).

In den untersuchten murinen BCC-Proben wurde eine Überexpression von Ror2 nachgewiesen (zwischen 6 - 37-fach; Abbildung 24E). Die ermittelten Werte waren für die 24d BCC im Vergleich zu den 300d BCC etwas geringer. Die Expression von Ror2 schien im späten Stadium des BCC erhöht zu sein.

Eine sehr deutliche Überexpression von Ror2 konnte für die humanen BCC-Proben ermittelt werden (100 - 326-fach; Abbildung 24F). Die Verteilung der ermittelten Daten korrelierte dabei mit der Höhe der Wnt5a-Expression in den Tumorproben (Abbildung 7B, S. 41).

Der Rezeptor Fzd4 wurde in den murinen BCC-Proben leicht überexprimiert (3,6 - 13-fach, Abbildung 24G). Für die 300d BCC konnte dabei im Vergleich zu den 24d BCC eine leicht höhere Expression von Fzd4 ermittelt werden.

Dagegen konnte in den analysierten humanen Proben eine geringere aber dennoch eindeutige Überexpression von Fzd4 nachgewiesen werden (3,57-fach für BCC1 bzw. 7,26-fach für BCC2, Abbildung 24H). 
Zusammenfassend zeigten die Expressionsanalysen, dass bei den humanen Tumoren eine eindeutige Überexpression der Rezeptoren bestand, über die Wnt5a den Wnt/Ca ${ }^{2+}$ - (Fzd2), den Wnt/JNK/AP1 - (Ror2) und den $\beta$ Cat-Signalweg (Fzd4) aktivieren kann. Fzd5, über den Wnt5a den Wnt/ $\mathrm{Ca}^{2+}$-Weg aktiviert, schien dagegen nicht eindeutig überexprimiert.

Bei den murinen 300d BCC fand sich ein ähnliches Ergebnis mit Überexpression von Rezeptoren aller drei Signalwege. In diesen Tumoren wurde der Rezeptor Fzd5 eindeutiger als Fzd2 überexprimiert (beide sind Rezeptoren, die den $\mathrm{Wnt} / \mathrm{Ca}^{2+}-\mathrm{Weg}$ aktivieren können). In den murinen 24d BCC schien nur der Rezeptor Fzd4 eindeutig überexprimiert zu sein. Die Signifikanz dieser Ergebnisse war jedoch aufgrund der geringen Größe der Stichprobe nicht eindeutig bestimmbar.

Auch in den Zelllinien wurde die Expression der Rezeptoren untersucht. Murines Fzd2 wurde in der Keratinozytenzelllinie C5N etwa 2,2-fach höher exprimiert als in der BCC-Zelllinie ASZ001 (Abbildung 25A). Dies war invers zur beobachteten Expression dieses Rezeptors in murinen BCC. Ähnliches wurde für die humane Kertinozytenzelllinie HaCaT gefunden, welche eine höhere Expression von Fzd2 im Vergleich zu normaler Haut zeigte. Die Expression war sogar höher als im nativen BCC (Abbildung 25B).

Die Expression von Ror2 war in der BCC-Zelllinie ASZ001 gegenüber C5N etwa 17-fach erhöht. Dies entsprach weitgehend den Expressionsverhältnissen bei normaler Haut und BCC, obwohl das Expressionsniveau in den Zelllinien sehr niedrig war und deutlich unter dem der Gewebeproben lag (Abbildung 25C). Der Wert für Ror2 in den HaCaT-Zellen war dem Wert normaler Haut ähnlich (Abbildung 25D).

Die Expressionsanalyse von Fzd4 zeigte, dass die Expression in ASZ001 gegenüber C5N erhöht war (Abbildung 25E). Dies spiegelte auch die Expressionsverhältnisse von normaler Haut und BCC wider. Die HaCaT-Zellen exprimierten Fzd4 fast ebenso stark wie normale native Haut (Abbildung 25F).

Eine Expressionsanalyse von Fzd5 wurde in den Zelllinien nicht durchgeführt.

Zusammenfassend kann festgehalten werden, dass die untersuchten HaCaT-, C5N- und ASZ001-Zelllinien mit Ausnahmne von Fzd2, welches sowohl in HaCaT als auch in C5N sehr stark überexprimiert war, ein ähnliches Rezeptorexpressionsmuster wie normale Haut oder BCC zeigten. 

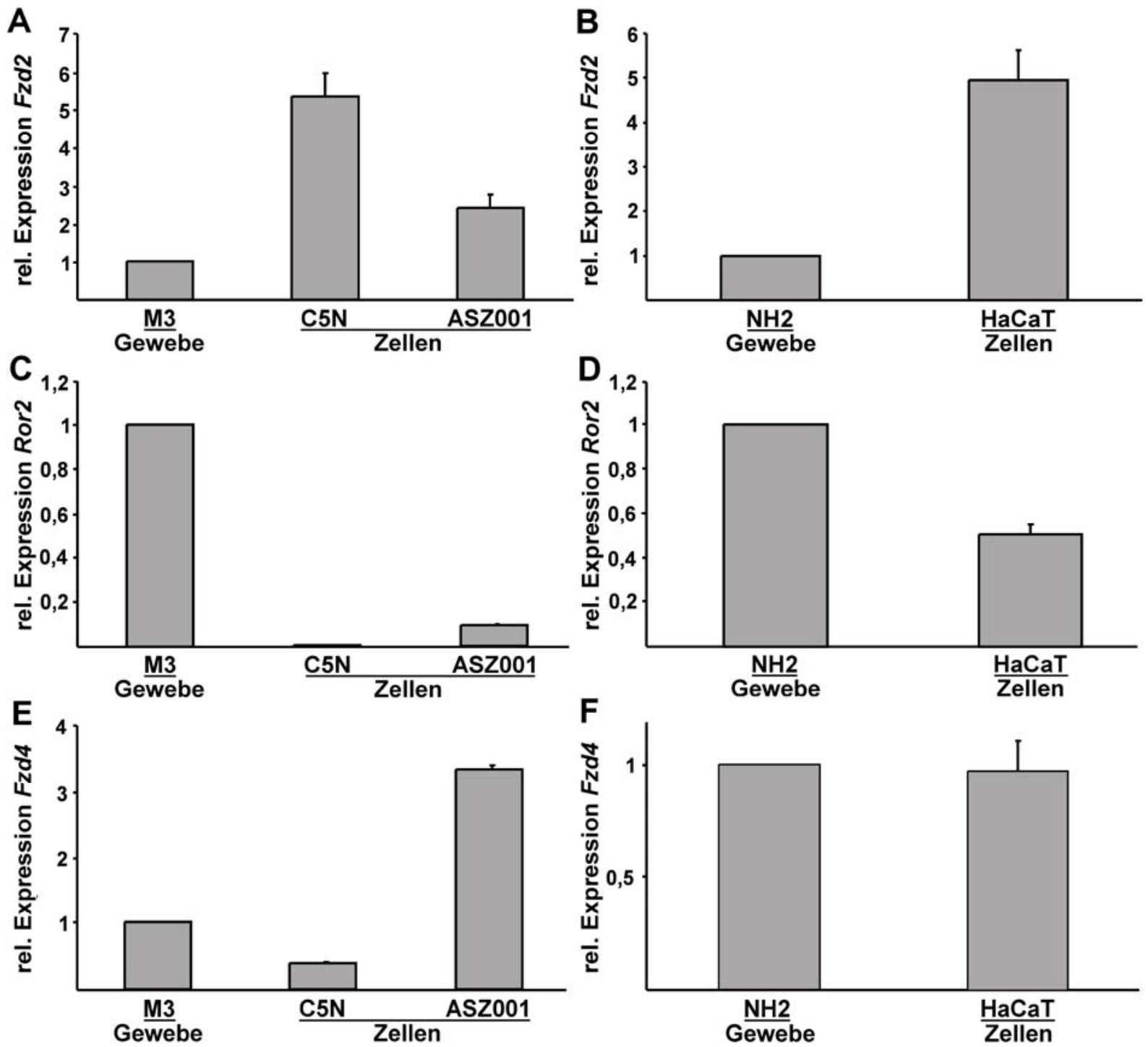

Abbildung 25: Quantifizierung der Expression ausgewählter Wnt5a-Rezeptoren in murinen und humanen Modellzelllinien.

Für die Analyse der Expression von Fzd2, Ror2 und Fzd4 wurde cDNA aus C5N und ASZ001 und murine Schwanzhaut-cDNA (A,C,E) bzw. cDNA aus HaCaT und humane ausgestanzte Haut-cDNA (B,D,F) in eine qRT- PCR mit jeweils sequenzspezifischen Oligonukleotiden eingesetzt. Jede Probe wurde in Triplikaten analysiert. Die ermittelten Werte wurden gegen die Werte der Expression von 18S rRNA als endogener Standard normalisiert. Die Werte M3 (A,C,E) bzw. NH2 (B,D,F) dienten als Kalibratoren und wurden auf den Wert = 1 gesetzt

Maus 3 (M2): Haut einer Kontrollmaus

NH2: normale humane Haut

Da die Keratinozytenzelllinie HaCaT auch für Gli1 und Wnt5a (Abbildung 8B und Abbildung 8D, S. 42) ein annähernd gleiches Expressionsmuster wie normale humane Haut zeigte, scheint diese Zelllinie ein besonders geeignetes Modellsystem für dieses Gewebe zu sein.

Obwohl die murinen Zelllinien ASZ001 und C5N zwar für Fzd4 und Ror2 ein ähnliches Expressionsmuster wie BCC und normale Haut zeigten, war die Gli1-Expression in C5N höher als in ASZ001. Der Einsatz dieser Zelllinie als Modellsystem für normale Haut erscheint für funktionelle Analysen daher nicht optimal. 
Man muss sich jedoch bewusst sein, dass ein direkter Vergleich der Ergebnisse zwischen einer Kertionzytenzellinie wie $\mathrm{C} 5 \mathrm{~N}$ oder $\mathrm{HaCaT}$ und normaler Haut suboptimal ist, da Kertinozyten in der normalen Haut nur einen kleinen Teil der Zellsubpopulationen ausmachen.

\subsection{Untersuchung der Regulation von Cutl1 durch den Hh-Signalweg}

Im Rahmen dieser Doktorarbeit wurde zusätzlich die Regulation von Cutl1 durch den HhSignalweg untersucht. Dies war deshalb interessant, da über die Transkriptionsregulation von Cutl1 in der Literatur nichts bekannt ist und da gezeigt werden konnte, dass Cutl1 die Expression von Wnt5a induzieren kann (Ripka et al., 2007).

Wie nun in der vorliegenden Arbeit im Kapitel 3.2.2 und 3.2.3 (S. 45 bzw. S. 46) gezeigt wurde, lies sich die Expression von Wnt5a in den verwendeten Keratinozyten- und BCCZelllinien durch Hh nicht stimulieren. Dagegen wurde die Wnt5a-Expression jedoch in Fibroblasten-Zellen durch Hh aktiviert. Da, wie bereits beschrieben, die Expression von Wnt5a von Gli-Transkriptionsfaktoren, und damit auch von kanonischen Hh-Signalweg unabhängig ist, ist es möglich, dass Hh in Fibroblasten-Zellen die Expression von Cutl1 induziert, welches wiederum die Expression von Wnt5a reguliert.

Wie in Abbildung 26 exemplarisch gezeigt wird, wurde die Transkription von Cutl1 in Fibroblasten tatsächlich durch eine Inkubation mit Shh gesteigert. Das Experiment wurde in zwei voneinander unabhängigen Ansätzen durchgeführt und 2x wiederholt. Dieser Versuch identifizierte die Hh-Signalkaskade als möglichen Regulator der Expression von Cutl1.

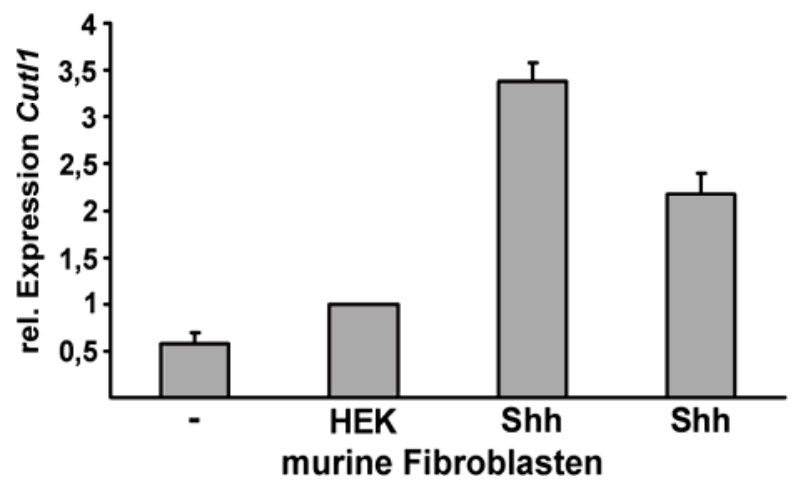

Abbildung 26: Quantifizierung der Cutl1-Expression in Shh-stimulierten Fibroblasten.

Für die Analyse der Expression von Cutl1 wurde cDNA aus Fibroblasten in eine qRT-PCR mit jeweils sequenzspezifischen Oligonukleotiden eingesetzt. Jede Probe wurde in Triplikaten analysiert. Die ermittelten Werte wurden gegen die Werte der Expression von 18S rRNA als endogener Standard normalisiert. Der Wert der mit dem HEK-Medium inkubierten Zellen diente als Kalibrator und wurde auf den Wert = 1 gesetzt

unbehandelte Zellen

HEK Zellen mit HEK-Kontrollmedium inkubiert

Shh Zellen mit Shh-Medium inkubiert 
In Abbildung 27 wird gezeigt, dass Cutl1 auch eindeutig in humanen BCC, nicht aber in murinen $\mathrm{BCC}$, überexprimiert war. So zeigten humane $\mathrm{BCC}$ eine erhöhte Expression von Cutl1 in den Tumoren gegenüber der Haut (Faktor 62 bzw. 58; Abbildung 27B). Diese BCC wiesen ebenfalls eine erhöhte Transkription von Wnt5a auf (Abbildung 7B, S. 41). Daher könnte in diesen Proben die Expression von Cutl1 tatsächlich in direktem Zusammenhang mit dem Hh-Signalweg und der beobachteten Wnt5a-Expression stehen.
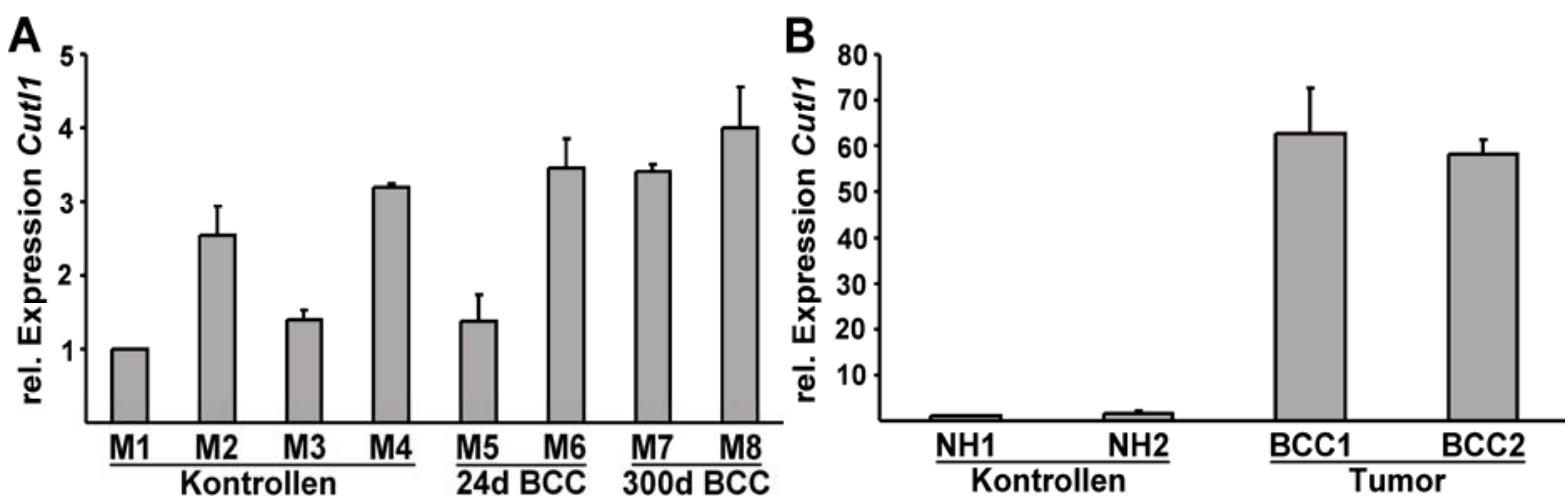

Abbildung 27: Quantifizierung der Cutl1-Expression in Geweben.

Für die Analyse der Expression von Cutl1 wurde murine Schwanzhaut-cDNA (A) bzw. humane ausgestanzte Tumor- und Haut-cDNA (B) in eine qRT-PCR mit jeweils sequenzspezifischen Oligonukleotiden eingesetzt. Jede Probe wurde in Triplikaten analysiert. Die ermittelten Werte wurden gegen die Werte der Expression von $18 \mathrm{~S}$ rRNA als endogener Standard normalisiert. Die Werte M1 (A) und NH1 (B) dienten als Kalibratoren und wurden auf den Wert $=1$ gesetzt

A: $\quad$ Maus 1 bis Maus 4 (M1-M4): Haut von Kontrollmäusen

Maus 5 und Maus 6 (M5-M6): BCC, Gruppe 24d

B: $\quad$ Maus 7 bis Maus 9 (M7-M9): 


\section{Diskussion}

\subsection{Ist Wnt5a ein Zielgen der Hh-Signalkaskade?}

BCC humaner und muriner Herkunft sind durch eine deregulierte, aktive Hh-Signalkaskade gekennzeichnet (Hahn et al., 1999; Evangelista et al., 2006). Gleichzeitig wird auch Wnt5a in den Tumoren überexprimiert (Abbildung 7, S. 41). Da die Wht5a-Expression während der Haarfollikelmorphogenese durch Shh positiv reguliert wird (Reddy et al., 2001), stellt sich die Frage, ob Wnt5a ein direktes Zielgen von Shh sein könnte.

In Keratinozyten ließ sich die Wnt5a-Expression nicht durch Shh stimulieren. Da in Keratinozyten jedoch auch eine Induktion des Transkriptionsfaktors Gli1 ausblieb, kann davon ausgegangen werden, dass eine Aktivierung der Hh-Signalkaskade in diesen Zellen nicht stattgefunden hat.

Von einer anderen Arbeitsgruppe ist für HaCaT-Zellen jedoch eine Überexpression von Gli1 nach Transfektion mit einem Shh-exprimierenden Plasmid beschrieben worden (Bigelow et al., 2005). Daher könnten die fehlende Aktivierung der Hh-Signalkaskade in unseren Experimenten auf eine zu geringe Konzentration von Shh im konditioniertem Medium oder eine zu geringe Dichte des Ptch-Rezeptors auf den Zellen zurückzuführen sein. Auch die 72stündige Inkubation der Zellen in Medium mit niedriger (2\%) FCS-Konzentration und die damit einhergehende Umstellung des Zellstoffwechsels könnten eine Rolle spielen.

Nichtsdestotrotz wiesen alle weiteren Experimente in der AG Hahn darauf hin, dass die Expression von Wht5a beim BCC unabhängig von der Hh-Signalkaskade induziert wurde. So konnte die Wnt5a-Expression weder in C5N, ASZ001, HaCaT, noch in 3T3-Fibroblasten durch die Transfektion mit einem oder einer Kombination der drei Gli-Transkriptionsfaktoren stimuliert werden. Hinzu kommt, dass die Wnt5a-Expression in vivo in murinen BCC auf das Tumorstroma beschränkt waren. Wht5a wurde nicht in Tumorzellen exprimiert, welche eine starke Aktivierung des Hh-Signalweges aufwiesen. Weiterhin haben Ko-Kulturen von stromalen Zellen und der BCC-Zelllinie ASZ001 gezeigt, dass die Wnt5a-Expression in den stromalen Zellen unabhängig vom Hh-Signalweg induziert wurde.

Diese Daten zeigten, dass Wnt5a im BCC-Stroma exprimiert wurde und dass die Expression von Wnt5a beim BCC nicht durch den aktiven Hh-Signalweg oder Gli induziert wurde.

Die beobachtete Induktion von Wnt5a in murinen Fibroblastenzellen nach Inkubation mit Shh-konditioniertem Medium steht hierbei in einem sehr interssanten Zusammenhang. So 
wurde in diesen Zellen nach Inkubation mit Shh neben Wnt5a auch die Expression von Gli1 und Cutl1 induziert.

Cutl1 ist ein Mitglied der Cut/Cux/CDP-Familie. Cutl1 ist zudem der einzige bisher bekannte Transkriptionsfaktor, der die Expression von Wnt5a induziert (Ripka et al., 2007). Es ist daher denkbar, dass das BCC-Stroma Shh exprimiert. Dies führt jedoch nur in Fibroblasten zur Aktivierung der Hh-Signalkaksade (in Keratinozyten lässt sich die Kaskade nicht induzieren; siehe Abbildung 11 und Abbildung 13, S. 45 bzw. S. 47). Da die Aktvierung der Hh-Signalkaksade wiederum Cutl1 induziert, wird in Fibroblasten letzendendlich Wnt5a vermehrt exprimiert. Dies könnte die im Mausmodell beobachtete stromale Expression von Wnt5a erklären. Nicht schlüssig ist hierbei die nicht nachzuweisende Überexpression von Cutl1 in den murinen BCC-Proben. Möglicherweise exprimiert jede Maus Cutl1 individuell in normaler Haut, sodass man in murinen BCC intraindividuell überprüfen muss, ob Cutl1 im Tumorstroma im Vergleich zur normalen Haut überexprimiert wird.

\subsection{Hat Wnt5a einen Effekt auf die Proliferation und/oder Differenzierung von BCC-Zellen?}

Wie oben beschrieben, wurde Wnt5a im Tumorstroma von BCC exprimiert. Dies bedeutet, dass potentielle Effekte von Wnt5a auf BCC-Zellen parakrin und nicht tumor-intrinsisch vermittelt werden. Daher wurde zur Untersuchung von Wnt5a-vermittelten Effekten auf BCC die Zelllinie ASZ001 (Modell für murine BCC) mit rekombinantem Wnt5a behandelt und das Proliferations- und Differenzierungsverhalten der Zellen untersucht. Hierzu wurden unterschiedliche Konzentrationen (50 ng und $100 \mathrm{ng}$ ) von rekombinantem murinem Wnt5a eingesetzt und die Expression von K1, K10 und Pcna mittels qRT-PCR gemessen. Die Keratine K1 und K10 werden innerhalb der Epidermis im Stratum spinosum exprimiert (Yuspa et al., 1991) und gelten als frühe Differenzierungsmarker (Yuspa et al., 1989). Pcna ist eine Komponente der DNA-Polymerase $\delta$ und zeigt seine höchste Konzentration in der SPhase des Zellzyklus (Celis et al., 1987). Daher ist Pcna ein Indikator für das proliferative Potential der untersuchten Zellen.

In den untersuchten murinen BCC waren K1, K10 und Pcna gegenüber normaler Haut überexprimiert. Tatsächlich wurde in den ASZ001 nach der Inkubation mit 100 ng rWnt5a eine Induktion der K10-Expression nachgewiesen. Das Ergebnis zeigt, dass Wnt5a möglicherweise einen positiven Effekt auf die Differenzierung von BCC haben könnte, indem es K10 induziert. Das Ergebnis konnte durch Wiederholungen anderer Mitglieder der AG Hahn bestätigt werden. Allerdings hat sich gezeigt, dass auch eine Konzentration von 50 ng 
rWnt5a im Medium die Expression von K10 in ASZ001 auslöst. Dasselbe trifft für HaCaTZellen zu, wobei durch rWnt5a neben $K 10$ auch die Expression von $K 1$ induziert wurde.

In HaCaT wurde im Gegensatz zu ASZ001 auch der Proliferationsmarker Cyclin-abhängige Kinase 2 (CDC2) vermehrt transkribiert (Daten nicht gezeigt). Dieser Befund konnte durch einen BrdU-Assay bestätigt werden. Für die murine Keratinozytenzelllinie C5N fand sich weder ein Effekt auf die Differenzierung noch auf die Proliferation.

Das Verhalten von murinen Keratinozyten in Kultur ist abhängig von der Konzentration an $\mathrm{Ca}^{2+}$ im Medium (Hennings et al., 1980). Bei geringen Konzentrationen von $\mathrm{Ca}^{2+}$ proliferieren die Zellen schnell und wachsen einschichtig $\left(\mathrm{Ca}^{2+}\right.$-Konzentration von 0,05 bis 0,1 mM). Bei einer $\mathrm{Ca}^{2+}$-Konzentrationen ab ca. 0,12 $\mathrm{mM}$ wird die terminale Differenzierung induziert. Die frühe Phase der Differenzierung von Keratinozyten in Zellkultur ist wie bei Keratinozyten in vivo durch die Expression von K1 und K10 gekennzeichnet (Yuspa et al., 1989). Der Anstieg der extrazellulären $\mathrm{Ca}^{2+}$-Konzentration wird dabei über den $\mathrm{Ca}^{2+}$ sensiblen Rezeptor $(\mathrm{CaR})$ an das Zellinnere vermittelt. Intrazellulär folgt dann die Öffnung von $\mathrm{Ca}^{2+}$-Speichern und es kommt zum Anstieg der intrazellulären $\mathrm{Ca}^{2+}$-Konzentration. Dieser Konzentrationsanstieg ist der eigentliche Trigger für die spezifische Zellantwort und die Aktivierung der zur Differenzierung führenden Gentranskription von K1 und K10 in Keratinozyten (Tu et al., 2007). Bei Abwesenheit von intrazellulärem $\mathrm{Ca}^{2+}$ bleibt die Differenzierung von Keratinozyten aus (Li et al., 1995).

Daher ist die durch rWnt5a hervorgerufene Induktion der K10-Expression in HaCaT und ASZ001 möglicherweise durch die $\mathrm{Ca}^{2+}$-induzierte Differenzierung zu erklären. Tatsächlich zeigte sich bei der Rezeptoranalyse, dass beide Zelllinien den Rezeptor Fzd2 exprimieren (Abbildung 25, S. 67), was die Aktivierung des Wnt/Ca ${ }^{2+}$-Signalweges durch rWnt5a möglich erscheinen lässt.

Obwohl auch die Zelllinie C5N den Rezeptor Fzd2 exprimiert, kam es nach Stimulation mit Wnt5a nicht zur Expression von K10. Der Grund kann im Verlust wichtiger physiologischer Eigenschaften innerhalb der Zelllinie selbst liegen. So ist bekannt, dass C5N-Keratinozyten trotz Kultivierung in einem Medium mit hoher Konzentration an $\mathrm{Ca}^{2+}$ nicht zur Differenzierung gebracht werden können (Kulesz-Martin et al., 1983; Holden et al., 1997). Wahrscheinlich ist es den Zellen nicht mehr möglich, adäquat auf Änderungen der intrazellulären $\mathrm{Ca}^{2+}$-Konzentration zu reagieren. 
Die Beobachtungen an den Zelllinien spielen eine wichtige Rolle bei der Interpratation des Tumorphenotyps von murinen BCC. Interessanterweise zeigten Untersuchungen der AG Hahn, dass murine BCC nach 200 Tagen einen differenzierten Phänotyp und in den meisten Fällen einen starken Rückgang im Tumorvolumen aufweisen. Mehrere Pathologen stellten anhand von Gewebeschnitten die Diagnose der Tumorregression. Diese Beobachtung passt sehr gut zu den bisherigen Ergebnissen dieser Arbeit. Spätstadien der murinen BCC zeigten nämlich gegenüber früheren Stadien eine erhöhte Expression von Wnt5a und schienen auch Fzd2 stärker zu exprimieren. Dies könnte möglicherweise bedeuten, dass die Aktivität des $\mathrm{Wnt} / \mathrm{Ca}^{2+}$-Signalweges in diesen Tumoren vermehrt induziert werden kann. Die Folge davon könnte die Induktion der terminalen Differenzierung in Tumorzellen sein, was sich histologisch dann als Tumorregression äußern könnte.

Der Wnt/JNK/AP1- und der Wnt/ßCat-Signalweg spielen bei der durch Wnt5a hervorgerufenen Differenzierung dagegen wahrscheinlich keine Rolle. In der Literatur wird ihnen die gegenteilige Funktion zugeschrieben. So führt die Überexpression von JNK in Keratinozyten in vitro zur Inhibition der Differenzierung. Nach Zugabe von JNK-Inhibitoren kommt es hingegen zur Differenzierung der Zellen mit Expression von K1 und K10 (Gazel et al., 2006). $\beta$ Cat hat eher eine proliferative Wirkung auf Keratinozyten (Yamazaki et al., 2001; Saldanha et al., 2004).

\subsection{Welche Wnt-Signalwege sind im BCC aktiv?}

Im Rahmen dieser Arbeit wurden die Expression und der Aktivierungszustand von Schlüsselproteinen der einzelnen Signalwege in murinen Tumor- und Hautproben untersucht. Wie bereits erwähnt, waren dies $\beta$ Cat für den kanonischen Signalweg, PKC für den Wnt $/ \mathrm{Ca}^{2+}$ Weg und JNK für den Wnt/JNK/AP1- Signalweg.

Die Analyse von $\beta$ Cat erbrachte keinen Hinweis auf die Aktivität des kanonischen Signalweges im murinen BCC. So wurde dieses Protein im WB in normaler Haut und BCC annähernd gleich stark exprimiert. Auch in der IHC konnte in keinem der Präparate eindeutig eine nukleäre Lokalisation dieses Proteins gezeigt werden. Diese Daten lassen vermuten, dass der kanonische Wnt-Signalweg eine untergeordnete Rolle bei murinen BCC spielt. Dies stimmt mit Analysen von Adolphe überein, die ebenfalls keinen Hinweis auf die Aktivierung 
des kanonischen Wnt-Signalweges in BCC von Krt6a-Cre:Ptch1 ${ }^{\text {neo/neo }}$-Mäusen detektieren konnte (Adolphe et al., 2006).

Auch bei humanen BCC herrscht bis heute Unklarheit, ob $\beta C$ at in den Nukleus gelangt. Die Studien von Yamazaki et al. (2001), El-Bahrawy et al. (2003), Saldanha et al. (2004) und Salto-Tellez et al. (2006) konnten eine nukleäre Akkumulation von $\beta C$ at zeigen, wogegen in den Arbeiten von Boonchai et al. (2000), Lo Muzio et al. (2002), Asplund et al. (2008) und in dieser Arbeit $\beta$ Cat lediglich extranukleär detektiert wurde. Der Grund für die kontroversen Ergebnisse liegt möglicherweise in den physikalischen und biochemischen Eigenschaften der verwendeten Antikörper. So könnte beispielsweise einer der Antikörper in den Nukleus gelangen oder aber mit ubiquitär in den Zellen vorhandenen Proteinen kreuzreagieren. Allerdings fand sich in der Rezeptoranalyse an humanen und murinen BCC eine Überexpression von Fzd4, welcher das Signal über den kanonischen Signalweg nach intrazellulär weitergeben kann, sodass die Aktivierung dieses Signalweges möglich sein sollte. Es ist aber möglich, dass Wnt5a im BCC nicht an diesen Rezeptor bindet, obwohl dies bei Embryonen von Xenopus und auch bei humanen Zellen (HEK293) gezeigt werden konnte (Umbhauer et al., 2000; Chen et al., 2003). Auch könnte ein Rezeptorantagonist extrazellulär bzw. ein Inhibitor intrazellulärer die Aktivierung von Zielgenen des kanonischen Signalweges verhindern. Dkk1 ist beispielsweise ein Rezeptorantagonist, der spezifisch den kanonischen Signalweg inhibiert (Kawano und Kypta, 2003). Die Expression von Dkk1 wurde im Rahmen dieser Arbeit untersucht und wurde zumindest in murinen BCC nicht überexprimiert (Daten nicht gezeigt). Als mögliche intrazelluläre Inhibitoren findet sich die Familie der SoxProteine, die durch die Verwandschaft zu den Tcf/Lef-Proteinen kennzeichnet ist. Sox6 beispielsweise bindet an die Armadillo-Wiederholungen des $\beta$ Cat und stört so dessen Funktion (Iguchi et al., 2007). Für Xenopus konnte gezeigt werden, dass das Protein Sox17 $\beta$ die Bindung von $\beta$ Cat an dessen genomische Zielsequenzen verhindert und so den kanonischen Signalweg inhibiert (Zorn et al., 1999). Auch Sox7 und Sox9 inhibieren spezifisch den kanonischen Signalweg (Zorn et al., 1999; Takash et al., 2001; Akiyama H et al., 2004). Tatsächlich wird aktiviertes Sox9 in allen Suytypen humaner BCC gefunden (Vidal et al., 2008). Schließlich könnte der kanonische Signalweg auch durch die Interaktionen mit den beiden anderen Wnt-Signalwegen gehemmt werden. So ist bekannt, dass Wnt5a nach Bindung an Ror2 die Aktivierung des Wnt/ßCat-Signalweges blockt (Mikels und Nusse, 2006). Auch die Aktivierung des $\mathrm{Wnt} / \mathrm{Ca}^{2+}$-Signalweg hat nach Bindung von Wnt5a an Fzd2 das Potential, den kanonischen Signalweg zu inhibieren (Saneyoshi et al., 2002). 
Die Aktivierung des Wnt/JNK/AP1-Weges wurde über den Nachweis von JNK und phosphoJNK mittels Antikörper durchgeführt. Möglicherweise war JNK in den murinen Tumorproben vermehrt exprimiert. Dies zeigten die Ergebnisse mit dem Antikörper SAPK/JNK \#9252 (Tabelle 10, S. 20), welcher JNK1, JNK2 und JNK3 detektiert. Exakte Aussagen über die Expression von phospho-JNK waren jedoch aufgrund der schlechten Antikörperqualität nur eingeschränkt möglich. Eine Etablierung für die IHC war nicht möglich, da die Antikörper für diese Methode nicht geeignet waren. Da jedoch murine und humane BCC Ror2 überexprimieren, welcher nach Bindung von Wnt5a JNK aktiviert (Oishi et al., 2003; Schambony und Wedlich, 2007), ist es möglich, dass der Wnt/JNK/AP1-Signalweg in BCC aktiv ist.

Murine BCC-Proben wiesen im Gegensatz zu normalen Hautproben eine Überexpression von phospho-PKC auf. Dies könnte auf eine erhöhte Aktivität des $\mathrm{Wnt} / \mathrm{Ca}^{2+}-\mathrm{Weges}$ in den Tumoren hindeuten. Der Befund stützt die in Kapitel 4.2 aufgestellte Hypothese über die Wnt5a-vermittelte Differenzierung von Keratinozyten. Die erhöhte Aktivität des $\mathrm{Wnt} / \mathrm{Ca}^{2+}$ Weges in $\mathrm{BCC}$ würde hierbei zum Anstieg der intrazellulären $\mathrm{Ca}^{2+}$-Konzentration und zur Induktion von K10 führen. Dies könnte sich histologisch als Tumorregression äußern. Außerdem könnte der aktive $\mathrm{Wnt} / \mathrm{Ca}^{2+}$-Signalweg wie bereits ausgeführt die kanonische Signalkaskade inhibieren.

Abschließend muss noch erwähnt werden, dass PKC und JNK Proteine sind, die an der Regulation vieler intrazellulärer Prozesse beteiligt sind und im Zuge verschiedener anderer Signalwege ebenfalls aktiviert werden können. Die Expression der jeweiligen Proteine könnte daher auch durch andere Mechanismen als die Wnt-Signalwege zustande kommen. Aus diesem Grunde sollten die hier beschriebenen Ergebnisse zur Aktivität der einzelnen WntSignalwege in weiteren Experimenten bestätigt werden. Geeignet wäre beispielsweise der Einsatz von Reporter-Assays in ASZ001-Zellen, welche die Aktivität der Signalwege zeigen könnten.

\subsection{Exprimieren BCC-Rezeptoren für Wnt5a?}

Voraussetzung für einen Effekt von Wnt5a ist das Vorhandensein von Rezeptoren an den Tumorzellen. Daher wurde die Expression ausgewählter Wnt5a-Rezeptoren untersucht. Obwohl auf die Expression der einzelnen Rezeptoren in BCC in den vorherigen Abschnitten 
schon teilweise eingegangen wurde, soll dieses Kapitel noch etwas ausführlicher diskutiert werden, da die Rezeptoren in verschiedenen Tumorstadien unterschiedlich exprimiert waren.

Die Analyse von murinen BCC zeigte, dass die Spätstadien (300 d nach Applikation von Tamoxifen) eine eindeutige Überexpression der hier exemplarisch untersuchten Rezeptoren des Wnt/Ca ${ }^{2+}$-(Fzd5), des Wnt/JNK/AP1-(Ror2) und des Wnt/ßCat-Weges (Fzd4) aufwiesen. Bei den frühen Tumoren ( $24 \mathrm{~d}$ nach Applikation von Tamoxifen) hingegen fand sich nur eine eindeutige Überexpression von Fzd4 und eventuell Ror2. Aussagen über die Signifikanz konnten aufgrund der geringen Probenzahl nicht gemacht werden.

Für humane BCC gibt es in der Literatur Angaben zur Expression einzelner Rezeptoren. So wird in der Literatur eine Überexpression von Fzd2 (Rezeptor des Wnt/Ca ${ }^{2+}$-Weges) beschrieben (8,94-fach; O’Driscoll et al., 2006), welche mit der Analyse dieser Arbeit übereinstimmt (17- bzw. 22-fach; Abbildung 24, S. 64). Dagegen wird Fzd4 (Rezeptor des kanonischen Signalweges) in unserer Analyse in den untersuchten BCC überexprimiert (3,5und 7-fach, Abbildung 24), wogegen in der Literatur eine verminderte Expression im Vergleich zu normaler Haut beschrieben wird (-2,78-fach; O’Driscoll et al., 2006). Die von O'Driscoll beschriebene verminderte Expression von Fzd4 stärkt unsere These zur untergeordneten Rolle des kanonischen Signalweges beim BCC, zumal bei O'Driscoll et al. insgesamt 20 BCC- und 5 Hautproben, in unserer Analyse jedoch nur 2 Haut- und 2 Tumorproben analysiert wurden.

Angaben zur Expression von Fzd5 und Ror2 im humanen BCC gibt es nicht. Jedoch zeigten unsere Analysen, dass zumindest Ror2 (Rezeptor des Wnt/JNK/AP1-Signalweges) in humanen BCC eindeutig überexprimiert war.

Zusammengefasst zeigten die Expressionsanalysen, dass murine und humane BCC Rezeptoren exprimierten, die eine Wnt5a-vermittelte Aktivierung aller drei Wnt-Signalwege zulassen würden. 


\section{Zusammenfassung der wichtigsten Ergebnisse und Modell der Rolle von Wnt5a beim Basalzellkarzinom}

Das Basalzellkarzinom (BCC) ist der häufigste Tumor des Menschen. Aufgrund des lokal destruktiven Wachstums und der sehr geringen Metastasierungsneigung ist die Therapie der Wahl die operative Entfernung des Tumors. Bedingt durch seine hohe Inzidenzrate und den prognostizierten Anstieg verursacht dies schon heute hohe und vermutlich weiter wachsende Kosten im Gesundheitswesen. Daher ist ein besseres Verständnis der Mechanismen, die zur Entstehung und Progression dieses Tumors beitragen, für die Etablierung von spezifischen und möglicherweise günstigeren Therapien von großer Bedeutung.

Der Hedgehog/Patched-Signalweg (Hh/Ptch) spielt eine bedeutende Rolle bei der Entwicklung der Haut und bei der Entstehung von humanen BCC. Bei BCC ist die Aktivität des $\mathrm{Hh} /$ Ptch-Signalwegs erhöht, was meist auf inaktivierenden Mutationen in Ptch beruht. Heute wird angenommen, dass die erhöhte Aktivität dieser Signalkaskade der Grund für die Entstehung dieser Tumoren ist. Interessanterweise wird laut Literatur auch Wnt5a in humanen BCC überexprimiert. Ob die Wnt5a-Überexpression durch den aktiven Hh/Ptch-Signalweg ausgelöst wird und welche Effekte Wnt5a auf das normale Wachstum von Keratinozyten und BCC-Zellen hat, war zu Beginn dieser Arbeit nicht bekannt.

Ziel dieser Arbeit war es, die mögliche Regulation von Wnt5a durch die Hh-Signalkaskade, den Effekt von Wnt5a auf die Keratinozyten sowie die Aktivität der einzelnen WntSignalwege in BCC näher zu untersuchen. Hierzu wurden murine BCC-Proben aus dem Ptch $^{\text {floxflox }}$; ERT2 ${ }^{+/}$-Mausmodell, humane BCC-Proben, die Keratinozytenzelllinien HaCaT (human) und C5N (murin), sowie die BCC-Zelllinie ASZ001 (murin) eingesetzt.

Im Rahmen dieser Arbeit konnte eine Überexpression von Wht5a-mRNA in humanen und auch in murinen BCC bestätigt werden. Im Tiermodell war die Wnt5a-Expression in bereits lange bestehenden Tumoren am höchsten.

Durch eine Inkubation mit Shh konnte keine Wnt5a-Expression in Keratinozyten induziert werden. Da jedoch auch die Expression von Gli1 ausblieb, kann man davon ausgehen, dass der Hh-Signalweg durch exogenes Shh in diesen Zellen nicht aktiviert wurde. Arbeiten von anderen Labormitgliedern zeigten daraufhin, dass selbst durch eine Überexpression von Gli- 
Proteinen keine Wnt5a-Expression in den Keratinozyten hervorgerufen werden konnte. Daher kann man davon ausgehen, dass die Expression von Wht5a in Keratinozyten nicht direkt durch die Hh-Signalkaskade reguliert wird. Tatsächlich wurde im Laufe dieser Arbeiten dann von anderen Labormitgliedern gezeigt, dass Wnt5a in murinen BCC nicht tumor-intrinsisch, sondern im Tumorstroma exprimiert wird und nicht im kausalen Zusammenhang mit aktivem $\mathrm{Hh} /$ Ptch-Signalweg in den BCC-Tumorzellen steht.

Hinsichtlich potentieller Wnt5a-Rezeptoren überexprimierten humane BCC-Proben im Vergleich zu normaler Haut eindeutig Fzd2 (vermittelt laut Literatur Aktivierung des Wnt/Ca ${ }^{2+}$ - Signalwegs durch Wnt5a), Ror2 (führt zur Aktivierung des Wnt/JNK/AP1Signalwegs durch Wnt5a), und Fzd4 (vermittelt die Aktivierung des kanonischen-Signalwegs durch Wnt5a). Murine BCC, die bereits lange bestanden, zeigten eine Überexpression von Fzd5 (Rezeptor des Wnt/Ca ${ }^{2+}$-Signalwegs), Ror2 und Fzd4. Auch die Zelllinien HaCaT, C5N und ASZ001 exprimieren die untersuchten Rezeptoren. Dies bedeutet, dass im BCC Rezeptoren exprimiert werden, die potentiell die Aktivierung aller drei Wnt-Signalwege durch Wnt5a ermöglichen würden.

In Western-Blot-Analysen an murinen BCC konnte gezeigt werden, dass der $\mathrm{Wnt} / \mathrm{Ca}^{2+}$-Weg in murinen BCC aktiv und der kanonische Signalweg inaktiv zu sein scheint. Das Ergebnis für den Wnt/JNK/AP1-Weg war nicht eindeutig. Wahrscheinlich ist aber auch dieser Weg aktiviert.

Da sich herausstellte, dass Wnt5a in vivo im Stroma von BCC exprimiert wird, wurde zur Untersuchung des Effekts von Wnt5a auf das Differenzierungs- und Proliferationsverhalten von Basaliomzellen die Zelllinie ASZ001 mit rekombinantem Wnt5a inkubiert. Hierdurch wurde ein Anstieg der Expression von K10 (einem Differenzierungsmarker), nicht jedoch von Pcna (einem Proliferationsmarker) induziert. Interessanterweise überexprimieren auch murine BCC, die Wnt5a im Tumorstroma exprimieren, K10.

Aufgrund dieser Daten kann man folgende Hypothese zur Rolle von Wnt5a beim BCC aufstellen:

Die erhöhte Aktivität der Hh-Signalkaskade in den Tumorzellen hat keinen Einfluss auf die Induktion von Wnt5a. Vielmehr wird Wnt5a im Tumorstroma durch noch unbekannte Mechanismen induziert. Wnt5a des Tumorstromas bindet an seine Rezeptoren an der 
Oberfläche der Tumorzellen, wodurch der Wnt/Ca ${ }^{2+}$ - und der Wnt/JNK/AP1-Signalweg im BCC aktiviert werden. Der kanonische Signalweg scheint hingegen inaktiv. Durch die Wnt5ainduzierte Aktivierung des $\mathrm{Wnt} / \mathrm{Ca}^{2+}$-Signalwegs und durch den damit einhergehenden Anstieg der intrazellulären $\mathrm{Ca}^{2+}$-Konzentration kommt es zur Induktion der Differenzierung der Tumorzellen. Auf molekularer Ebene findet sich dabei eine erhöhte Expression des Differenzierungsmarkers K10. Tatsächlich zeigten Spätstadien muriner BCC eine Regression mit Abnahme des Tumorvolumens. Aufgrund dieser Ergebnisse könnte es sein, dass Wnt5a einen tumorsuppressorischen Effekt auf BCC ausübt.

$\mathrm{Ob}$ diese Hypothese stimmt und auch auf humane BCC zutrifft, muss noch durch weitere Versuche unterlegt werden. 


\section{Abkürzungen (alphabetisch)}

A

AP

AP1

APC

APS

Aqua dest.

$\beta$ Cat

BCC

BSA

$\mathrm{Ca}^{2+}$

$\mathrm{CaCl}_{2}$

CamKII

$\mathrm{CaR}$

CK1

c-Myc

CRD

$\mathrm{C}_{\mathrm{T}}$

d

$\mathrm{Da}$

DAG

Dhh

Dkk

DMEM

DMSO

Dsh

EDTA

FCS

FRP

Fzd

G418

Gli

GSK3

$\mathrm{h}$

$\mathrm{Hh}$

HRP

IHC

Ihh

$\mathrm{IP}_{3}$

JNK

K1

K10

Lef

LRP

$\mathrm{M}$

$\mathrm{NaCl}$

$\mathrm{Na}_{2} \mathrm{HPO}_{4}$

$\mathrm{NaH}_{2} \mathrm{PO}_{4}$

NFAT
SI-Einheit Ampere

alkalische Phosphatase

Aktivatorprotein 1

Adenomatosis polyposis coli

Ammoniumperoxodisulfat

destilliertes Wasser

$\beta$-Catenin

Basalzellkarzinom (engl. basal cell carcinoma)

Rinderserumalbumin (engl. Bovine serum albumine)

ionisches Kalzium

Kalziumchlorid

$\mathrm{Ca}^{2+} /$ Calmodulin-abhängige Kinase

Kalziumrezeptor

Casein-Kinase 1

Myelocytomatosis Onkogen

cysteinreiche Domäne

Schwellenwertzyklus (engl. Threshold Cycle)

Tag

Dalton

Diacylglycerol

Desert Hedgehog

Dickkopf

Dulbecco's Modified Eagle Medium

N.N.-Dimethylsulfoxid

Dishevelled

Ethylendiamintetraessigsäure

fetales Kälberserum (engl. fetal calf serum)

Frizzled-related protein

Frizzled

Geneticinsulfat

Gliom-assoziierte Zinkfinger-Transkriptionsfaktoren

Glykogen-Synthase-Kinase 3

Stunde

Hedgehog

Meerrettichperoxidase (engl. horseradish peroxidase)

Immunhistochemie

Indian Hedgehog

Inositoltrisphosphat

Jun N-terminale Kinase

Keratin 1

Keratin 10

engl. lymphoid enhancer factor

LDL-receptor-related protein

Einheit molare Masse, molar

Natriumchlorid

di-Natriumhydrogenphosphat

Natriumdihydrogenphosphat

engl. nuclear factor of activated $\mathrm{T}$ cells 


$\begin{array}{ll}\text { NH } & \text { normale Haut } \\ \text { O.D. } & \text { optische Dichte } \\ \text { PAGE } & \text { Polyacrylamidgelelektrophorese } \\ \text { PBS } & \text { Phosphat-gepufferte NaCl-Lsg. } \\ \text { Pcna } & \text { nukleäres Antigen proliferierender Zellen (engl. proliferating cell } \\ & \text { nuclear antigen) } \\ \text { PCR } & \text { Polymerase-Kettenreaktion (engl. polymerase chain reaction) } \\ \text { PMSF } & \text { Phenylmethylsulfonylfluorid } \\ \text { Ptch } & \text { Patched } \\ \text { qRT PCR } & \text { quantitative Real-Time PCR } \\ \text { Ror2 } & \text { engl. Orphan receptor tyrosine kinase 2 } \\ \text { rRNA } & \text { ribosomale Ribonukleinsäure } \\ \text { RT } & \text { Raumtemperatur } \\ \text { RT-PCR } & \text { Real-Time PCR } \\ \text { S } & \text { Seite } \\ \text { SDS } & \text { Natriumdodecylsulfat (engl. sodium dodecyl sulfate) } \\ \text { sec } & \text { Sekunde } \\ \text { Shh } & \text { Sonic Hedgehog } \\ \text { Smo } & \text { Smoothened } \\ \text { Tam } & \text { Tamoxifen } \\ \text { Taq } & \text { Thermus aquaticus } \\ \text { TBS } & \text { Tris-gepufferte NaCl-Lsg. } \\ \text { Tcf } & \text { T-Zell-Faktor (engl. T-cell factor) } \\ \text { TEMED } & \text { N,N,N',N'-Tetramethylethylendiamin } \\ \text { U } & \text { Einheit Unit (Einheit der Enzymaktivität) } \\ \text { V } & \text { Einheit Volt } \\ \text { v/v } & \text { Volumen / Volumen } \\ \text { WB } & \text { Western Blot } \\ \text { WIF } & \text { Wnt-inhibitorischer Faktor } \\ \text { Wnt } & \text { Wingless } \\ \text { w/v } & \text { Gewicht / Volumen } \\ \text { ZNS } & \text { zentrales Nervensystem } \\ & \\ & \\ & \end{array}$




\section{$7 \quad$ Literaturverzeichnis (alphabetisch)}

Adolphe C, Hetherington R, Ellis T, Wainwright B (2006): Patched 1 functions as a gatekeeper by promoting cell cycle progression. Cancer Res 66: 2081-8

Akimoto K, Mizuno K, Osada S, Hirai S, Tanuma S, Suzuki K, Ohno S (1994): A new member of the third class in the protein kinase $\mathrm{C}$ family, PKC lambda, expressed dominantly in an undifferentiated mouse embryonal carcinoma cell line and also in many tissues and cells. J Biol Chem 269: 12677-83

Akiyama T (2000): Wnt/beta-catenin signaling. Cytokine Growth Factor Rev 11: 273-82

Akiyama H, Lyons JP, Mori-Akiyama Y, Yang X, Zhang R, Zhang Z, Deng JM, Taketo MM, Nakamura T, Behringer RR, McCrea PD, de Crombrugghe B (2004): Interactions between Sox 9 and beta-catenin control chondrocyte differentiation. Genes Dev 18: $1072-87$

Asplund A, Gry Björklund M, Sundquist C, Strömberg S, Edlund K, Ostman A, Nilsson P, Pontén F, Lundeberg J (2008): Expression profiling of microdissected cell populations selected from basal cells in normal epidermis and basal cell carcinoma. Br J Dermatol 158: $527-38$

Athar M, Tang X, Lee JL, Kopelovich L, Kim AL (2006): Hedgehog signalling in skin development and cancer. Exp Dermatol 15: 667-77

Barr RK, Bogoyevitch MA (2001): The c-Jun N-terminal protein kinase family of mitogenactivated protein kinases (JNK MAPKs). Int J Biochem Cell Biol 33: 1047-63

Bigelow RL, Jen EY, Delehedde M, Chari NS, McDonnell TJ (2005): Sonic hedgehog induces epidermal growth factor dependent matrix infiltration in HaCaT keratinocytes. $\mathrm{J}$ Invest Dermatol 124: 457-65

Birkenfeld HP, McIntyre BS, Briski KP, Sylvester PW (1996): Protein kinase C isoenzyme expression in normal mouse mammary epithelial cells grown in primary culture. Proc Soc Exp Biol Med 213: 65-70

Blanc E, Goldschneider D, Douc-Rasy S, Bénard J, Raguénez G (2005): Wnt5a gene expression in malignant human neuroblasts. Cancer Lett 228: 117-23

Bonifas JM, Pennypacker S, Chuang PT, McMahon AP, Williams M, Rosenthal A, de Sauvage FJ, Epstein Jr EH (2001): Activation of Expression of Hedgehog Target Genes in Basal Cell Carcinomas. J Invest Dermatol 116: 739-42

Boonchai W, Walsh M, Cummings M, Chenevix-Trench G (2000): Expression of betacatenin, a key mediator of the Wnt signaling pathway, in basal cell carcinoma. Arch Dermatol 136: 937-8 
Boukamp P, Petrussevska RT, Breitkreutz D, Hornung J, Markham A, Fusenig NE (1988): Normal keratinization in a spontaneously immortalized aneuploid human keratinocyte cell line. J Cell Biol 106: 761-71

Breitkreutz D, Braiman-Wiksman L, Daum N, Denning MF, Tennenbaum T (2007): Protein kinase C family: on the crossroads of cell signaling in skin and tumor epithelium. J Cancer Res Clin Oncol 133: 793-808

Ceilley RI, Del Rosso JQ (2006): Current modalities and new advances in the treatment of basal cell carcinoma. Int J Dermatol 45: 489-98

Celis JE, Madsen P, Celis A, Nielsen HV, Gesser B (1987): Cyclin (PCNA, auxiliary protein of DNA polymerase delta) is a central component of the pathway(s) leading to DNA replication and cell division. FEBS Lett 220: 1-7

Chen W, ten Berge D, Brown J, Ahn S, Hu LA, Miller WE, Caron MG, Barak LS, Nusse R, Lefkowitz RJ (2003): Dishevelled 2 recruits beta-arrestin 2 to mediate Wnt5Astimulated endocytosis of Frizzled 4. Science 301: 1391-4

Conze D, Krahl T, Kennedy N, Weiss L, Lumsden J, Hess P, Flavell RA, Le Gros G, Davis RJ, Rincón M (2002): c-Jun NH(2)-terminal kinase (JNK)1 and JNK2 have distinct roles in $\mathrm{CD} 8(+) \mathrm{T}$ cell activation. J Exp Med 195: 811-23

Dahmane N, Lee J, Robins P, Heller P, Ruiz i Altaba A (1997): Activation of the transcription factor Gli1 and the Sonic hedgehog signalling pathway in skin tumours. Nature $\underline{389}$ : 876-81

Daya-Grosjean L, Couvé-Privat S(2005): Sonic hedgehog signaling in basal cell carcinomas. Cancer Lett 225: 181-92

de Vries E, van de Poll-Franse LV, Louwman WJ, de Gruijl FR, Coebergh JW (2005): Predictions of skin cancer incidence in the Netherlands up to 2015. Br J Dermatol 152: 481-8

Dong C, Davis RJ, Flavell RA (2001): Signaling by the JNK group of MAP kinases. c-jun Nterminal Kinase. J Clin Immunol 21: 253-7

El-Bahrawy M, El-Masry N, Alison M, Poulsom R, Fallowfield M (2003): Expression of beta-catenin in basal cell carcinoma. Br J Dermatol 148: 964-70

Evangelista M, Tian H, de Sauvage FJ (2006): The Hedgehog Signaling Pathway in Cancer. Clin Cancer Res 12: 5924-28

Gailani MR, Bale AE (1997): Developmental genes and cancer: role of patched in basal cell carcinoma of the skin. J Natl Cancer Inst 89: 1103-9

Gazel A, Banno T, Walsh R, Blumenberg M (2006): Inhibition of JNK promotes differentiation of epidermal keratinocytes. J Biol Chem 281: 20530-41 
Ghali L, Wong ST, Green J, Tidman N, Quinn AG (1999): Gli1 protein is expressed in basal cell carcinomas, outer root sheath keratinocytes and a subpopulation of mesenchymal cells in normal human skin. J Invest Dermatol 113:595-9

Goodrich LV, Milenković L, Higgins KM, Scott MP (1997): Altered neural cell fates and medulloblastoma in mouse patched mutants. Science 277:1109-13

Gorlin RJ (2004): Nevoid basal cell carcinoma (Gorlin) syndrome.

Genet Med $\underline{6}:$ 530-9

Hahn H, Christiansen J, Wicking C, Zaphiropoulos PG, Chidambaram A, Gerrard B, Vorechovsky I, Bale AE, Toftgard R, Dean M, Wainwright B (1996): A Mammalian patched Homolog Is Expressed in Target Tissues of sonic Hedgehog amd Maps to a Region Associated with Developmental Abnormalities. J Biol Chem 271: 12125-28

Hahn H, Wojnowski L, Zimmer AM, Hall J, Miller G, Zimmer A (1998): Rhabdomyosarcomas and radiation hypersensitivity in a mouse model of Gorlin syndrome. Nat Med $\underline{4}:$ 619-22

Hahn H, Wojnowski L, Miller G, Zimmer A (1999): The patched signaling pathway in tumorigenesis and development: lessons from animal models. J Mol Med 77: 459-68

Hameyer D, Loonstra A, Eshkind L, Schmitt S, Antunes C, Groen A, Bindels E, Jonkers J, Krimpenfort P, Meuwissen R, Rijswijk L, Bex A, Berns A, Bockamp E (2007): Toxicity of ligand-dependent Cre recombinases and generation of a conditional Cre deleter mouse allowing mosaic recombination in peripheral tissues. Physiol Genomics 31: 3241

Hammerschmidt M, Brook A, McMohan AP (1997): The world according to hedgehog. Trends Genet 13: 14-21

Harris RB, Griffith K, Moon TE (2001): Trends in the incidence of nonmelanoma skin cancers in southeastern Arizona, 1985-1996. J Am Acad Dermatol 45: 528-36

He X, Saint-Jeannet JP, Wang Y, Nathans J, Dawid I, Varmus H (1997): A member of the Frizzled protein family mediating axis induction by Wnt-5A. Science 275: 1652-4

Hennings H, Michael D, Cheng C, Steinert P, Holbrook K, Yuspa SH (1980): Calcium regulation of growth and differentiation of mouse epidermal cells in culture. Cell 19: $245-54$

Hoey SE, Devereux CE, Murray L, Catney D, Gavin A, Kumar S, Donnelly D, Dolan OM (2007): Skin cancer trends in Northern Ireland and consequences for provision of dermatology services. Br J Dermatol 156: 1301-7

Holden PR, McGuire B, Stoler A, Balmain A, Pitts JD (1997): Changes in gap junctional intercellular communication in mouse skin carcinogenesis. Carcinogenesis 18: 15-21 
Hooper JE, Scott MP (2005): Communicating with Hedgehogs. Nat Rev Mol Cell Biol $\underline{6}$ : 306-17

Iguchi H, Urashima Y, Inagaki Y, Ikeda Y, Okamura M, Tanaka T, Uchida A, Yamamoto TT, Kodama T, Sakai J (2007): SOX6 suppresses cyclin D1 promoter activity by interacting with beta-catenin and histone deacetylase 1 , and its down-regulation induces pancreatic beta-cell proliferation. J Biol Chem 282: 19052-61

Ikram MS, Neill GW, Regl G, Eichberger T, Frischauf AM, Aberger F, Quinn A, Philpott M (2004): GLI2 is expressed in normal human epidermis and BCC and induces GLI1 expression by binding to its promoter. J Invest Dermatol 122: 1503-9

Itoh K, Jacob J, Y Sokol S (1998): A role for Xenopus Frizzled 8 in dorsal development. Mech Dev 74: 145-57

Kasper M, Regl G, Frischauf Am, Aberger F (2006): Gli transcription factors: mediators of oncogenic Hedgehog signalling. Eur J Cancer 42: 437-45

Katoh M (2005): WNT/PCP signaling pathway and human cancer (Review). Oncol Rep 14: $1583-8$

Kawano Y, Kypta R (2003): Secreted antagonists of the Wnt signalling pathway. J Cell Sci 116: $2627-34$

Koivunen J, Aaltonen V, Peltonen J (2006): Protein kinase C (PKC) family in cancer progression. Cancer Lett 235: 1-10

Kolligs FT, Bommer G, Göke B (2002): Wnt/beta-catenin/tcf signaling: a critical Pathway in gastrointestinal tumorigenesis. Digestion 66: 131-44

Kremenevskaja N, von Wasielewski R, Rao AS, Schöfl C, Abdersson T, Brabant G (2005): Wnt5a has tumor suppressor activity in thyroid carcinoma. Oncogene 24: 2144-54

Kühl M, Sheldahl LC, Malbon CC, Moon RT (2000 a): $\mathrm{Ca}^{2+} /$ Calmodulin-dependent protein kinase II is stimulated by Wnt and Frizzled homologs and promotes ventral cell fates in Xenopus. J Biol Chem 275:12701-11

Kühl M, Sheldahl LC, Park M, Miller JR, Moon RT (2000 b): The Wnt/Ca ${ }^{2+}$ pathway: a new vertebrate Wnt signaling pathway takes shape. Trends Genet 16:279-83

Kulesz-Martin M, Kilkenny AE, Holbrook KA, Digernes V, Yuspa SH (1983): Properties of carcinogen altered mouse epidermal cells resistant to calcium-induced terminal differentiation. Carcinogenesis $\underline{4}$ : 1367-77

Li L, Tucker RW, Hennings H, Yuspa SH (1995): Inhibitors of the intracellular Ca(2+)ATPase in cultured mouse keratinocytes reveal components of terminal differentiation that are regulated by distinct intracellular $\mathrm{Ca} 2+$ compartments. Cell Growth Differ $\underline{6}: 1171-84$ 
Liu G, Bafico A, Aaronson SA (2005): The mechanism of endogenous receptor activation functionally distinguishes prototype canonical and noncanonical Wnts. Mol Cell Biol 25: $3475-82$

Lo Muzio L, Pannone G, Staibano S, Mignogna MD, Grieco M, Ramires P, Romito AM, De Rosa G, Piattelli A (2002): WNT-1 expression in basal cell carcinoma of head and neck. An immunohistochemical and confocal study with regard to the intracellular distribution of beta-catenin. Anticancer Res 22: 565-76

Mancuso M, Pazzaglia S, Tanori M, Hahn H, Merola P, Rebessi S, Atkinson MJ, Di Majo V, Covelli V, Saran A (2004): Basal cell carcinoma and its development: insights from radiation-induced tumors in Ptch-1 deficient mice. Cancer Res 64: 934-41

Mao B, Wu W, Davidson G, Marhold J, Li M, Mechler BM, Delius H, Hoppe D, Stannek P, Walter C, Glinka A, Niehrs C (2002): Kremen proteins are Dickkopf receptors that regulate Wnt/beta-catenin signalling. Nature 417: 664-7

Matise MP, Joyner AL (1999): Gli genes in development and cancer. Oncogene 18: 7852-9

Mikels AJ, Nusse R (2006): Purified Wnt5a protein activates or inhibits beta-catenin-TCF signaling depending on receptor context. PLoS Biol 4: 570-82

Miller JR (2001): The Wnts. Genome Biol $\underline{3}$ reviews 3001.1-3001.15

Neill GW, Ghali LR, Green JL, Ikram MS, Philpott MP, Quinn AG (2003): Loss of protein kinase Calpha expression may enhance the tumorigenic potential of Glil in basal cell carcinoma. Cancer Res 63: 4692-7

O'Driscoll L, McMorrow J, Doolan P, McKiernan E, Mehta JP, Ryan E, Gammell P, Joyce H, O'Donovan N, Walsh N, Clynes M (2006): Investigation of the molecular profile of basal cell carcinoma using whole genome microarrays. Mol Cancer 5: 74

Oishi I, Suzuki H, Onishi N, Takada R, Kani S, Ohkawara B, Koshida I, Suzuki K, Yamada G, Schwabe GC, Mundlos S, Shibuya H, Takada S, Minami Y (2003): The receptor tyrosine kinase Ror2 is involved in non-canonical Wnt5a/JNK signalling pathway. Genes Cells $\underline{8}:$ 645-54

Oro AE, Higgins KM, Hu Z, Bonifas JM, Epstein EH, Scott MP (1997): Basal Cell Carcinomas in Mice Overexpressing Sonic Hedgehog. Science 276: 817-21

Pukrop T, Binder C (2008): The complex pathways of Wnt 5a in cancer progression. J Mol Med 흐:259-66

Qian D, Jones C, Rzadzinska A, Mark S, Zhang X, Steel KP, Dai X, Chen P (2007): Wnt5a functions in planar cell polarity regulation in mice. Dev Biol $\underline{306}$ : 121-33

Reddy S, Andl T, Bagasra A, Lu MM, Epstein DJ, Morrisey EE, Millar SE (2001): Characterization of Wnt gene expression in developing and postnatal hair follicles and identification of Wnt5a as a target of Sonic hedgehog in hair follicle morphogenesis. Mech Dev 107: 69-82 
Reifenberger J (2007): Basalzellkarzinom. Molekulare Genetik und ungewöhnliche klinische Manifestationen. Hautarzt 58: 406-11

Reifenberger J, Wolter M, Knobbe CB, Köhler B, Schönicke A, Scharwächter C, Kumar K, Blaschke B, Ruzicka T, Reifenberger G (2005): Somatic mutations in the PTCH, SMOH, SUFUH and TP53 genes in sporadic basal cell carcinomas. Br J Dermatol 152: 43-51

Ripka S, König A, Buchholz M, Wagner M, Sipos B, Klöppel G, Downward J, Gress T, Michl P (2007): WNT5A--target of CUTL1 and potent modulator of tumor cell migration and invasion in pancreatic cancer. Carcinogenesis 28: 1178-87

Roewert-Huber J, Lange-Asschenfeldt B, Stockfleth E, Kerl H (2007): Epidemiology and aetiology of basal cell carcinoma. Br J Dermatol 157: 47-51

Rubin AI, Chen EH, Ratner D (2005): Basal-cell carcinoma. N Engl J Med 353: 2262-69

Saldanha G, Ghura V, Potter L, Fletcher A (2004): Nuclear beta-catenin in basal cell carcinoma correlates with increased proliferation. Br J Dermatol 151: 157-164

Salto-Tellez M, Peh BK, Ito K, Tan SH, Chong PY, Han HC, Tada K, Ong WY, Soong R, Voon DC, Ito Y (2006): RUNX3 protein is overexpressed in human basal cell carcinomas. Oncogene 25: 7646-9

Sambrook J: Quantitation of DNA and RNA; in: Molecular cloning-A laboratory manual, Band 3; hrsg. v. Sambrook J, Fritsch I, Maniatis T u.a.; Cold Spring Harbor Laboratory Press, New York/USA 1989, E5

Schambony A, Wedlich D (2007): Wnt-5A/Ror2 regulate expression of XPAPC through an alternative noncanonical signaling pathway. Dev Cell 12: 779-92

Saneyoshi T, Kume S, Amasaki Y, Mikoshiba K (2002): The Wnt/calcium pathway activates NF-AT and promotes ventral cell fate in Xenopus embryos. Nature 417: 295-9

Sheldahl LC, Park M, Malbon CC, Moon RT (1999): Protein kinase C is differentially stimulated by Wnt and Frizzled homolgs in a G-protein-dependent manner. Curr Biol $\underline{9}$ : 695-8

Slusarski DC, Corces VG, Moon RT (1997): Interaction of Wnt and a Frizzled homologue triggers G-protein linked phosphatidylinositol signaling. Nature $\underline{390}$ : 410-3

Smith CP, Oh JD, Bibbiani F, Collins MA, Avila I, Chase TN (2007): Tamoxifen effect on LDOPA induced response complications in parkinsonian rats and primates. Neuropharmacology 르: 515-26

So PL, Langston AW, Daniallinia N, Hebert JL, Fujimoto MA, Khaimskiy Y, Aszterbaum M, Epstein EH Jr (2006): Long-term establishment, characterization and manipulation of cell lines from mouse basal cell carcinoma tumors. Exp Dermatol 15: 742-50 
Staples MP, Elwood M, Burton RC, Williams JL, Marks R, Giles GG (2006): Non-melanoma skin cancer in Australia: the 2002 national survey and trends since 1985. Med J Aust 184: 6-10

Taipale J, Chen JK, Cooper MK, Wang B, Mann RK, Milenkovic L, Scott MP, Beachy PA (2000): Effects of oncogenic mutations in Smoothened and Patched can be reversed by cyclopamine. Nature 406: 1005-9

Takash W, Cañizares J, Bonneaud N, Poulat F, Mattéi MG, Jay P, Berta P (2001): SOX7 transcription factor: sequence, chromosomal localisation, expression, transactivation and interference with Wnt signalling. Nucleic Acids Res 29: 4274-83

Ting PT, Kasper R, Arlette JP (2005): Metastatic basal cell carcinoma: report of two cases and literature review. J Cutan Med Surg 9: 10-5

Tu CL, Chang W, Bikle DD (2007): The role of the calcium sensing receptor in regulating intracellular calcium handling in human epidermal keratinocytes. J Invest Dermatol 127: 1074-83

Uhmann A, Dittmann K, Nitzki F, Dressel R, Kovela M, Frommhold A, Zibat A, Binder C, Adham I, Nitsche M, Heller I, Armstrong V, Schulz-Schaeffer W, Wienands J Hahn H (2007): The hedgehog receptor Patched controls lymphoid lineage commitment. Blood 110: $1814-23$

Umbhauer M, Djiane A, Goisset C, Penzo-Méndez A, Riou JF, Boucaut JC, Shi DL (2000): The C-terminal cytoplasmic Lys-thr-X-X-X-Trp motif in frizzled receptors mediates Wnt/beta-catenin signalling. EMBO J $\underline{19}$ : 4944-54

Varjosalo M, Taipale J (2008): Hedgehog: functions and mechanisms. Genes Dev. 22: 245472

Vidal VP, Ortonne N, Schedl A (2008): SOX9 expression is a general marker of basal cell carcinoma and adnexal-related neoplasms. J Cutan Pathol 35: 373-9

Weeraratna AT, Jiang Y, Hostetter G, Rosenblatt K, Duray P, Bittner M, Trent JM (2002): Wnt5a signaling directly affects cell motility and invasion of metastatic melanoma. Cancer Cell 1: 279-88

Wetsel WC, Khan WA, Merchenthaler I, Rivera H, Halpern AE, Phung HM, Negro-Vilar A, Hannun YA (1992): Tissue and cellular distribution of the extended family of protein kinase C isoenzymes. J Cell Biol 117: 121-33

Willert K, Jones KA (2006): Wnt signaling: is the party in the nucleus? Genes Dev 20: 1394404

Yamazaki F, Aragane Y, Kawada A, Tezuka T (2001): Immunohistochemical detection for nuclear beta-catenin in sporadic basal cell carcinoma. Br J Dermatol 145: 771-7

Yu XJ, Li CY, Dai HY, Cai DX, Wang KY, Xu YH, Chen LM, Zhou CL. (2007): Expression and localization of the activated mitogen-activated protein kinase in lesional psoriatic skin. Exp Mol Pathol $\underline{83}$ : 413-8 
Yuspa SH, Kilkenny AE, Steinert PM, Roop DR (1989): Expression of murine epidermal differentiation markers is tightly regulated by restricted extracellular calcium concentrations in vitro. J Cell Biol 109: 1207-17

Yuspa SH, Kilkenny A, Cheng C, Roop D, Hennings H, Kruszewski F, Lee E, Strickland J, Greenhalgh DA (1991): Alterations in epidermal biochemistry as a consequence of stage-specific genetic changes in skin carcinogenesis. Environ Health Perspect 93: 3-10

Zibat A, Uhmann A, Nitzki F, Wijgerde M, Frommhold A, Heller T, Armstrong V, Wojnowski L, Quintanilla-Martinez L, Reifenberger J, Schulz-Schaeffer W, Hahn H (2009): Time-point and dosage of gene inactivation determine the tumor spectrum in conditional Ptch knockouts. Carcinogenesis 30:918-26

Zorn AM, Barish GD, Williams BO, Lavender P, Klymkowsky MW, Varmus HE (1999): Regulation of Wnt signaling by Sox proteins: XSox17 alpha/beta and XSox3 physically interact with beta-catenin. Mol Cell $\underline{4}:$ 487-98 


\section{Danksagungen}

Die vorliegende Arbeit wurde am Institut für Humangenetik (Leitung Prof. Dr. med. W. Engel) bei der Schwerpunktprofessur Molekulare Entwicklungsgenetik im Zentrum für Hygiene und Humangenetik der Georg-August Universität in Göttingen angfertigt.

Mein Dank gilt in erster Linie Frau Prof. Dr. Heidi Hahn für die Bereitstellung des spannenden Themas, die intensive Betreuung und die vielen Gespräche.

Ebenso möchte ich Dr. Arne Zibat für seine gute Betreuung danken. Er hat nicht nur die Entstehung der vorliegenden Arbeit mit vielen wertvollen Anregungen begleitet, sondern mich gleichzeitig auch geduldig in das wissenschaftliche Arbeiten und die Methodik eingearbeitet.

Ein großer Dank gebührt auch der gesamten Arbeitsgruppe für die entspannte und sehr kollegiale Arbeitsatmosphäre. Im Besonderen danke ich Dr. Frauke Nitzki, Dr. Anja Uhmann Ina $\mathrm{He} ß$ und Anke Frommhold für die Unterstützung bei der Durchführung der Experimente und der Anfertigung dieser Arbeit sowie für die geduldige Beantwortung meiner vielen Fragen.

Abschließend möchte ich mich auch bei PD Dr. W. Schulz-Schaefer für die Interpretation und die Hilfe bei der Durchführung histologischer Färbungen sowie bei Prof. Dr. F. Brembeck und Dr. T. Pukrop und allen anderen Arbeitsgruppen bedanken, die mir freundlicherweise Antikörper zur Verfügung gestellt haben. 


\section{Lebenslauf}

Ich, Per-Ole Carstens, wurde am 09.07.1982 als erster Sohn von Johannes und Inge Carstens, geborene Rübke, in Verden an der Aller geboren.

In Langwedel besuchte ich von 1989 bis 1993 die Grundschule und von 1993 bis 1995 die Orientierungsstufe. Meine allgemeine Hochschulreife erlangte ich mit dem Abitur am Domgymnasium Verden, welches ich von 1995 bis 2002 besuchte.

Im Rahmen des Zivildienstes arbeitete ich von 2002 bis 2003 in der Helene Grulke Schule für geistig behinderte Kinder in Cluvenhagen.

Im Wintersemester 2003/2004 immatrikulierte ich mich zum Studium der Humanmedizin an der Georg-August-Universität in Göttingen, an der ich im September 2005 den ersten Abschnitt der ärztlichen Prüfung bestand. Zum Sommersemester 2009 begann ich das praktische Jahr im Diakoniekrankenhaus Rotenburg Wümme mit dem Wahlfach Neurologie. Den zweiten Abschnitt der ärztlichen Prüfung werde ich voraussichtlich im April 2010 absolvieren und das Studium im Sommer 2010 beenden. 